\title{
Chapter 7.2 Mount Erebus
}

Kenneth WW Sims ${ }^{1 \#}$, Rick Aster ${ }^{2}$, Glenn Gaetani ${ }^{3}$, Janne Blichert-Toft ${ }^{4}$, Erin H. Phillips $^{1,5}$, Paul J. Wallace ${ }^{6}$, Glen S. Mattioli ${ }^{7}$, Dan Rasmussen ${ }^{8}$, and Eric S. Boyd ${ }^{9}$

${ }^{1}$ Department of Geology and Geophysics, University of Wyoming, Laramie, WY 82071 USA

${ }^{2}$ Department of Geosciences, Warner College of Natural Resources, Colorado State University, Fort Collins, CO 80523 USA

${ }^{3}$ Department of Geology and Geophysics, Woods Hole Oceanographic Institution, Woods Hole, MA 02543 USA

${ }^{4}$ Laboratoire de Géologie de Lyon, Ecole Normale Supérieure de Lyon, CNRS UMR 5276, Université de Lyon, 46 Allée d'Italie, 69007 Lyon, France

${ }^{5}$ Center for Economic Geology Research, University of Wyoming, Laramie, WY 82071 USA

${ }^{6}$ Department of Earth Sciences, University of Oregon, Eugene, OR 97403 USA

${ }^{7}$ UNAVCO, Inc. Boulder, CO 80301-5554

${ }^{8}$ Lamont-Doherty Earth Observatory, Columbia University, Palisades, NY 10964 USA

${ }^{9}$ Department of Microbiology and Immunology, Montana State University, Bozeman, MT 59717 USA

\# Corresponding Author: ksims7@uwyo.edu 


\begin{abstract}
Erebus volcano, Antarctica, is the southern-most active volcano on the globe. Despite its remoteness and harsh conditions, Erebus volcano provides an unprecedented and unique opportunity to study the petrogenesis and evolution, as well as the passive and explosive degassing, of an alkaline magmatic system with a persistently open and magma-filled conduit. In this invited contribution, we review nearly five decades of scientific research related to Erebus volcano, including geological, geophysical, geochemical, and microbiological observations and interpretations. Mt Erebus truly is one of the world's most significant natural volcano laboratories where the lofty scientific goal of studying a volcanic system from mantle to microbe is being realized.
\end{abstract}

\title{
1. Introduction
}

Mount Erebus in Antarctica, or Erebus volcano (EV) as the volcanically active part of the mountain is referred to in more recent literature, is the southern-most active volcano on Earth and one of Earth's rare alkaline volcanoes (Figures 1 and 2). Despite its remote location, and the fact that the conditions at or near its summit and upper slopes can be some of the harshest on the planet, Erebus volcano has provided unprecedented and unique opportunities to study the petrogenesis and evolution of alkaline magmas. First, EV's lavas and tephras span a wide compositional range from primitive basanite to evolved, anorthoclase-rich phonolite (Kyle et al., 1992). Second, EV's regular Strombolian activity has continuously ejected bombs from a persistent lava lake onto the crater rim and beyond, delivering samples of Erebus magma almost continuously from 1972 until the present (Dunbar et al., 1994; Sims et al., 2008a, 2013). Third, the well-dated lava sequence at EV provides a temporal record ranging from 1.3 Ma to the present, providing a comprehensive record of the long-term evolution of the volcano (Harpel et al., 2004; Esser et al., 2004, Kelly et al., 2008a,b; Sims et al., 2008a; 2013). Fourth, EV's persistent lava lake represents an open conduit degassing magmatic system, which provides a unique natural laboratory for studying magma degassing in an alkaline system (Giggenbach et al., 1973; Zreda-Gostynska et al., 1997; Oppenheimer and Kyle, 2008 a,b) as well as the behavior of open-vent volcanoes. Fifth, EV's location on Ross Island 35 km north of McMurdo Station, which is the main base for all US Antarctic Program support and scientific activities on 
the continent make it logistically accessible for detailed monitoring studies. As such, a remarkable wealth of observational, geophysical, petrological, and geochemical data on Erebus volcano now exists which, together, provide a comprehensive and detailed perspective of the petrogenesis and evolution of this unique alkaline volcanic system as well as the dynamics of its persistent lava lake.

In this review we present an overview of the most salient aspects of this large body of work. The review is divided into three sections. In section 1, we provide an overview of EV's volcanic characteristics and a synopsis of the geophysical, geochemical, and microbiological measurements conducted on Erebus Volcano since 1972. In section 2, we detail how these geological observations and geophysical and geochemical measurements address the following overarching topics and associated questions relating to the driving forces, melting process, magmatic evolution, eruptive behavior, and potential hazards of Erebus volcano.

- Erebus volcanic rocks have a unique HIMU isotopic signature defined by their highly radiogenic $\mathrm{Pb}$ isotopic compositions, the origin of which is of long-standing debate. How do geophysical and geochemical measurements inform on the origin of EV's distinctive HIMU-like source and the causes of volcanism at Erebus volcano and Ross Island?

- Erebus volcano is a rare, active alkaline volcanic system that provides an important window into mantle melting processes. What do geochemical measurements of its lavas reveal about the depth of melting and lithology of the mantle source of Mt Erebus?

- Erebus volcano hosts a unique, long-lived lava lake that allows for direct, long-term study of an open-conduit, alkaline magmatic system. What constraints do geophysical measurements place on the geometry of the EV magmatic plumbing system from the vent down to the lower crust? How do surface gas measurements inform on subsurface processes (magma differentiation and degassing) occurring within the volcanic conduit? What is known about the timescales of magma evolution, crystallization, and magma degassing in the Erebus magmatic system? 
- The Erebus Ice Tower Fumaroles and hot ground regions host a unique and largely endemic community of microbial life in Antarctica. What is the relationship between EV's magmatic and hydrothermal systems and its biosphere?

- The location of Erebus volcano makes it a threat to both US and international Antarctic science programs and personnel. How do the observed patterns and changes in magmatic and volcanic activity over both long and short timescales forewarn about potential future eruptive behavior and help in the assessment of hazards associated with Erebus volcano? Which observations, monitoring and warning systems, and protocols are needed to best forecast short- and long-term volcanic hazards at Erebus volcano and Ross Island?

Finally, in section 3, we provide a summary of the key results.

\subsection{Geological, Geochemical, Geophysical, and Microbiological Observations}

\subsection{Geological Setting of Erebus Volcano}

Mt Erebus (Figure 1 and 2) was discovered by Captain James Clark Ross in January 1841.

"it proved to be a mountain twelve thousand four hundred feet of elevation.... emitting flame and smoke in great profusion... as we drew nearer, its true character became manifest... I named it 'Mount Erebus'...” (Ross, 1847).

Mt Erebus is the largest of four volcanic centers forming Ross Island: Mt. Erebus (3794 m elevation, $2170 \mathrm{~km}^{3}$ ), Mt. Terror (3262 m, $\left.1700 \mathrm{~km}^{3}\right)$, Mt. Bird $\left(1800 \mathrm{~m}, 470 \mathrm{~km}^{3}\right)$, and Hut Point Peninsula $\left(100 \mathrm{~km}^{3}\right)$. About $4,520 \mathrm{~km}^{3}$ of volcanic material has been erupted on Ross Island over the last $4 \mathrm{Ma}$ (Esser et al., 2004; Kelly et al., 2008a). The occurrence, formation, and evolution of Erebus volcano can only be fully understood in the context of these other neighboring volcanoes.

Ross Island is located in the Ross Sea, near the western margin of the Transantarctic Mountains. Ross Island lies at the southern end of the intraplate Terror Rift, which is the locus of the most recent extension within the West Antarctic Rift System (WARS; e.g., Behrendt, 1999). 
Crustal thickness in the immediate Ross Island region ranges from $\sim 19$ to $25 \mathrm{~km}$ (Bannister et al., 2003; Finotello et al., 2011; Chaput et al., 2014).

Late Cenozoic, silica-undersaturated, alkaline volcanic rocks erupted on the western margin of the Ross Embayment belong to the McMurdo Volcanic Group (MVG; Kyle (1990a). Ross Island is part of the Erebus volcanic province (Kyle, 1990a), within the regional McMurdo Volcanic Group of the southern Ross Sea and McMurdo Sound (Kyle, 1990b).

Erebus is an active, polygenetic, alkaline composite volcano (Figures 1-6). Highprecision ${ }^{40} \mathrm{Ar} /{ }^{39} \mathrm{Ar}$ dating (Esser et al., 2004; Harpel et al., 2004; Kelly et al., 2008a) has been used to demarcate the volcanic history into three distinct phases (Figures 4 and 5; Supplemental Table): 1) The proto-Erebus shield-building phase (1.3-1.0 Ma), during which basanites were erupted; this phase represents a transition from subaqueous to subaerial activity. Subaqueous activity is characterized by hyaloclastite deposits, while subaerial deposits are distinguished as lava flows with occasional tephra. 2) The proto-Erebus cone-building phase (1.0 Ma-750 ka), dominated by more evolved phonotephrite lavas that largely form the present steep slopes of the volcano. Eruptions were typically effusive with some explosive activity reflected in tephra layers. This phase was terminated by a caldera collapse around 750 ka. 3) The "modern" Erebus cone-building phase (250 ka-present), which formed the present near-summit edifice (Figures 46). Large volumes of anorthoclase-phyric tephriphonolite and phonolite lavas (Figure 7) were extruded, with minor trachyte also erupted at about $170 \mathrm{ka}$ during the third phase of activity. This phase is characterized by two caldera collapses, an older collapse between 80 and $25 \mathrm{ka}$ and a younger, smaller collapse, between 25 and $11 \mathrm{ka}$. Modern Erebus activity has been within the older caldera structure and is dominantly characterized by lava flows, radially distributed around the present crater, although individual eruptive episodes appear to be confined to specific sectors of the volcano with the youngest episode being directed towards the northwest. Activity at Mt Erebus during historic times has been characterized by the presence of an active lava lake within the innermost crater, which shows significant variations in elevation. Rising gas bubbles/gas slugs disrupt the lake, with the largest producing Strombolian explosions and the ejection of bombs (Figure 7), some of which have reached up to $10 \mathrm{~m}$ in dimension. The majority of these bombs fall within 500 to 1000 meters of the crater. 
Finally, Erebus hydrothermal systems, which are extensively manifest in warm ground and ice tower fumaroles (Figure 8), host abundant biodiverse microbial communities (Herbold et al., 2014 a,b) comprised of thermophilic Archaea, Bacteria, and Eukarya supported by a variety of metabolic functionalities. The habitability of these environments for supporting microbial activity appears to be a direct consequence of continued volcanic activity.

\subsection{A Unique and Persistent Lava Lake}

Erebus volcano's persistent, convecting, and degassing lava lake of anorthoclase-phyric phonolite magma daylights an open conduit magma system. This unique magma conduit makes $\mathrm{EV}$ an unequaled natural laboratory for studying processes of magma formation, evolution, and degassing in an alkaline magmatic system (Figure 6 and 7). The Erebus lava lake was "first observed directly by a scientific party" in December 1972 (Giggenbach et al., 1973; Kyle et al., 1982); however, it likely was extant for much longer. During the first ascent of Mt Erebus on March 10, 1908, by a party from Shackleton's Nimrod Expedition (Figure 3), the existence of a lava lake is supported by notes made by T.W. Edgeworth David, the expedition's geologist from the University of Sydney (Shackleton et al., 1909):

“... After a continuous loud hissing sound, lasting for some minutes, there would come from below a big dull boom, and immediately great globular masses of steam would rush upwards to swell the volume of the snow-white cloud which ever sways over the crater. This phenomenon recurred at intervals during the whole of our stay at the crater. Meanwhile, the air around us was extremely redolent of burning sulphur..."

Further, the fact that James Ross reported significant activity, “...emitting flame and smoke in great profusion..." suggests that the lava lake also existed in 1841 when Erebus was first discovered.

The EV lava lake is located on the northern floor of the Inner Crater, which sits inside the Main Crater. The main, prominent, persistent open conduit lava lake is named Ray's Lava Lake after the New Zealand seismologist Ray Dibble. Adjacent to Ray’s Lava Lake are two equally prominent degassing vents, which are referred to as "Werner's fumarole' and the 'Active vent' 
(Kyle et al., 1982; Oppenheimer and Kyle, 2008 a,b). Werner's fumarole occasionally becomes a small active second lava lake (Oppenheimer and Kyle, 2008a,b; Csatho et al., 2008, Molina et al., 2012).

The EV phonolite lava lake is the top of an open convecting magma conduit, which is continuously and quiescently degassing (Figures 1, 4 and 6). All historic eruptive activity has originated from this phonolite lava lake and adjacent vents. Observationally, the EV lava lake surface shows a steady bidirectional flow of upwelling vesicular magma associated with explosive Strombolian eruptions and downwelling degassed magma. New magma pulses rise to refill the lava lake within about 10 minutes after an explosive eruption indicating a shallow magma body with which the lava lake is in "magmastatic equilibrium" (Oppenheimer et al., 2008).

Strombolian eruptions (with attendant minor ash) characterize the vast majority of recent eruptive activity (Kyle et al., 1982, 1992; Rowe et al., 2000; Gerst et al., 2008). The explosions are well situated for observations conducted locally and from the crater rim, and have been studied using video [e.g., Dibble et al., 2008], seismic [e.g., Aster et al., 2008], radar [Gerst et al., 2008], and infrasound [e.g., Johnson et al., 2008] techniques. In addition to the surface explosions, the eruptions and subsequent refilling of the lava lake produce longer-period seismic signals that arise from a deeper source within the conduit system. The corresponding source centroid for a stack of 293 lava lake eruptions between January 2005 and April 2006 was located $\leq 400 \mathrm{~m}$ beneath the lava lake and somewhat to the west of the lake center [Aster et al., 2008]; however, evidence from the directionality of ejecta and observations of the post-eruptive lava lake indicate that the uppermost tens of meters of the conduit are nearly vertical [Gerst et al., 2008].

The style and magnitude of EV's Strombolian eruptions have varied over the years the volcano has been under direct observation. Between 1973 and 1984 there were roughly six small Strombolian eruptions per day. In 1984, their frequency and intensity increased dramatically; then, starting in September 1984, there was an exceptional four-month period during which Strombolian eruptions were sending bombs of up to $10 \mathrm{~m}$ in diameter more than $2 \mathrm{~km}$ from the 
Erebus summit vent (Dibble et al., 1984; Kyle et al., 1990, 1992, 1994). From 2001 through 2004 Strombolian eruptions were much less frequent, with a notable hiatus during 2004. Since mid-2005, there has been a return to more frequent Strombolian activity. In October 1993, a powerful gas and steam eruption ejected large lithic bombs and ash beyond the crater rim and created a new vent at the edge of the inner crater. The exact reasons for these changes in lava lake eruptive style are not understood explicitly but are likely related to processes of gas accumulation at depth in the conduit system feeding the convecting lava lake (Aster et al., 2008; Sweeney et al., 2008).

The Strombolian eruptions often eject phonolite bombs to and beyond the crater rim where they can be sampled (Figure 7). These bombs have provided a nearly continuous record of lava lake magma composition from the early 1970s on (Kelly et al., 2008b; Sims et al., 2008a; 2013). While the exact dates and times of eruption are known for some bomb samples (Sims et al., 2013a), the young ages for other samples were inferred on the basis of their 'fresh appearance' at the time of collection. Recently erupted bombs have a distinctive metallic to iridescent vitreous luster that is quickly lost ( 1-2 weeks) upon exposure to the acidic gases emitted from the lava lake and surrounding fumaroles.

\subsection{Petrological, Geochemical, and Isotopic Evolution of Erebus Volcano from Source to Lava Lake}

\subsubsection{From Basanite to Phonolite: A Simple Magmatic Evolution}

While the most recent EV eruptions are composed of phonolitic lava containing large anorthoclase megacrysts, earlier eruptions and those from surrounding volcanoes show a range of compositions from basanite to phonolite (Table 1). The magmatic evolution of EV lavas has been studied extensively and is interpreted as a simple coherent magma differentiation trend from mantle-derived basanite to highly evolved phonolite (Figure 9; Kyle et al., 1992). Lavas on Ross Island show two major magmatic lineages, the Dry Valley Drilling Project (DVDP) lineage (Kyle, 1981b) and the Erebus Lineage (EL; Kyle et al., 1992). The DVDP lineage consists predominantly of basanite with minor microporphyritic kaersutite-bearing intermediate 
differentiates and phonolite. Petrologic/geochemical studies undertaken on flank lavas from Mt. Terror, Mt. Bird, and Hut Point Peninsula show the presence of kaersutite (Kyle, 1990a; Phillips et al., 2018). The Erebus lineage constitutes a coherent fractionation trend defined by a single liquid-line of descent from basanite to phonolite with a complete sequence of intermediate (phonotephrite, tephriphonolite) eruptive products (Kyle et al., 1992). Minor volumes of more iron-rich and less silica under-saturated benmoreite and trachyte, termed the enriched Fe series (EFS), occur as isolated outcrops on the flanks of EV and on adjacent islands in Erebus Bay. The EFS lavas follow a different liquid-line of descent and the trachytes are interpreted to have undergone both shallow crustal assimilation and fractional crystallization during their evolution.

Primitive mantle-normalized trace element patterns for Erebus and other volcanic rocks from Ross Island are shown in Figure 10 (Phillips et al., 2018). These data show several features that have important petrological implications:

1) Erebus phonolite glass from historic bombs contain the highest overall abundances of incompatible trace elements.

2) The phonolite glass (minus the anorthoclase phenocrysts) is depleted in Ba and Sr because of the relative compatibility of these elements in anorthoclase (Kelly et al., 2008b; Sims et al., 2013a).

3) Erebus lavas display elevated $\mathrm{Nb} / \mathrm{La}$ relative to lavas from peripheral Ross Island volcanoes, reflecting variable extents of apatite crystallization, a phase present in Erebus lavas at $\sim 0.5 \%$ modal abundance (Kyle, 1981b; Kyle et al., 1992).

4) All lavas are light rare earth element (REE)-enriched suggesting small degrees of partial melting; differences between the highest $\mathrm{Mg \#}$ basanites and lowest $\mathrm{Mg \#}$ samples are consistent with crystal fractionation models for the Erebus lineage (Kyle, 1981b; Kyle et al., 1992).

5) The high-Mg\# parental basanites from Ross Island lavas and tephras are depleted in heavy compared to middle $\mathrm{REE}$ (mean $\mathrm{Dy}_{\mathrm{N}} / \mathrm{Yb}_{\mathrm{N}} \cong 1.4$ ) suggesting the presence of residual garnet in their source (Sun and Hanson, 1975; 1976; Sims and Hart, 2006; Sims et al., 2013a).

6) The radiogenic isotopes and major and trace element abundances and patterns of the highMg\# parental basanites from Ross Island lavas and tephras closely resemble HIMU (high- $\mu=$ high ${ }^{238} \mathrm{U} /{ }^{204} \mathrm{~Pb}$ ) basalts from St. Helena (Willbold and Stracke, 2006), which is the mantle endmember that most closely resembles the Erebus and Ross Island lavas (see section 2.3.3). 


\subsubsection{Unique Mineralogy of EV Eruptive Products}

The Erebus phonolite magma, as represented by erupted bombs, contains matrix glass ( 67 vol\%; microlite-free), anorthoclase feldspar ( 30 vol\%), titanomagnetite ( 1 vol\%), fayalitic olivine ( $\sim 0.8 \mathrm{vol} \%)$, clinopyroxene ( 0.6 vol\%), fluor-apatite ( 0.6\%), and occasional blebs of pyrrhotite (Kyle, 1977; 1992; Kelly et al., 2008b). Textural relationships among these phases suggest that the pyroxene, titanomagnetite, and olivine crystallized first (Kelly et al., 2008b). Textures and mineralogical compositions of young lava bombs are consistent with crystallization at low degrees of undercooling in a growth-dominated regime (Kelly et al., 2008b). Anorthoclase feldspar is the only phase showing compositional zoning.

A unique feature of the Erebus phonolite magma is the presence of abundant large anorthoclase feldspar megacrystals, up to $\sim 10 \mathrm{~cm}$ in length (Figure 7). These crystals are striking because of their size, complex internal zoning, and abundance of melt inclusions - up to 30 vol\% - as well as for their inclusions of other crystalline phases such as pyroxene, apatite, magnetite, and pyrrhotite (Kyle, 1977, Dunbar et al., 1994; Kelly et al., 2008b). Large melt inclusions (up to $\sim 1 \mathrm{~mm}$ in length) typically are irregularly shaped (Dunbar et al., 1994). However, the anorthoclase megacrystals also contain a population of negative crystal shape inclusions that are 10-40 microns in diameter. Populations of melt inclusions are trapped along what appear to be growth zones in the host crystal, producing a banded appearance in back-scattered electron (BSE) microscope images. The anorthoclase megacrystals are complexly compositionally zoned at a number of scales and show evidence for periods of resorption during crystal growth (Dunbar et al., 1994; Sumner, 2007, Kelly et al, 2008b). The compositional range of anorthoclase is An $\mathrm{n}_{10-}$ ${ }_{23} \mathrm{Ab}_{62-68} \mathrm{Or}_{11-17}$ (Kelly et al., 2008b). The dominant compositional zoning is defined by high- and low-Ca zones in the crystal and is attributed to either convective processes (Kelly et al, 2008b) or boundary layer effects during crystallization (Sumner, 2007). The growth rates of the anorthoclase megacrystals are discussed in detail in section 3.3.3.

\subsubsection{Sr, $\mathrm{Nd}, \mathrm{Hf}$, and Pb Isotopic Compositions of Erebus Lavas: A HIMU-like source}

The EV lava samples (Figures 11 and 12) have highly radiogenic ${ }^{206} \mathrm{~Pb} /{ }^{204} \mathrm{~Pb}$ (Sun and Hansen, 1975; Sims and Hart, 2006 Sims et al., 2008a), low ${ }^{87} \mathrm{Sr} /{ }^{86} \mathrm{Sr}$ (Kyle et al., 1992; Sims 
and Hart, 2006; Sims et al., 2008a), and intermediate ${ }^{143} \mathrm{Nd} /{ }^{144} \mathrm{Nd}$ and ${ }^{176} \mathrm{Hf} /{ }^{177} \mathrm{Hf}$ (Sims and Hart, 2006; Sims et al., 2008a). The highly radiogenic ${ }^{206} \mathrm{~Pb} /{ }^{204} \mathrm{~Pb}$ (Sun and Hansen, 1975; Sims and Hart, 2006; Sims et al., 2008a) is considered to be the defining isotopic signature for categorizing these lavas as "HIMU", which is an acronym derived from the inference that lavas with high ${ }^{206} \mathrm{~Pb} /{ }^{204} \mathrm{~Pb}$ originate from a source with high time-integrated ${ }^{238} \mathrm{U} /{ }^{204} \mathrm{~Pb}$, which is referred to as $\mathrm{mu}(\mu)$ in isotope nomenclature. Lavas from St. Helena volcano in the Atlantic represent the end-member HIMU mantle component, and the origin of the source of these lavas has been discussed in numerous publications (e.g., Hart, 1988; Willbold and Stracke, 2006; French and Romanowicz, 2015; Weiss et al., 2016).

There have been several studies on the isotopic composition of the lavas from Erebus volcano and the other volcanic centers on Ross Island:

- Sun and Hansen (1975) measured Pb isotopes by thermal ionization mass spectrometry (TIMS) on a limited number of basanites and related differentiates from the Erebus volcanic province. They were the first to note the unique HIMU-like, or radiogenic, $\mathrm{Pb}$ isotopic signature for the McMurdo Volcanic Group (MVG) lavas.

- Stuckless and Ericksen (1976) published low-precision Sr isotopic data on samples from the Erebus volcanic province, including a few samples from DVDP cores.

- Kyle et al. (1992) measured Sr isotopes on several samples from the EL and EFS suites. They concluded that: 1) the uniform $\mathrm{Sr}$ isotopes from basanite to phonolite supported major-element modeling which indicates that the EL resulted from simple fractional crystallization of a parental basanite derived from a homogeneous mantle source; and 2) the high ${ }^{87} \mathrm{Sr} /{ }^{86} \mathrm{Sr}$ of the trachyte indicates that continental crust was assimilated during evolution of the EFS.

- Sims and Hart (2006) reported Nd, Sr, Th, and Pb isotopic compositions of four historic bombs as part of a global study evaluating the relationship between U-Th disequilibria systematics and long-lived radiogenic $\mathrm{Nd}, \mathrm{Sr}$, and $\mathrm{Pb}$ isotope systematics (see section 2.3.4).

- Sims et al. (2008a) reported Nd, Sr, Hf, and Pb isotope systematics on samples from all three eruptive phases of EV over the entire compositional range from basanite to phonolite which defines the EL. Specific emphasis was placed on analyzing the complete liquid-line 
of descent: this included basanitic DVDP and early phase-one EL samples, which are used as parental end-members for calculating the liquid-line of descent for the EL (Kyle et al., 1992); early-stage phonotephrites; dated upper-summit phonolite lavas (Esser et al., 2004); and a suite of historic phonolite bombs collected over the past 30 years. Sims et al. (2008a) came to three conclusions:

1. Isotopic data show a marked distinction between the early-stage basanites and phonotephrites, whose $\mathrm{Nd}, \mathrm{Hf}, \mathrm{Sr}$, and $\mathrm{Pb}$ isotope compositions are variable (particularly $\mathrm{Pb}$ ), and the later, evolved phonolitic lavas and bombs, whose $\mathrm{Nd}, \mathrm{Hf}, \mathrm{Sr}$, and $\mathrm{Pb}$ isotope compositions are essentially invariant (see Figures 5 and 6 in Sims et al., 2008a). The observation that the Erebus lineage lavas define a trend of decreasing isotopic variability with increasing extent of differentiation indicates that magma mixing has played a fundamental role in establishing the isotopic and compositional uniformity of the more recent phonolites erupted from EV (Sims et al., 2008a).

2. In multiple isotope space, the Erebus lineage lavas lie along a mixing trajectory between the two mantle end-members DMM (depleted MORB (mid-ocean ridge basalts) mantle) and HIMU (Sims et al., 2008a). Because of the position of these mantle components within the "Mantle Tetrahedron" they also lie between HIMU and the theoretical mantle component 'FOZO' as defined by Hart et al. (1992).

3. All four isotope systems, $\mathrm{Sr}, \mathrm{Nd}, \mathrm{Hf}$, and $\mathrm{Pb}$, are coherent in their mixing relationships with the HIMU end-member defined by St. Helena, thereby placing important constraints on both the age (Archean or early Proterozoic) and origin of the HIMU-like mantle source of Erebus lavas (see section 3.1).

- Phillips et al. (2018) measured major and trace element concentrations and $\mathrm{Sr}, \mathrm{Nd}, \mathrm{Pb}$, and Hf isotope compositions of 57 samples from the three peripheral volcanic centers, Mt. Terror, Mt. Bird, and Hut Point Peninsula, that surround EV on Ross Island. These samples are mostly older ( 0.3 to $4 \mathrm{Ma}$ ) and mainly basanitic in composition. The Ross Island samples analyzed by Phillips et al. (2018) have ${ }^{87} \mathrm{Sr} /{ }^{86} \mathrm{Sr}$ ranging from 0.702907 0.703147 , $\varepsilon_{\mathrm{Nd}}$ ranging from +4.3 to +6.3 , $\varepsilon_{\mathrm{Hf}}$ ranging from +5.6 to +8.6 , and ${ }^{206} \mathrm{~Pb} /{ }^{204} \mathrm{~Pb}$ ranging from 19.3 to 20.2. The $\mathrm{Sr}, \mathrm{Nd}, \mathrm{Hf}$, and $\mathrm{Pb}$ isotope compositions for all four volcanoes of Ross Island (Erebus, Terror, Bird, and Hut Point Peninsula) fall on a mixing line between the HIMU and DMM mantle end-members, with a very small contribution 
from an EM (enriched mantle) component. Small differences in the isotopic compositions of the four volcanoes, most notably Mt. Bird, imply mantle source heterogeneity on a length scale of less than $40 \mathrm{~km}$.

The HIMU-like $\mathrm{Pb}$ isotopic signature observed for Erebus lineage lavas is a pervasive feature of rocks from Antarctica, the sub-Antarctic islands, and some New Zealand Cenozoic volcanism as well (Sun and Hansen, 1975; Rocholl et al., 1995; Hart et al., 1995; 1997; Finn et al., 2005; Panter et al, 2000; 2006; Sims and Hart, 2006; Sims et al., 2008a; Phillips et al., 2018). The origin of this HIMU-like signature is a matter of long-standing debate and will be discussed in section 3.1 .

\subsubsection{U- and Th-Decay Series Measurements of Erebus Lava Bombs of Known Age}

The open conduit degassing and pyroclastic bombs of known age regularly ejected by Strombolian eruptions at EV make it an ideal system to measure U-series disequilibria to evaluate both the depth of melting and the timescales of magma genesis, melt evolution, crystal growth rates, and magma degassing.

U- and Th-decay series nuclides are ideal for determining both the chronology and timescales of the magmatic processes occurring at EV, for three reasons: 1) the elemental characteristics and chemical affinities of the different nuclides make them applicable to a wide range of chemical processes including mantle melting, anorthoclase crystallization, and magma degassing; 2) the half-lives of the relevant nuclides are commensurate with the timescales of these processes; and 3) the principles of secular and transient equilibrium (Bateman, 1910) constrain the initial relative abundances of parent and daughter nuclides and thus provide an important and unique constraint on elemental fractionation processes. U-series disequilibria measurements of lava bombs of known age from EV provide important constraints on the timescales of the magmatic processes occurring in the shallow portion of the EV lava lake, namely crystallization rates, magma residence times, and degassing rates. U-series measurements also provide constraints on deep melting processes, assuming one can confidently see through disequilibrium effects caused by shallow-level processes.

It is important to note for the following that isotopic abundances are expressed in terms of activity/per unity weight (e.g., disintegrations per minute/gram of rock; dpm/g), where the 
activity is defined as the nuclide's decay constant multiplied by its molar atomic abundance. Activities are denoted by the use of parentheses () around the nuclide in question. This is a convenient formalism making the comparison of parent/daughter activity ratios a direct measure of the extent of elemental fractionation that occurred within a given isotope system.

There have been three studies measuring U-series disequilibria in Erebus lavas.

- Reagan et al. (1992) used $\left({ }^{238} \mathrm{U}\right)-\left({ }^{230} \mathrm{Th}\right)-\left({ }^{226} \mathrm{Ra}\right)$ and $\left({ }^{232} \mathrm{Th}\right)-\left({ }^{228} \mathrm{Ra}\right)$ disequilibria to obtain internal isochrons to constrain the magma residence times for anorthoclase-glass separates from bombs erupted in 1984 and 1988. Reagan et al. (1992) showed that the anorthoclase crystals were strongly enriched in ${ }^{226} \mathrm{Ra}$ over ${ }^{230} \mathrm{Th}$, whereas glass separates had ${ }^{226} \mathrm{Ra}$ deficits. Assuming that $\mathrm{D}_{\mathrm{Ra}}=\mathrm{D}_{\mathrm{Ba}}$ during crystal growth, and using two-point $\left({ }^{226} \mathrm{Ra}\right) / \mathrm{Ba}$ vs $\left({ }^{230} \mathrm{Th}\right) / \mathrm{Ba}$ isochrons (anorthoclase and glass pairs) for the two samples, calculated ages of 2,520 years for the 1984 sample and 2,225 years for the 1988 sample were obtained. Using the activity of ${ }^{228} \mathrm{Th}$ as a proxy for ${ }^{228} \mathrm{Ra}$ (which is reasonable given the very short half-life of ${ }^{228} \mathrm{Th}$ ), Reagan et al. (1992) also measured significant $\left({ }^{228} \mathrm{Th} /{ }^{232} \mathrm{Th}\right)$ disequilibrium in the anorthoclase megacrystals $(\sim 2.16)$, whereas the glass was in equilibrium with $\left({ }^{228} \mathrm{Th}\right) /\left({ }^{232} \mathrm{Th}\right)$ of 1.0 . Because of the short half-life of ${ }^{228} \mathrm{Ra}\left(\mathrm{t}_{1 / 2}\right.$ $=5.77$ years) this result implies that the anorthoclase crystals grew recently and rapidly. As such, Reagan et al. (1992) suggested that the ${ }^{228}$ Th disequilibria arise from the presence of young rims with ${ }^{228} \mathrm{Ra}$ excesses.

- Subsequently, Sims and Hart (2006) measured Nd, Sr, Th, and Pb isotopes on four historic bombs as part of a global study evaluating the relationship between $\left({ }^{238} \mathrm{U}\right)$ $\left({ }^{230} \mathrm{Th}\right)$ disequilibria systematics and long-lived radiogenic $\mathrm{Nd}, \mathrm{Sr}$, and $\mathrm{Pb}$ isotope systematics. Their results showed that the $\left({ }^{230} \mathrm{Th} /{ }^{232} \mathrm{Th}\right)$ and $\left({ }^{238} \mathrm{U} /{ }^{232} \mathrm{Th}\right)$ of Erebus bombs are intermediate relative to other ocean island and mid-ocean ridge basalts and fall on the HIMU end-member in plots of $\mathrm{Pb}$ isotopes versus $\left({ }^{230} \mathrm{Th} /{ }^{232} \mathrm{Th}\right)$ and $\left({ }^{238} \mathrm{U} /{ }^{232} \mathrm{Th}\right)$. For the ${ }^{238} \mathrm{U}-{ }^{230} \mathrm{Th}$ isotope system, Erebus represents the best end-member approximation of the HIMU source, because there are no samples young enough for ${ }^{238} \mathrm{U}^{230} \mathrm{Th}$ disequilibria studies from St Helena and Mangai-Tubai (HIMU endmembers). They also noted that the ${ }^{230} \mathrm{Th} /{ }^{238} \mathrm{U}>1$ in all of the samples required melting in the presence of residual garnet, consistent with fractionations observed for the middle to heavy REE. 
- Sims et al. (2013) measured ${ }^{238} \mathrm{U}^{230} \mathrm{Th}^{226}{ }^{22} \mathrm{Ra}_{-}{ }^{210} \mathrm{~Pb}-{ }^{210} \mathrm{Po},{ }^{232} \mathrm{Th}^{228} \mathrm{Ra}^{228} \mathrm{Th}$ and ${ }^{235} \mathrm{U}-$ ${ }^{231} \mathrm{~Pa}^{227} \mathrm{Ac}$ in a suite of 22 phonolite volcanic bombs erupted between 1972 and 2005 , and five anorthoclase megacrysts separated from bombs erupted in 1984, 1989, 1993, 2004, and 2005 (Figures 13 and 14). It is noteworthy that these were the first measurements of ${ }^{231} \mathrm{~Pa}^{227} \mathrm{Ac}$ in volcanic samples, and thus the first data set for any volcanic system to examine the entire suite of relevant ${ }^{238} \mathrm{U},{ }^{235} \mathrm{U}$, and ${ }^{232} \mathrm{Th}$ decay series nuclides. As will be discussed in section 3.3.3, these results allowed Sims et al. (2013) to place constraints on both the residence time of anorthoclase in the Erebus magmatic system, and thus crystal growth rates, and the depths and timescales of magma degassing.

\subsubsection{Measurements of Aerosols and Gases from Erebus Volcano}

The persistent, open-vent degassing of EV makes it a significant point source of gases and aerosol to the austral polar troposphere. Scientific interest in EV's gaseous emissions are driven by several factors, including: 1) the potential impact of EV's sulfur, halogens, and NOx emissions on the nearly pristine south polar atmospheric environment (Zoller et al., 1974; Radke, 1982; Zreda-Gostynska et al., 1993, 1997; Oppenheimer et al., 2005, 2009; Ilyanskaya et al., 2010); 2) EV's dynamic open-conduit lava lake and Strombolian activity; 3) the high altitude and dry climate of EV's crater and the continuously degassing active lava lake which minimize scrubbing of gas emissions and facilitate remote measurements such as open-path Fourier Transform Infrared (FTIR) Spectroscopy, Correlation Spectroscopy (COSPEC), and Differential Optical Absorption Spectroscopy (DOAS); and 4) EV's location next to the United States Antarctic Program's (USAP) McMurdo Station, which makes access and working conditions logistically feasible and relatively safe, even almost comfortable, when compared to other alkaline volcanoes with persistent lava lakes (e.g., Nyiragongo or Erta Ale). Gas measurements, particularly $\mathrm{SO}_{2}$ and $\mathrm{CO}_{2}$ fluxes and ratios, are important for volcano hazard assessment and, as such, should be an integral part of any monitoring program to evaluate the current state of the EV system and its possible threat to McMurdo Station personnel.

Since the late 1970s, there have been many studies measuring Erebus gas compositions and fluxes. These studies have included: aerosol sampling (Radke, 1982; Chuan et al., 1986; 
Zreda-Gostynska et al., 1993, 1997; Ilyinskaya et al., 2010); ultraviolet spectroscopy for $\mathrm{SO}_{2}$ flux measurements (Rose et al., 1985; Kyle et al., 1990, 1994; Sweeney et al., 2008; Boichu et al., 2010); open-path FTIR spectroscopy of magma degassing (Oppenheimer and Kyle, 2008b, Oppenheimer et al., 2011; Illanko et al., 2015); and infrared analysis of flank $\mathrm{CO}_{2}$ abundance and flux (Wardell et al., 2003; 2004).

\subsubsection{Filter Measurements of Erebus Plume Aerosols and Gases}

Volcanic aerosols are typically collected on filter packs or cascade impactors, and the filters are analyzed by scanning electron microscopy, ion chromatography, neutron activation analyses, or inductively coupled plasma mass spectrometry. Kyle et al. (1990) showed that the Erebus plume is enriched in the trace metals In, $\mathrm{As}, \mathrm{Hg}, \mathrm{Zn}, \mathrm{Au}, \mathrm{Se}, \mathrm{Co}, \mathrm{W}, \mathrm{Cs}, \mathrm{Mo}, \mathrm{Rb}, \mathrm{Cu}, \mathrm{Na}$, and $\mathrm{K}$ and has elevated abundances of halogens $\left(\mathrm{Cl}, \mathrm{Fl}, \mathrm{Br}\right.$, etc.) relative to $\mathrm{SO}_{2}$ and other alkaline volcanoes. In fact, gases from EV have some of the highest halogen $/ \mathrm{SO}_{2}$ ratios of volcanoes globally with $\mathrm{HF} / \mathrm{SO}_{2}$ mass ratios > 0.2 and $\mathrm{HCl} / \mathrm{SO}_{2}$ mass ratios > 0.5 (Kyle, 1990c; Pyle and Mather, 2009; Ilyinskaya et al., 2010; Boichu et al., 2011).

Aerosol measurements have shown that Erebus volcano represents a potentially important point source of chemical species to a wide region of the Polar Plateau (Zoller et al., 1974; Chuan et al., 1986; Chuan, 1994; Meeker et al., 1991; Zreda-Gostynska et al., 1997; Wardell, 2008; Ilyinskaya et al., 2010). As such, the signature and distribution of aerosols from EV has been extensively investigated (Zoller et al., 1974; Chuan et al., 1986; Chuan, 1994; Meeker et al., 1991; Ilyinskaya et al., 2010). Noteworthy discoveries from early studies were the occurrence of elemental gold in aerosol samples, possibly formed by reduction of $\mathrm{Au}-\mathrm{Cl}$ complexes by sulfur (Meeker et al., 1991), and that aerosol mass was narrowly confined to particles with a diameter of $\sim 0.1 \mathrm{~mm}$ (Radke, 1982), substantially finer than observed at other volcanoes (e.g., Mather et al., 2003; Martin et al., 2008). The latter observation is an important constraint on the dispersal of aerosols and led Radke (1982) to conclude that up to $32 \%$ of the Antarctic sulfate budget observed at the South Pole could be attributed to Erebus. Zreda-Gostynska et al. (1997) calculated emission rates (using $\mathrm{SO}_{2}$ fluxes from Kyle et al., 1990) and enrichment factors (using the method of Zoller et al., 1983) for a large suite of trace metals and halogens and concluded that the similarity of trace element patterns of aerosols collected over the South Pole indicates 
that the Erebus gas plume provides a significant contribution to the aerosol inventory observed in deep interior Antarctic snow. Lastly, Ilyinskaya et al. (2010) measured the chemical composition and size distribution of the Erebus aerosols, focusing on the water-soluble fraction. They show that: 1) Erebus aerosols are distinct from other volcanic sources in that they are dominated by chloride-bearing particles (over $30 \%$ of total mass) and have an unusually high $\mathrm{Cl}^{-} / \mathrm{SO}_{4}{ }^{2-}$ molar

ratio of 3.5, similar to early conclusions of Kyle et al. (1990); 2) water soluble aerosols have high concentrations of $\mathrm{F}^{-}, \mathrm{Cl}^{-}, \mathrm{Br}^{-}$, and $\mathrm{SO}_{4}{ }^{2-}$ in a very narrow particle size range $(0.1-0.25 \mathrm{~mm})$; this small size fraction is important for aerosol dispersal (Radke, 1982). Furthermore, the detection of particulate $\mathrm{Br}^{-}$implies that quiescent Erebus emissions can contribute to tropospheric ozone depletion (Boichu et al., 2011); and 3) halide-alkali metal salts $(\mathrm{Na}, \mathrm{K})(\mathrm{Cl}, \mathrm{F})$ are the most abundant chemical species in the aerosol population. Collectively, aerosol research conducted to date shows that EV's emissions have regional significance, contribute to the Antarctic atmosphere, and are preserved in glacio-chemical records.

\section{$\underline{\text { 2.3.5.2 Ultraviolet Spectroscopy for } \mathrm{SO}_{2} \text { Flux Measurements }}$}

The measurement of $\mathrm{SO}_{2}$ flux from volcanoes is of major importance for both hazard assessment and the evaluation of a volcano's environmental impact. These flux measurements also provide a critical reference value by which to determine emission rates of other chemical species (Kyle et al., 1990; Sweeney et al., 2008).

$\mathrm{SO}_{2}$ measurements using UV spectroscopy have evolved significantly over the past several decades (e.g., McGonigle and Oppenheimer, 2003) with EV having played a significant early role in the development of this technology (Symonds et al., 1985; Kyle and McIntosh, 1989; Kyle et al., 1990; 1994; Sweeney et al., 2008; Boichu et al., 2010). Measurements of volcanic $\mathrm{SO}_{2}$ gas fluxes on Erebus have used scattered light ultraviolet spectroscopy (Correlation Spectroscopy (COSPEC) or Differential Optical Absorption Spectroscopy (DOAS)). The lower Erebus hut has provided an ideal location from which to profile the plume across its transport direction utilizing a scanning UV zenith-viewing telescope (Kyle and McIntosh, 1989; Kyle et al., 1990; 1994; Sweeney et al., 2008). Importantly, at Erebus volcano, measurement of $\mathrm{SO}_{2}$ is facilitated by its persistent and degassing lava lake and its high altitude $(3700 \mathrm{~m})$ and resulting 
dry climate which help minimize hydrothermal scrubbing of its emissions and facilitate remote COSPEC and DOAS measurement techniques (Symonds et al., 1985; Oppenheimer et al., 2011).

New Mexico Tech's Mount Erebus Volcano Observatory (MEVO) conducted decades of COSPEC and DOAS measurements of $\mathrm{SO}_{2}$ in the Erebus gas plume. Sweeney et al. (2008), in a well-considered interpretation of this decade-long effort, assembled 8064 individual $\mathrm{SO}_{2}$ emission rates measured at EV between 1992 and 2005. The compilation shows a normal distribution skewed slightly toward higher values and ranges from $0.3 \mathrm{Mg} \mathrm{d}^{-1}\left(0.003 \mathrm{~kg} \mathrm{~s}^{-1}\right)$ to $224 \mathrm{Mg} \mathrm{d}^{-1}\left(2.6 \mathrm{~kg} \mathrm{~s}^{-1}\right)$ with an average $61 \pm 27 \mathrm{Mg} \mathrm{d}^{-1}\left(0.7 \pm 0.3 \mathrm{~kg} \mathrm{~s}^{-1}\right.$; Figure 15). Sweeney et al. (2008) also demonstrated fluctuations in $\mathrm{SO}_{2}$ emission rates occurring on short timescales, with wavelengths varying between $\sim 10$ minutes and 3 hours, as well as long-term variations on the timescales of days. Additionally, they note that an increase in average $\mathrm{SO}_{2}$ emission rates since 1996 from $39 \pm 17 \mathrm{Mg} \mathrm{d}^{-1}\left(0.5 \pm 0.2 \mathrm{~kg} \mathrm{~s}^{-1}\right)$ to $\sim 80 \pm 25 \mathrm{Mg} \mathrm{d}^{-1}\left(0.9 \pm 0.3 \mathrm{~kg} \mathrm{~s}^{-1}\right)$ in 2005 (Sweeney et al., 2008). In a follow-up study, Boichu et al. (2010) noted that an important source of uncertainty in flux measurements (which is the product of the gas column abundance, integrated across the plume section, and the plume transport speed) on Erebus is the estimation of plume speed, which is typically assumed to be the wind speed at or near the gas plume altitude (Boichu et al., 2010). To eliminate this source of error in $\mathrm{SO}_{2}$ flux measurements, Boichu et al. (2010) employed a technique using two UV spectrometers equipped with wide-field-of-view telescopes (dual-wide-field-of-view DOAS) that instantaneously collect light from two narrow and parallel entire cross-sections of the plume. This method obviates the need to scan the plume and also greatly enhances estimates of the plume velocity and calculated gas fluxes (Boichu et al., 2010). In a single $\sim 2 \mathrm{~h}$ experiment on December 2006, their results showed that $\mathrm{SO}_{2}$ flux varied from $0.17-0.89 \pm 0.2 \mathrm{~kg} \mathrm{~s}^{-1}$, the vertical plume velocity varied from $1-2.5 \pm 0.1 \mathrm{~m} \mathrm{~s}^{-1}$, and the flux had a cyclicity ranging from about 11-24 min.

Two important first-order geochemical observations have been made of sulfur degassing at Erebus volcano:

- The EV average $\mathrm{SO}_{2}$ emission rate of $61 \mathrm{Mg} \mathrm{d}^{-1}\left(0.7 \mathrm{~kg} \mathrm{~s}^{-1}\right)$ is low compared to other persistently active volcanoes (Andres and Kasgnoc, 1998), presumably due to the phonolitic magma's evolved nature and subsequent low sulfur content. Basaltic volcanoes, such as Etna $\left(58 \mathrm{~kg} \mathrm{~s}^{-1}\right)$ and Stromboli $\left(3.5 \mathrm{~kg} \mathrm{~s}^{-1}\right)$, emit considerably more 
$\mathrm{SO}_{2}$ (Caltabiano et al.,1994; Caltabiano et al., 2004) than EV. This difference in $\mathrm{SO}_{2}$ flux is attributed to the formation of EV's phonolite magma, modeled as a $25 \%$ residual liquid that formed through crystal fractionation of a mantle-derived parental basanite, during which sulfur is removed from the system by the crystallization of pyrrhotite (Kyle et al., 1994).

- The phonolitic melts of EV have estimated oxygen fugacities that are 0.5 log units below the quartz-fayalite-magnetite buffer (QFM; Burgisser et al., 2012), making them very reduced. At such oxygen fugacities, the equilibrium gas composition released from the phonolitic magma should have molar $\mathrm{H}_{2} \mathrm{~S}_{\mathrm{SO}}$ of $\sim 0.2$ to 1.2 (Burgisser et al., 2012). $\mathrm{H}_{2} \mathrm{~S}$ has not been detected, however, in the gaseous emissions of EV. Two possible reasons, which could act collectively, have been proposed for the lack of $\mathrm{H}_{2} \mathrm{~S}$ : 1) $\mathrm{H}_{2} \mathrm{~S}$ is being oxidized by reaction with $\mathrm{O}_{2}$ from ambient air at the magma-air interface (Kyle et al., 1990; 1994; Sweeney et al., 2008); or, 2) $\mathrm{H}_{2} \mathrm{~S}$ degasses at greater depth and higher pressure in the magmatic system and converts to $\mathrm{SO}_{2}$ during transport to the surface (e.g., de Moor et al., 2013 on the reduced lava lake of Erta Ale volcano, Ethiopia).

\subsubsection{Infrared Spectroscopy of Magma Degassing}

An important development in the interpretation and understanding of degassing processes at EV has been the introduction of infrared spectroscopy. Infrared spectroscopic techniques now reliably measure $\mathrm{CO}, \mathrm{CO}_{2}, \mathrm{OCS}, \mathrm{H}_{2} \mathrm{O}, \mathrm{SO}_{2}, \mathrm{HCl}$, and $\mathrm{HF}$, and have thus provided a wealth of new data for investigating degassing processes in the EV conduit system.

Wardell et al. (2004) reported the first measurements of $\mathrm{CO}$ and $\mathrm{CO}_{2}$ flux from $\mathrm{EV}$. These novel measurements were made by airborne profiling of $\mathrm{CO}_{2}$ abundances in the plume using an infrared analyzer plumbed to an outside inlet attached to the helicopter's nose antenna. CO was measured via Open Path Fourier Transform Infrared Spectroscopy (OP-FTIR) using an infrared lamp sited on the crater rim as a thermal source with the FTIR spectrometer located at various distances ( 100 plus meters) down the flank. Significant results of this study are:

- The $\mathrm{CO}_{2}$ flux estimated by airborne profiling of $\mathrm{CO}_{2}$ abundances (Wardell et al. 2003; 2004) was calculated to be $22.3 \pm 1.0 \mathrm{~kg} / \mathrm{s}(\sim 1900 \mathrm{Mg} / \mathrm{d})$ from the average of three years 
of measurements: $21.4 \mathrm{~kg} / \mathrm{s}$ for 18 December 1997; $23.3 \mathrm{~kg} / \mathrm{s}$ for 17 December 1999; and $22.2 \mathrm{~kg} / \mathrm{s}$ for 16 January 2001.

- Results from the FTIR measurements collected in December 1995 yield a range for the $\mathrm{CO} / \mathrm{SO}_{2}$ molar ratio from 2.51 to 3.28 with an average of $2.96 \pm 10 \%$. Using a corresponding unpublished $\mathrm{SO}_{2}$ flux from EV as measured by COSPEC of $0.58 \mathrm{~kg} / \mathrm{s}$ (50 $\mathrm{Mg} /$ day), Wardell et al. (2004) calculate a CO flux of $1.74 \mathrm{~kg} / \mathrm{s}$ (150 Mg/day).

All subsequent OP-FTIR measurements have used the Erebus lava lake as the thermal source. The maximum OP-FTIR signal was reasonably interpreted to be the hottest part of the lava lake (Oppenheimer and Kyle, 2008b; Oppenheimer et al., 2009; 2011; Burgisser et al., 2012; Illanko et al., 2015). The following results are highlights from these studies:

- From measurements in December 2004, Oppenheimer and Kyle (2008b) report measurements of $\mathrm{H}_{2} \mathrm{O}, \mathrm{CO}_{2}, \mathrm{CO}, \mathrm{SO}_{2}, \mathrm{HF}, \mathrm{HCl}$, and $\mathrm{OCS}$ (in order of molar abundance) in the gas column rising from the lava lake. Volcanogenic $\mathrm{CH}_{4}, \mathrm{H}_{2} \mathrm{~S}, \mathrm{NO}, \mathrm{NO}_{2}, \mathrm{HBr}$, or $\mathrm{SiF}_{4}$, however, were not detected. Based on OP-FTIR's detection limit for $\mathrm{H}_{2} \mathrm{~S}$, the abundance of $\mathrm{SO}_{2}$ exceeds that of $\mathrm{H}_{2} \mathrm{~S}$ by a factor of at least $\sim 50$. As discussed above, this is an important observation given the reduced nature of the Erebus phonolitic lava lake (Oppenheimer and Kyle, 2008b).

- Using independent $\mathrm{SO}_{2}$ flux determinations via DOAS and measured gas ratios, Oppenheimer and Kyle (2008b) report the first fluxes of $\mathrm{H}_{2} \mathrm{O}$ and carbonyl sulfide ( $\sim 0.5$ $\mathrm{Mg} \mathrm{d}-1)$. These $\mathrm{SO}_{2}$-derived fluxes, given as mass, but listed in order of molar abundance are: $\mathrm{H}_{2} \mathrm{O}\left(\sim 860 \mathrm{Mg} \mathrm{d}^{-1}\right) ; \mathrm{CO}_{2}\left(1330 \mathrm{Mg} \mathrm{d}^{-1}\right) ; \mathrm{CO}\left(54 \mathrm{Mg} \mathrm{d}^{-1}\right) ; \mathrm{SO}_{2}(74 \mathrm{Mg}$ $\left.\mathrm{d}^{-1}\right) ; \mathrm{HCl}\left(21 \mathrm{Mg} \mathrm{d}^{-1}\right) ; \mathrm{HF}\left(21 \mathrm{Mg} \mathrm{d}^{-1}\right)$; and OCS $\left(\sim 0.5 \mathrm{Mg} \mathrm{d}^{-1}\right)$ for a total flux of 2360 $\mathrm{Mg} \mathrm{d}^{-1}$ (Oppenheimer and Kyle, 2008b). This shows that while $\mathrm{H}_{2} \mathrm{O}$ has the highest emission in terms of molar abundance, by mass $\mathrm{CO}_{2}$ is the dominant component of the Erebus gas plume (Oppenheimer and Kyle, 2008b).

- During the December 2004 gas measurements at EV, two lava lakes (the periodic Werner's lava lake and the long-lived Ray's lava lake) were present. The gas compositions of the individual plumes emitted by the two lava lakes are distinct (particularly the $\mathrm{H}_{2} \mathrm{O} / \mathrm{CO}_{2}$ ratio and $\mathrm{HF}$ ) and point to a more 'evolved' gas being released from Werner's lava lake. This difference was interpreted to suggest that 
Werner's lava lake is fed by a shallow offshoot of the conduit that supplies Ray's lava lake, or that magma feeding Werner's lava lake is more degassed due to a higher degree of crystallization (Oppenheimer and Kyle, 2008b).

- Focusing on the passive degassing regime from the data collected in December 2004, Oppenheimer et al. (2009) identified significant oscillatory variations in gas composition during passive degassing with cycles of 4 to 15 min (Oppenheimer et al., 2009).

- In December 2005, Oppenheimer et al. (2010) conducted concurrent gas measurements using infrared spectrometers sited both on the crater rim and out to $\sim 56 \mathrm{~km}$ downwind, using a Twin Otter aircraft. Based on wind speeds, the calculated ages of the plume gases sampled ranged from $<1 \mathrm{~min}$ to as long as $9 \mathrm{~h}$. Three species (CO, OCS, and $\mathrm{SO}_{2}$ ) were measured from both air and ground. While CO and OCS were conserved in the plume, consistent with their long atmospheric lifetimes, the downwind measurements indicate a $\mathrm{SO}_{2} / \mathrm{CO}$ ratio of $\sim 20 \%$ of that observed at the crater rim, suggesting rapid chemical conversion of $\mathrm{SO}_{2}$ to $\mathrm{H}_{2} \mathrm{SO}_{4}$.

- Using measurements made in December 2005 during a period when intermittent Strombolian eruptions were occurring in the lava lake, Oppenheimer et al. (2011) found a significant difference in the $\mathrm{CO}_{2} / \mathrm{H}_{2} \mathrm{O}$ mass ratio between passive degassing ( $\sim 1.8$ by mass) and the eruption of the gas slugs during Strombolian events ( $\sim 43$ by mass).

- Using the December 2005-January 2006 data set, Burgisser et al. (2012) noted large differences in the molar $\mathrm{CO}_{2} / \mathrm{CO}$ ratios between passive degassing ( 14.8) and Strombolian eruptions ( 29 and 65; Figure 16). The observation that the passive degassing was uniform while the two Strombolian eruptions had very different ratios led to a model wherein adiabatic variances in degassing of phonolitic magma is causing differences in this ratio, which is in stark contrast to Oppenheimer et al. (2011) who call for Strombolian eruption gases to come from a deeper basanitic source.

- Using the OP-FTIR gas measurements from December 2004, Illanko et al. (2015) use wavelet-based frequency analysis for a time-series gas emission measurement from the lava lake. This frequency analysis reveals a cyclic change in total gas column amount with a period of about $10 \mathrm{~min}$, and a similarly phased cyclic change in proportions of volcanic gases, which they attribute to differences in pressure-dependent solubilities. 
- Finally, in addition to the gas emissions from the open conduit lava lake, degassing also occurs from the flanks of Erebus volcano through warm ground and fumarolic ice towers within and around the summit. On Erebus the fumarolic ice towers allow diffuse degassing to be visually identified (Figure 8). Measuring the $\mathrm{CO}_{2}$ concentration, air-flow velocity, and size of the exit orifice at 43 actively degassing ice towers, Wardell et al. (2004) reported $\mathrm{CO}_{2}$ fluxes ranging from $<0.0001$ to $0.034 \mathrm{~kg} \mathrm{~s}^{-1}$, with small patches of steaming warm ground contributing an additional $0.010 \mathrm{~kg} \mathrm{~s}^{-1}$. Delta ${ }^{13} \mathrm{C}$ of the highest temperature fumaroles ranged from -2.1 to $-4.7 \%$, suggesting a magmatic origin for the $\mathrm{CO}_{2}$. The estimated output of flank $\mathrm{CO}_{2}$ degassing is $0.46 \mathrm{~kg} \mathrm{~s}^{-1}\left(40 \mathrm{Mg} \mathrm{d}^{-1}\right)$. Compared with direct airborne measurements of the volcanic plume, passive flank emissions constitute less than $2 \%$ of the total volcanic $\mathrm{CO}_{2}$ budget emitted from Erebus volcano. Subsequent isotopic measurements of these passive flank gases have been shown to be a mixture of magmatic/mantle-derived $\mathrm{CO}_{2}$ and helium with ambient atmosphere (Fischer et al., 2013).

\subsubsection{Melt Inclusion Measurements}

The study of mineral-hosted melt inclusions can place important constraints on magmatic plumbing systems through measurements of pre-eruptive volatile contents, and, with the application of solubility models, determination of the depths at which inclusions were entrapped within growing crystals. Several melt inclusion studies have targeted EV, as well as the volcanic centers on the periphery of Ross Island (e.g., Dunbar et al., 1994; Eschenbacher, 1999; Seaman et al., 2006; Oppenheimer et al., 2011; Rasmussen et al., 2017). Dunbar et al. (1994) measured the concentrations of $\mathrm{H}_{2} \mathrm{O}(\sim 0.15 \mathrm{wt} \%), \mathrm{F}(\sim 0.28 \mathrm{wt} \%)$, and $\mathrm{Cl}(\sim 0.18 \mathrm{wt} \%)$ in phonolitic melt inclusions hosted in clinopyroxene and anorthoclase, as well as the co-existing matrix glass $\left(0.10 \pm 0.08 \mathrm{wt} \% \mathrm{H}_{2} \mathrm{O} ; 0.30 \pm 0.02 \mathrm{wt} \% \mathrm{~F} ; 0.18 \pm 0.01 \mathrm{wt} \% \mathrm{Cl}\right)$ from Erebus phonolite bombs. The striking similarity in concentrations among inclusions and matrix glass led them to conclude that crystallization occurred at shallow levels in the magmatic system. They used solubility modeling to estimate melt inclusion entrapment pressures of less than $\sim 30 \mathrm{MPa}$, although the lack of data on $\mathrm{CO}_{2}$ concentrations makes this a minimum value. Eschenbacher (1999) reported similarly low concentrations of $\mathrm{H}_{2} \mathrm{O}(0.15 \pm 0.04 \mathrm{wt} \%)$ in anorthoclase-hosted phonolitic melt inclusions, and found an average $\mathrm{CO}_{2}$ concentration of $670 \pm 120 \mu \mathrm{g} / \mathrm{g}$. Volatile 
contents were also determined for Erebus lineage olivine-hosted melt inclusions collected from Turk's Head (basanite, phonotephrite, and tephriphonolite), Inaccessible Island (tephriphonolite), and Tent Island (phonotephrite and tephriphonolite). The concentrations of $\mathrm{H}_{2} \mathrm{O}(0.13 \pm 0.05$ $\mathrm{wt} \%)$ and $\mathrm{CO}_{2}(800 \pm 500 \mu \mathrm{g} / \mathrm{g})$ are similar to those measured in the Erebus inclusions, with the exception of inclusions from Inaccessible Island, which contain systematically higher concentrations of $\mathrm{H}_{2} \mathrm{O}(0.53 \pm 0.07 \mathrm{wt} \%)$ and $\mathrm{CO}_{2}(2400 \pm 700 \mu \mathrm{g} / \mathrm{g})$. Here we estimated entrapment pressures from these concentrations using the solubility model of Ghiorso and Gualda (2015), which accurately reproduces results from solubility experiments performed on an Erebus phonotephrite by Iacovino et al. (2013). Our results suggest that the Erebus crystals and those from Turks Head and Tent Island grew at pressures of $\sim 100 \mathrm{MPa}$, whereas those collected on Inaccessible Island crystallized at $\sim 200 \mathrm{MPa}$. These pressures correspond to crystallization depths of $\sim 4$ and $\sim 9 \mathrm{~km}$, respectively, for an assumed crustal density of $2.7 \mathrm{~g} / \mathrm{cm}^{3}$. These values represent minimum depths if the inclusions contain $\mathrm{CO}_{2}$-rich vapor bubbles (e.g., Hartley et al., 2014; Moore et al., 2015).

Volatile concentrations in basanitic olivine-hosted melt inclusions from the peripheral volcanic centers - Mt Terror, Mt Bird, and Hut Point Peninsula - contrast sharply with those from Mt Erebus. They are associated with the DVDP lineage, which is defined by the presence of kaersutite, and are much richer in $\mathrm{H}_{2} \mathrm{O}$ and $\mathrm{CO}_{2}$. Eschenbacher (1999) measured $\mathrm{H}_{2} \mathrm{O}$ and $\mathrm{CO}_{2}$ in melt inclusions recovered from depths of $283 \mathrm{~m}$ and $295 \mathrm{~m}$ in the DVDP 3 drill core on Hut Point Peninsula. The DVDP 3 drill core inclusions are relatively $\mathrm{H}_{2} \mathrm{O}$ - and $\mathrm{CO}_{2}$-rich $(\sim 1.5$ wt $\%$ and $\sim 5,500 \mu \mathrm{g} / \mathrm{g}$, respectively), consistent with entrapment pressures of $\sim 330 \mathrm{MPa}$ (depths of $\sim 12 \mathrm{~km}$ ), significantly deeper than inferred for the Erebus lineage magmas. The $\mathrm{CO}_{2}$ in vapor bubbles - which can account for the majority of the $\mathrm{CO}_{2}$ in a melt inclusion - has not been accounted for in these estimates of entrapment pressures. Rasmussen et al. (2017) studied 90 olivine-hosted melt inclusions from nine DVDP lineage basanites from Hut Point Peninsula, Mt Terror, and Mt Bird and took into account the $\mathrm{CO}_{2}$ sequestered in vapor bubbles, providing the most robust estimates for magma storage depths beneath these volcanic centers. The glasses in these inclusions contain $0.4-2.0 \mathrm{wt} \% \mathrm{H}_{2} \mathrm{O}$ and $0.2-0.9 \mathrm{wt} \% \mathrm{CO}_{2}$. The total entrapped $\mathrm{CO}_{2}$ ranges from 0.2 to $1.8 \mathrm{wt} \%$, after correction for vapor bubbles. Entrapment pressures calculated

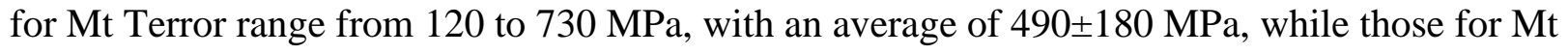




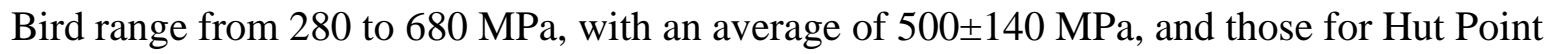
range from 160 to $650 \mathrm{MPa}$, with an average of $390 \pm 100 \mathrm{MPa}$. This large range of calculated entrapment pressures below Mt Terror, Mt Bird, and Hut Point Peninsula indicate crystallization and storage depths from $\sim 6 \mathrm{~km}$ to $>19 \mathrm{~km}$ (Rasmussen et al., 2017), with this deeper limit approaching the moho depth for this region (19-27 km; Finotello et al., 2011).

The picture that emerges from these melt inclusion studies suggests that magma storage beneath EV is relatively shallow $(\sim 4-9 \mathrm{~km})$, whereas beneath the peripheral eruptive centers it is deep ( 15-19 km). This has important implications for the volatile contents of parental magmas of the EV and DVDP lineages. It has long been held that magmas parental to both lineages are basanites that are nearly indistinguishable in composition except for their volatile contents, as suggested by the presence of amphibole in the DVDP lineage and its absence in the Erebus lineage (Kyle et al. 1992). A comparison of the $\mathrm{H}_{2} \mathrm{O}$ concentrations in the Erebus lineage olivine-hosted melt inclusions $(\sim 0.15 \mathrm{wt} \%)$ with those from the DVDP lineage $(\sim 1.2 \mathrm{wt} \%)$ would seem to support this conclusion. However, it must be recognized that while these values may reflect pre-eruptive concentrations, they do not necessarily represent the initial $\mathrm{H}_{2} \mathrm{O}$ contents of the parental magmas, as a result of processes that can occur before and after the inclusions were trapped. Melt inclusions trap samples of melt from which the olivine crystal is growing. The pressures of inclusion trapping for the Mt Terror, Mt Bird, and Hut Point basanites are in the lower crust, so the $\mathrm{H}_{2} \mathrm{O}$ content of parental magmas could have been modified during their transport from the mantle source region into the crust where they began to crystallize. Because of the relatively high solubility of $\mathrm{H}_{2} \mathrm{O}$ in silicate melts, the deep transport stage from mantle to crust is unlikely to have resulted in $\mathrm{H}_{2} \mathrm{O}$ loss from the melts, but other process such as vapor-saturated fractional crystallization or fluxing with relatively $\mathrm{CO}_{2}$-rich vapor could potentially have caused $\mathrm{H}_{2} \mathrm{O}$ changes (Rasmussen et al., 2017). After entrapment, olivine-hosted melt inclusions are physically isolated from most processes affecting the external magma, but rapid diffusion of $\mathrm{H}^{+}$through the host olivine causes the inclusions to be susceptible to modification as the external magma degasses (e.g., Chen et al., 2011; Gaetani et al., 2012; Bucholz et al., 2013; Chen et al., 2013). It is probable, therefore, that the low $\mathrm{H}_{2} \mathrm{O}$ concentrations that characterize EV lineage olivine-hosted melt inclusions reflect storage at shallow depths rather than low $\mathrm{H}_{2} \mathrm{O}$ concentrations at the time of entrapment. The lack of kaersutite in EV 
lineage lavas reflects their low $\mathrm{H}_{2} \mathrm{O}$ contents as they cooled in shallow reservoirs to temperatures at which amphibole becomes stable $\left(\sim 1050-1100{ }^{\circ} \mathrm{C}\right)$, rather than their initial $\mathrm{H}_{2} \mathrm{O}$ contents. A single, $\mathrm{H}_{2} \mathrm{O}$-rich magma was likely parental to both lineages.

The very low $\mathrm{H}_{2} \mathrm{O}$ contents of phonolitic melt inclusions (Dunbar et al., 1994; Eschenbacher, 1999) is interesting in light of the relatively high $\mathrm{H}_{2} \mathrm{O}$ of basanite parental magmas. Fractional crystallization of a basanite parent to a highly evolved melt, without any loss of $\mathrm{H}_{2} \mathrm{O}$ by degassing, should yield phonolitic melts with relatively high $\mathrm{H}_{2} \mathrm{O}$ contents (cf., rhyolitic melts at Hekla volcano formed by extensive crystal fractionation from a basaltic parent have 3.3-6.2 wt.\% $\mathrm{H}_{2} \mathrm{O}$; Portnyagin et al., 2012). Experimental phase equilibria for Erebus magma compositions constrain the pressures of differentiation from the basanite parent to $\sim 100$ $200 \mathrm{MPa}$ (Iacovino et al., 2016), at which pressure $\mathrm{H}_{2} \mathrm{O}$ is still relatively soluble. The low $\mathrm{H}_{2} \mathrm{O}$ contents of the phonolitic melt inclusions in anorthoclase phenocrysts thus seems to require substantial fluxing of $\mathrm{CO}_{2}$-rich vapor through the upper crustal storage and differentiation region (to reduce the dissolved $\mathrm{H}_{2} \mathrm{O}$ content; this effect is also confirmed by the phase equilibria). Further modification by $\mathrm{H}^{+}$diffusive loss post-entrapment may also have occurred when phonolitic magma with entrained anorthoclase phenocrysts was transported and stored at shallow depths beneath and in the lava lake.

Iacovino (2016) coupled the interpretation of melt inclusion volatile concentrations and gas emissions from the lava lake using thermodynamic calculations and mixing models. As discussed in Section 3.3.2, the modeling results support the hypothesis that the surface gas emissions from the EV lava lake are dominated by degassing from the deep basanite but include significant contributions from the phonolitic lava lake.

Melt inclusions can also provide constraints on the chemical and isotopic composition of the magma at the time of crystallization. In some studies, the range of the isotopic compositions among melt inclusions significantly exceeds the isotopic variation in the volcanic suite from which the lava was collected (Saal et al., 1998), in principle reflecting isotopic heterogeneity in the pre-aggregated melt. To evaluate this possibility for the EV and Ross Island lavas, Sims et al. (2008a) used secondary ionization mass spectrometry (SIMS) to measure the in-situ $\mathrm{Pb}$ isotope 
compositions of four anorthoclase-hosted melt inclusions from a 1984 bomb together with four olivine-hosted melt inclusions from DVDP. Their results showed that the Pb isotopes in the anorthoclase megacrysts are uniform and, within analytical uncertainties, similar to those of the host phonolitic lava. The olivine-hosted melt inclusions, however, show a large range in isotopic composition, but this variability is within analytical uncertainty of the host DVDP samples.

\subsubsection{Constraints on Temperature, Viscosity, and Oxygen Fugacity of the Erebus Phonolitic Magma}

\subsubsection{Magma Temperature}

The temperature of the EV phonolitic silicate liquid has not been measured directly in the lava lake. Early indirect estimates of the lava lake temperature were based on optical pyrometry and mineral thermometry (Kyle, 1977), melt inclusion homogenization (Dunbar et al., 1994), olivine-cpx thermometry (Caldwell and Kyle, 1994), and Forward Looking InfraRed (FLIR; Calkins et al., 2008). All these methods converged on a temperature of roughly $1000{ }^{\circ} \mathrm{C}$. Subsequent estimates from phase-equilibrium experiments on EV phonolite (Moussallam et al. 2013) gave a similar value of $925-975^{\circ} \mathrm{C}$, whereas thermodynamic modelling of gas redox pairs provides a much higher estimate of $1060-1080{ }^{\circ} \mathrm{C}$ (Burgisser et al. 2012).

\subsubsection{Magma Viscosity}

Le Losq et al. (2015) compared the explosivity of Vesuvius and EV phonolites and used experimental data to establish a model of phonolite viscosity that explicitly considers the effects of crystals, bubble fraction, variations of the iron redox state, and $\mathrm{CO}_{2}$ content. In the temperature range of $949-1046{ }^{\circ} \mathrm{C}$ (the temperature range over which the experiments were conducted), the viscosity of the EV anhydrous and crystal-free melt varies between $10^{10}$ and $10^{12}$ $\mathrm{Pa}$. Using reported ranges for temperature $\left(950-1080{ }^{\circ} \mathrm{C}\right)$, crystal abundance $\left(30\right.$ vol\%), $\mathrm{H}_{2} \mathrm{O}$ concentrations ( $\sim 0.2 \mathrm{wt} \%$; Oppenheimer et al., 2011; Moussallam et al., 2013), and iron redox state, Le Losq et al. (2015) calculated that the magma viscosity in the upper region of the plumbing system of Erebus ranges between $10^{5}$ and $10^{7} \mathrm{~Pa}$, with an uncertainty of, at most, \pm 0.45 $\log (\mathrm{Pa})$. We note that iron is mostly present as $\mathrm{Fe}^{2+}$ in the $\mathrm{EV}$ phonolite magma $\left(\mathrm{Fe}^{3+} /\left[\mathrm{Fe}^{3+}+\mathrm{Fe}^{2+}\right] \sim 0.2\right.$ to 0.3 ; Moussallam et al., 2014, whereas in their experiments, it is mostly present as $\mathrm{Fe}^{3+}\left(\mathrm{Fe}^{3+} /\left[\mathrm{Fe}^{3+}+\mathrm{Fe}^{2+}\right]>0.9\right.$; see discussion in Losq et al., 2015). 


\subsubsection{Magma Oxygen Fugacity}

Oxygen fugacity $\left(\mathrm{fO}_{2}\right)$ was estimated from olivine, titanomagnetite, and clinopyroxene mineral compositional data in EV bombs and lavas using the QUILF computer program (Andersen et al., 1993) and an assumed temperature of $1000{ }^{\circ} \mathrm{C}$ and pressure of 1 bar. Kelly et al. (2008b) obtain a $\log \left(\mathrm{fO}_{2}\right)$ of $-11.86 \pm 0.03(\Delta \log \mathrm{FMQ}-0.88 \pm 0.03)$ and a silica activity of $0.461 \pm 0.007$ for magma in the lava lake. The presence of pyrrhotite in EV tephra is consistent with reducing conditions and has been used to constrain the sulfur fugacity in the melt (Kyle, 1977). Based on gas measurements and equilibria constraints, Burgisser et al. (2012) confirmed that EV phonolitic melts are very reduced at $-0.5 \Delta \log \mathrm{FMQ}$.

In a set of phase equilibria experiments, Iacavino et al. (2016) evaluated the $\mathrm{P}-\mathrm{T}-\mathrm{X}-\mathrm{fO}_{2}$ conditions of deep and intermediate magma storage. Given that the natural phase assemblages were reproduced under relatively oxidizing experimental conditions, Iacavino et al. (2016) infer a relatively oxidizing environment for the deep and intermediate lavas. Basanites have an oxygen fugacity of $+1.5 \Delta \log \mathrm{FMQ}$ at $1100^{\circ} \mathrm{C}$ and $450 \mathrm{MPa}$ (Iacavino et al., 2016) and intermediate tephriphonolites, based on oxide pairs, have an estimated oxygen fugacity of $-0.44 \Delta \log$ FMQ at $1081^{\circ} \mathrm{C}$ and $300 \mathrm{MPa}$ (Kyle et al., 1992). This is in marked contrast to the reducing conditions $(-0.5 \Delta \log \mathrm{FMQ})$ in the Erebus phonolite "reservoir" (Moussallam et al., 2013) and $(-1.22 \Delta \log$ FMQ) in the Erebus phonolite lava lake suggesting upward reduction in redox conditions. This upward reducing redox trend is confirmed by the systematic analyses of the Fe redox state of a suite of melt inclusions at Erebus, which have conclusively shown a strong reduction trend as pressure decreases (Moussallam et al., 2014). It is posited that the large $\mathrm{CO}_{2}$ flux proposed as the mechanism for dehydrating Erebus magmas may also contribute to the reduction in oxidation state of the shallow Erebus system by reducing $\mathrm{H}_{2} \mathrm{O}$ fugacity.

\subsection{Geophysical Studies of Erebus Volcano}

The open-conduit system of EV has been observed to produce a range of eruptive styles that include ashy vent eruptions, small inner crater lava flows, and at least one (1993) phreatic explosion. However, the most common and characteristic type of eruption is the large bubblebursting lava lake events. The existence and accessibility of a persistently active 
volcanic/magmatic system, and its strongly excited elastic wavefield in the solid Earth and atmosphere, has made the volcano an attractive target for a range of geophysical investigations utilizing seismic, infrasonic, magnetic, gravity, magnetotelluric, and geodetic methods from the earliest days of the modern investigation of EV (e.g., Dibble et al., 1984). During the last two decades, a succession of increasingly advanced seismic, photographic/video, and infrasonic investigations have revealed increasing levels of understanding and detail regarding the volcano's internal structure and eruption dynamics.

The first seismic and infrasonic observations for monitoring and study of EV initiated in 1974 with a small network of short-period (1 s natural period) vertical-component seismographs, which soon grew into the International Mount Erebus Seismic Study (IMESS) project led by Philip Kyle at New Mexico Tech with geophysical technical assistance from Ray Dibble of Victoria University, Wellington (e.g., Dibble et al., 1984). During the early 2000's the IMESS instrumentation was integrated into the Mount Erebus Volcano Observatory (MEVO; Aster et al., 2004. MEVO incorporated additional infrasound as well as intermediate-period (30 s natural period) seismomographs and a continuous recording system. The MEVO system functioned until late 2016, when the instruments were removed at the conclusion of funding. Currently, recording of EV near-summit activity is presently being provided by a 4-station temporary seismic network maintained by the Incorporated Research Institutions for Seismology (IRIS) Consortium. For many years spanning the IMESS and MEVO projects, seismicity associated with eruptive activity was valuably complemented by video records obtained from successive generations of cameras deployed at the EV crater rim.

Seismic and infrasonic records together provide for highly reliable monitoring and quantification of lava lake explosions from EV because of their strongly impulsive and strong sonic signatures (Figure 17). Lava lake eruptions tend to occur at highly variable intervals, with eruptive rates observed to vary strongly on timescales of weeks to months but can occur in swarms of up to many tens or more strong events per day (e.g., Rowe et al., 2000). Seismic and infrasonic signals, corroborated by video, show that many of these events are relatively simple bubble bursts that sometimes span the entire (variably $\sim 5-10$ m wide) lava lake. Remarkably for an active volcano, tremor-like signals are rare at EV, and later study revealed that early 
observed tremor episodes were probably caused by repetitive, stick-slip, tabular-iceberg collisional or grounding events occurring near Ross Island, which are seismically observable in Antarctica up to hundreds of km from their sources (MacAyeal et al., 2008; Martin et al., 2010) and hydroacoustically observable as far away as the south Pacific (Talandier et al, 2006). In addition, large internal seismic events or swarms are not observed (e.g., Dibble et al., 1984). Lack of tremor or other internal seismicity is likely a manifestation of the EV's open vent conditions, which obviates the buildup of sufficient deviatoric stress or magmatic pressures within the system to generate significant and measurable seismicity.

The multi-season seismic and infrasonic networks were augmented by increasingly extensive and focused deployments of portable seismographs in the late 1990s (e.g., Aster et al., 2005) supported by the IRIS Portable Array Seismic Studies of the Continental Lithosphere (PASSCAL) Instrument Center. Especially notable portable deployments included the first broadband instruments in December 1996 - January 1997, which revealed very-long-period signals ( 8 - $30 \mathrm{~s})$ associated with lava lake explosions (Rowe et al., 1998), and the large-scale Tomo Erebus imaging-focused deployments of 23 broadband and 100 short-period near-summit stations between 2007 and 2009 (Figure 18; Zandomeneghi et al., 2013).

Broadband observations of the EV lava lake eruptive process have been particularly valuable in quantifying and understanding both the explosive decomposition signal of the emerging over-pressured gas slug and the subsequent minutes-long response of the magmatic conduit as it re-establishes equilibrium during system refill. A remarkable feature of these events is that the system is nearly reset after this process concludes, so that the next lava lake eruption may generate nearly identical seismograms and infrasonograms. This quasi-repeating elastic radiation from Erebus's lava lake explosions is highly unusual for an eruptive source and reflects the non-destructive and self-reconstructing nature of the erupting and refilling lava lake system. Waveform similarities have been valuably exploited in detection, stacking (so as to greatly increase signal-to-noise levels for imaging and source studies), and to reveal temporal changes within the magmatic system. 
Lava lake eruptions are created by the explosive decompression of a large rising gas slug, or slugs, at the surface of the terminal conduit. The eruption mechanism was studied in detail by Gerst et al. (2013), who utilized doppler radar, seismology, infrasound, and video data to constrain the mass and energy balance of the system, and its energy budget as a function of time for kinetic, dissipative, surface, infrasonic, and seismic energy terms for "Type I" eruptions. These observations showed clear lava-lake spanning inflation prior to bursting. A second class of more impulsive, "Type II" eruptions that burst through the lake surface without coherent inflation of the entire lava lake (perhaps because of strength weaknesses at the top of the lake along convective cell boundaries) were noted but not analyzed further in this study (see Figure 19). The modeling in Gerst et al. (2013) invoked a spherically expanding and, subsequently, bursting shell of magma with a basal diameter equal to that of the lava lake. This study, as well as independent infrasonic estimates (Johnson et al., 2008), indicated a bubble overpressure near $400 \mathrm{kPa}$ at the initiation of the eruption, which declines to near $100 \mathrm{kPa}$ at the time of bursting, and typical gas volumes at local $\mathrm{T}$ and $\mathrm{P}$ inside the bubble immediately prior to bursting of 1000 $-2000 \mathrm{~m}^{3}$. A commonly observed inflection in bubble expansion velocity measured by radar was interpreted as splitting of the rising slug upon entering an expanded terminus from a narrower subsurface conduit.

The relatively geometrically simple and impulsive lava lake eruption process has also made the volcano a target for infrasound study. Infrasound can be particularly diagnostic of surface or near-surface explosive sources because of the strong radiation of such sources into the infrasonic wavefield and a relatively simple path function (i.e., Green's function) within the atmosphere, particularly at short ranges. Infrasonic propagation becomes much more complex and subject to temporal variations from atmospheric effects beyond a few $\mathrm{km}$. Infrasonic data have been primarily collected using nearby $(<2 \mathrm{~km})$ infrasonic microphones (Dibble et al., 1984; Johnson et al., 2003; Johnson et al., 2004; Johnson and Aster, 2005; Johnson et al., 2008; Jones et al., 2008), but eruptions are also observed regularly at the Comprehensive Test Ban Treaty Organization infrasonic array at Windless Bight on the Ross Ice Shelf (Dabrowa et al., 2014). Although eruptive detection is reliable at Windless Bight, signals must propagate to that site across a distance of $\sim 25 \mathrm{~km}$ and an altitude change of nearly $4,000 \mathrm{~m}$, and infrasound propagation can thus be strongly affected by variable atmospheric wind and temperature 
conditions. Johnson and Aster (2005) noted that the relative unconstrained surface explosion of lava lake events produced a high and consistent volcano acoustic-seismic elastic wave energy ratio (near 8) relative to that observed at other volcano systems (e.g., Karymsky) with more restricted terminal conduit systems. Johnson et al. (2008) noted that the eruptions were well modeled by a monopole source with a smaller component of dipole acoustic radiation oriented by jetting asymmetries. Jones et al. (2008) further demonstrated the ability of a three-station infrasonic near-summit infrasonic network to monitor activity at multiple inner-crater vents and to locate source locations within the lava lake with accuracies as high as a few meters.

Seismology also has significantly contributed to the present state of knowledge and conceptualization of EV eruptive sources and structure. The volcano is constituted of heterogeneous lava, ash, and other features of varying ages with an embedded magmatic system. This creates a complex and seismically contrasting structure that can confound classical seismological analytical methods premised upon direct ray paths and clear seismic phases. In contrast, the path influence at many volcanoes for high-frequency (above $\sim 1 \mathrm{~Hz}$ ) seismic signals is commonly very strong, so that multipath, rather than direct ray path, energy may predominate. At EV, this seismic multipathing is extreme (Chaput et al., $2015 \mathrm{a}, \mathrm{b}$ ), such that seismograms at higher frequencies are dominated by strong scattered waves. This multipathing greatly reduces the amplitude of the initial (P wave) arrival and creates a highly extended (up to tens of seconds) "coda" of scattered waves with a cigar-shaped amplitude envelope after even just a few km of propagation (Figure 20). Strong multipath propagation obscure source information, and icequakes, artificial explosions, and eruptions produce grossly similar high-frequency seismograms at EV.

A breakthrough in studying the lava lake eruption source and plumbing of the upper conduit system was the recognition (initially in Rowe et al., 1998, and subsequently expanded in Aster et al., 2003) of highly repeatable very-long-period (VLP) signals that were not strongly affected by volcano structure and thus could be analyzed to reveal aspects of the conduit response prior to and following eruptions (Figure 21). EV VLP signals have a period content between approximately 8 and $30 \mathrm{~s}$, are much less affected by the strong structural heterogeneity due to their very long wavelengths, and provide unique constraints on magma- and gas-generated 
source forces and processes in this period range. VLP signals initiate a few seconds prior to the lava lake surface explosion during the final expansion of the gas slug and bulging of the lava lake prior to rupture, but are predominantly a post-eruptive phenomenon that persists for up to several minutes and ceases after the lava lake refills from a deeper magmatic reservoir.

Aster et al. (2008) applied moment rate tensor inversion for the VLP source process using stacked similar seismograms from multiple eruptions to reduce microseismic and other noise levels. This inversion determined that VLP sources had a centroid location approximately 0.5 $\mathrm{km}$ NW of the lava lake and at a depth of approximately $0.4 \mathrm{~km}$. The associated couples and forces in the moment rate source were determined as a superposition pressurization, (minor) shear components, and an inclined, approximately north-dipping, single force. The general interpretation is that they represent pressurization and advective (reaction) forces primarily associated with the post-eruptive recovery and return to gravitational equilibrium of the lava lake system following the eruptive removal of lava lake mass. The centroid location of the associated forces suggests the presence of an important constrictive region at this location.

A second breakthrough in understanding the shallow eruptive system has been the application of coda wave autocorrelation (Chaput et al., 2012) to identify and localize scattering from high impedance contrast interfaces within the volcano. Combining this scattering tomography with P-wave active artificial explosion tomography and a large number of stations deployed in the near-summit region during the Tomo Erebus project, a cogent image of the uppermost $\sim 2 \mathrm{~km}$ of the volcano was obtained (Figure 18; Zandomeneghi et al., 2013).

The near-summit model described in Zandomeneghi et al. (2013) is constrained by P wave arrival times, and by autocorrelations of icequakes (Chaput et al., 2015a,b) and eruption seismograms recorded at 91 stations that were deployed across an approximately 4 by $4 \mathrm{~km}$ expanse of the uppermost volcano (Figure 18). P wave tomography was realized by these instruments coupled with 12 prepared ice borehole shots. A P-wave-tomography code (Toomey et al., 1994) suitable for accommodating the large velocity contrasts expected in magmatic systems was used to model the seismic observations. Prominent features were interpreted to represent regions of fumarolic ice cave hydrothermal systems, a prominent radial dike, and a 
near-summit magma body (NSMB) residing 500 - $1000 \mathrm{~m} \mathrm{NW}$ of the lava lake and extending to depths in excess of $500 \mathrm{~m}$ below the surface. The NSMB underlies the prominent Tramway Ridge warm ground region of the summit plateau area of high surface temperatures and gas emissions. The terminal conduit was not resolved in this study, which indicates that it is likely narrower than approximately $10 \mathrm{~m}$ in its uppermost few hundred $\mathrm{m}$. If the conduit extends to the nearest edge of the NSMB and the VLP source region, then it would have an inclination of approximately $60^{\circ}$ and a length of approximately $500 \mathrm{~m}$, although there is no reason to assume a simple upper conduit geometry. Indeed, the presence of additional sporadically active vents within the inner crater implies a branching or otherwise complex terminal geometry in at least the uppermost few 100's of m below the inner crater (Figures $21-23$ ).

The VLP seismograms associated with eruptions, observed by broadband seismic stations near the summit, are highly repeatable but also display systematic timing shifts relative to the short-period (SP) surface explosion source (Figure 24). Knox et al. (2018) documented these VLP-SP lag variations and showed that they are consistent across the seismic network (and are thus a source effect). The VLP-SP observations were then used to refine a general system model for the uppermost conduit and lava lake eruptive system. The essence of the model put forward in Knox et al. (2018) is that the VLP moment tensor source centroid represents a zone of important constriction within the uppermost conduit system. Gas slugs pass through this restriction (perhaps accumulating behind it) aseismically, buoyantly rising to explode at the surface of the lava lake. Once ejecta mass has been removed from the conduit tip (estimated to be approximately $8 \times 10^{7} \mathrm{~kg}$ for conduit-spanning gas slug eruptions; Aster et al., 2008), the resulting decompression propagates down the conduit to the NSMB and the VLP source zone, stimulating rapid (on the order of several minutes) refilling of the system from the deeper reservoir. Knox et al. (2018) investigated several types of elastic processes for facilitating the VLP-SP elastodynamic communication through a magma-filled conduit (Figure 25). They concluded that an elastic Stoneley (boundary) wave was consistent with VLP-SP timing observations, and that small changes in the effective width of the conduit can explain the observed lag variations, provided that the magma kinematic fluid viscosity is sufficiently large $\left(10^{4}-10^{5} \mathrm{~Pa}\right.$; Dibble et al., 1984; Le Losq et al., 2015) and the conduit is, on average, 
sufficiently narrow $(4-8 \mathrm{~m})$ over several hundreds of meters, consistent with its non-detection in near-summit seismic tomography (Figure 26).

Seismic imaging and seismogram analysis-based conclusions of a narrow conduit and the prominent presence of the NSMB just to the NW of the EV crater is also consistent with nearsummit gravimetric observations made at a spacing of 100-200 m. Gravimetric lows were observed to correlate with low seismic velocity anomalies, including an $8 \mathrm{mGal}$ Bouguer minimum above the NW magma body (Mickus and Kyle, 2013; 2014).

EV and Ross Island have also been noted to be promising locales for Magnetotelluric imaging of Earth conductivity structure, including the imaging of magmatic structures, as a complement to seismology. A recent collection of MT instruments across the summit region and the island is currently being analyzed and early results indicate that these data will provide new insights into presently unimaged magmatic structures in the crust and uppermost mantle (Hill et al., 2017; P. Wannamaker, pers. commun.).

Eruption-associated geophysical highlights are:

- Lava lake eruption frequency is highly variable from year to year, suggesting a complex and evolving near-vent plumbing system that affects the formation and delivery of the large gas slugs that drive this eruptive style (Rowe et al., 2000; Knox, 2018).

- Lack of internal transient or tremor seismicity reflects a highly steady-state, open vent magmatic system and indicates a lack of deviatoric stress or pressure accumulation within the volcano.

- Lava lake eruptions produce two distinct types of seismic signals from two different processes; a short period $(1-8 \mathrm{~Hz})$ signal associated with the surface gas slug explosion and a very long period $(8-30 \mathrm{~s})$ signal associated with pre- and post-eruptive gas and magma transport (Rowe et al., 1998, 2000; Aster et al., 2003).

- The lava lake eruption system is nearly self-reconstructing, in that the system returns to nearly the same state following lava lake refill. This situation produces highly repeating infrasonic and seismic signals from eruption to eruption. The passage of the conduit- 
spanning gas slugs through the uppermost conduit is thus generally non-destructive to the terminal conduit (Aster et al., 2003; Knox et al., 2018). These highly repetitive signals have proven valuable for improving signal to noise in studying the eruptive process and for assessing progressive changes within the volcano.

- Doppler radar, infrasound, and seismic integrative study of lava-lake spanning eruptions established an energy budget for the process and determined that eruptive slugs have typical overpressures between 100 and $600 \mathrm{KPa}$ at the onset of explosion (Gerst et al., 2013).

- Moment tensor inversion of very long period post-eruptive signals indicate that the force centroid for these events is about $400 \mathrm{~m}$ below the lava lake and offset to the northwestern quadrant of the summit plateau, with an inclined single force component that suggest a northwesterly inclined near-summit conduit. (Aster et al., 2008).

- Repeating short-period and very long period signals from numbers of eruptions show evolving relative timing shifts on the order of \pm 1 s consistent with progressive smallscale conduit widening and narrowing occurring on day to week time scales within a near-summit conduit that includes constricted segments with cross sections as narrow as $4-8 \mathrm{~m}$ (Knox et al., 2018).

Geophysical imaging highlights are:

- The internal structure of the volcano is extremely seismically and structurally heterogeneous, consistent with lava flows, ash deposits, and an intersecting active magmatic system (Chaput, 2012).

- Independent tomography results using scattered wave energy (Chaput et al., 2012; 2015a) and P-wave tomography from artificial shots in the summit region (Zandomeneghi et al., 2013), corroborated with gravity measurements (Mickus and Kyle, 2013; 2014) together suggest the presence of a low-velocity, low density, nearsummit magma body residing beneath the summit plateau, northwest of the lava lake and underlying the prominent Tramway Ridge warm ground area. 
- The non-imaging of a prominent conduit immediately beneath the lava lake in seismic imaging provides additional evidence that the terminal conduit is narrow within its final several hundred meters (e.g., < $10 \mathrm{~m}$ in places).

\subsection{Microbiological Studies of the Erebus Volcanic System}

Despite extremes in temperature, oxygen availability, and geochemical conditions, volcanically impacted environments such as hot springs, thermally heated soils, and fumaroles host unique, diverse, and numerically abundant microbial communities that are distinct in composition from those of non-volcanic areas (Colman et al., 2016; Boyd et al., 2013; Power et al., 2018). Microorganisms inhabiting volcanic environments are often supported by chemical energy (chemosynthesis), rather than light energy (photosynthesis). This is particularly true for microorganisms that inhabit hot springs with temperatures $>70^{\circ} \mathrm{C}$ (Boyd et al., 2012; Boyd et al., 2010; Hamilton et al., 2012; Cox et al., 2011; Brock, 1967), regardless of their location globally (Castenholz, 1969; Brock \& Brock, 1969). Sources of chemical energy that can support microbial growth in such hot spring environments come in the form of disequilibrium in oxidation-reduction reactions (Amend \& Shock, 2001; Shock et al., 2010) generated by mixing of reduced volcanic fluids with oxidized atmospheric fluids (Colman et al., 2019). Volcanically influenced fluids are often enriched in reduced compounds such as hydrogen, methane, and a variety of sulfur compounds that can serve as electron donors for microbial metabolism, whereas atmospheric influenced fluids are often enriched in oxidized compounds such as oxygen or nitrate that can serve as electron acceptors. Below, we review existing studies of the EV geothermal system as a unique habitat for microbial life. For a recent review of microbiological geothermal habitats across the Antarctic continent, the reader is referred to Herbold et al. (2014b).

Early studies of the EV system by Ugolini and Starkey (Ugolini, 1967; Ugolini \& Starkey, 1966) extended the paradigm of the importance of chemosynthesis in supporting microorganisms in higher temperature Antarctic hydrothermal systems. Importantly, unlike most other global hydrothermal systems, the EV chemosynthetic communities are largely supplied by water in the form of steam (Broady, 1984). In these early studies, two volcanic soils were collected, one from a lower elevation where fumaroles keep snow and ice from accumulating and 
the other from near EV's crater. Neither of the soils sampled were found to host extensive macrobiological life, likely due to extreme acidity ( $\mathrm{pH} 2.7$ and 4.2) and extensive mineralization of the soils (Ugolini \& Starkey, 1966). The acidity in these two soils likely developed through the oxygen-dependent oxidation of hydrogen sulfide or native sulfur (Colman et al., 2018), the latter of which was enriched in both soil types (Ugolini, 1967). Early efforts to characterize microbial communities in these samples used traditional cultivation-based methods, relying on nutrient agar that would allow for the growth and differentiation of bacteria and fungi (Ugolini \& Starkey, 1966). Cultivatable cells were not detected in the most acidic soil, a finding that was ascribed to the extreme acidic and dry nature of the soils. In contrast, the less acidic soil was found to host up to $\sim 10^{6}$ bacterial cells and $\sim 10^{4}$ fungal cells. Surprisingly, morphological identification suggested that the fungi were apparently strains that are commonplace to nonvolcanic environments, including Penicillium and Aspergillus, among others.

In lower temperature volcanically influenced soils $\left(<70^{\circ} \mathrm{C}\right)$, phototrophic metabolism is possible (Boyd et al., 2012; Boyd et al., 2010; Cox et al., 2011; Hamilton et al., 2012), with eukaryotic algae tending to be the dominant phototrophs in acidic systems and cyanobacteria tending to be the dominant phototroph in moderately acidic to alkaline systems (Brock, 1973; Hamilton et al., 2012; Doemel \& Brock, 1970). Broady (1984) characterized the diversity of phototrophic organisms in fumarolic soils collected at an elevation of $3500 \mathrm{~m}$ on EV. Intriguingly, phototrophic cultivars included both cyanobacteria and chlorophyte algae. Cyanobacteria affiliated with the genera Mastigocladus, Phormidium, and Lyngbya, all of which are common in hydrothermal environments (Castenholz, 1969; Brock, 1967), were also recovered. The dominant algal genus recovered was related to Chlorella, which has also been detected in algal mats sampled from other lower temperature $\left(<30^{\circ} \mathrm{C}\right)$ hydrothermal systems (Boyd et al., 2009). In a separate study, a phototrophic Scenedesmus algal strain was isolated from a microbial mat community that was growing on fumarolic soils near Tramway Ridge (Lesser et al., 2002). The ambient temperature of soils where the strain was isolated was $20^{\circ} \mathrm{C}$, although the temperature increased to $60.6^{\circ} \mathrm{C}$ at a depth of only $6 \mathrm{~cm}$, underscoring the extreme thermal gradients in the Tramway Ridge fumarolic field. Intriguingly, this algal strain was shown to be particularly well adapted to stress imposed by ultraviolet light, which would be expected to be intense given the temporal and yearly variation in the UV-attenuating atmospheric ozone in 
Antarctica (Farman et al., 1985). Other studies have revealed that the microbial mats that colonize lower temperature $\left(\sim 20^{\circ} \mathrm{C}\right)$ geothermally heated soils on Erebus also comprise higher order photosynthetic plants in the form of the moss Campylopus pyriformis (Skotnicki et al., 2004).

Carbon-fixing activity of phototrophic bacteria, algae, and plants likely provide organic forms of carbon (chemosynthate) to support secondary consumers (termed heterotrophs) in such environments, providing motivation for the study of the prevalence of heterotrophic bacteria in fumarolic soils. In higher temperature soils, the phototrophs Lyngbya (Broady, 1984) and Mastigocladus (Melick et al., 1991), which were shown to be active at temperatures up to $59^{\circ} \mathrm{C}$ and $50^{\circ} \mathrm{C}$, respectively, dominated the communities. Soils were sampled for geochemical and cultivation-based analyses (Hudson \& Daniel, 1988). The temperature of the soils ranged from 37 to $60^{\circ} \mathrm{C}$ while the $\mathrm{pH}$ of the soils ranged from 3.1 to 8.1. Microorganisms that could catalyze organic carbon oxidation under oxic conditions (termed aerobic heterotrophs) were identified in soils sampled from seven of the eight locations, whereas those that could catalyze organic carbon oxidation under anoxic conditions (termed anaerobic heterotrophs) were identified in six of the eight locations. Intriguingly, one of the soils in which aerobic and anaerobic heterotrophs were not detected was shown to support organisms that catalyzed the oxidation of thiosulfate. The organisms used this energy to support inorganic carbon fixation (termed chemoautotrophy) (Hudson \& Daniel, 1988). Thiosulfate is a common intermediate in the oxidation of sulfur compounds (Xu et al., 2000), and its oxidation is often coupled to autotrophic growth (Friedrich et al., 2001). Subsequent isolation and characterization of this strain showed that it was closely related to the firmicute bacterium Bacillus schlegelii (Hudson et al., 1988), relatives of which are commonly found inhabiting geothermally heated soils on Erebus (Nicolaus et al., 2000) and in other geothermal habitats such as those in Yellowstone National Park, Wyoming, U.S.A. (Belly \& Brock, 1974). This strain was shown to also be capable of both heterotrophic and autotrophic growth. Under autotrophic conditions, hydrogen could also serve as an electron donor. Other cultivation-based studies by this same group provide evidence supporting the prevalence of Bacillus spp. in geothermally heated soils on Erebus, including those that are acidic (Hudson et al., 1989). Intriguingly, an extremely halotolerant (growth up to $4.2 \mathrm{M} \mathrm{NaCl}$ ) thermotolerant (growth up to $40^{\circ} \mathrm{C}$ ) gram positive Micrococcus strain was also isolated from geothermally 
heated soils collected near Tramway Ridge (Nicolaus et al., 1992), which might be attributed to the low water content (low water activity) associated with these environments.

Evidence of thermophilic organisms in geothermally heated soils from these early studies provided impetus to apply next generation molecular biological techniques, often in combination with cultivation-based approaches, to more comprehensively characterize the composition of microbial communities in geothermally heated soils and in ice caves. Motivation for these more recent studies was likely driven, at least in part, by the recognition of the numerous attributes that EV's volcanically impacted habitats hold as analogs for early Earth and extraterrestrial environments. Attributes that are sought after for such studies include geographic isolation (lower risk of exogenous input of organisms or contaminants) and extremes in $\mathrm{pH}$, salinity, water content, and chemistry as well as the extreme thermal gradients between volcanically impacted environments and their surroundings (Rothschild \& Mancinelli, 2001). These studies have largely been spearheaded by the labs of Ian McDonald and S. Craig Cary out of New Zealand and include the first molecular characterization of mineralized soils from Tramway Ridge (Soo et al., 2009).

Sequencing of $16 \mathrm{~S}$ rRNA genes and intragenic spacer regions in rRNA operons in DNA extracted from soils along a thermal and chemical gradient extending from an active fumarole at Tramway Ridge confirmed that those sampled near the active fumarole were distinct from those located more distally (Soo et al., 2009). Temperature gradients in sampled soils spanned $62^{\circ} \mathrm{C}$ near the fumarole to $<5^{\circ} \mathrm{C}$ at more distal sites, whereas $\mathrm{pH}$ spanned 6.8-7.2 near the fumarole to $\sim 4.0$ at more distal sites. This likely reflects oxidation of volcanic sulfur at lower temperatures where oxygen can fuel aerobic microbial activity (Colman et al., 2018). Mineralized soils sampled near the fumarole vent hosted communities that were distinct from those previously identified in volcanically hosted environments, and many were deeply branching in phylogenetic reconstructions. Many of the bacterial 16S rRNA gene sequences were distantly related to known taxa (85-93\% sequence identities) and included a novel lineage that branched between the metabolically diverse and early evolving Chloroflexi and the candidate division OP10. Surprisingly, archaeal 16S rRNA gene sequences were closely affiliated with sequences of yetto-be cultivated crenarchaeotes previously identified in deep subsurface environments. These 
observations point to the unique biological diversity associated with EV's volcanic environments, which may hold new insight into the metabolic strategies on a volcanically more active early Earth.

In a similar study, biological diversity associated with fumarolic soils from Tramway Ridge was examined along two vertical depth profiles (Herbold et al., 2014a). This innovative study showed that soils nearer the atmosphere-soil interface harbored microbial communities that consisted of populations that are more closely related to those identified in other geographicallydistinct, volcanically impacted environments than those sampled from depth. Since this ice-free area has been designated as an Antarctic Specially Protected Area (ASPA), cross-contamination of this study site from other volcanic activity via human activities is likely to be minimal to nonexistent. Moreover, temperature and geochemical profiles, the major determinant of the composition of microbial communities (Colman et al., 2016; Power et al., 2018, Coleman et al., 2019), were nearly constant along the vertical, soil-depth profiles. The abundance of total extractable DNA, however, decreased significantly with depth. Thus, these observations were interpreted to reflect aeolian dispersal of viable microorganisms and colonization of near-surface soils at EV, with endemic microbial communities capable of outcompeting exogenous organisms in deeper soil profiles. Of particular intrigue was the identification of an archaeal sequence that is distantly related $(<89 \%)$ to relatives of the Thaumarchaeota, Aigarchaeota, and Crenarchaeota. Further cultivation or cultivation-independent (i.e., metagenomic) efforts are likely to reveal a novel metabolism associated with this unique taxon that is apparently endemic to the Tramway Ridge ASPA.

In an effort to better constrain the types of metabolisms supporting microbial life in geothermally heated soils from Tramway Ridge, and to link it with the unique physicochemical properties of this particular volcanic environment, Vickers et al. (2016) characterized edaphic qualities of soils along three vertical soil samples collected near a fumarole $\left(60-65^{\circ} \mathrm{C}\right)$ on Tramway Ridge and subjected soil-associated populations to a battery of physiological analyses. This included an analysis of soil-moisture content, concentrations of total nitrogen, carbon, and organic carbon, as well as concentrations of a variety of major and trace elements at 0-2, 2-4, and 4-8 cm vertical depths (Vickers et al., 2016). Surprisingly, statistical analyses showed that 
variation in the location of the soil cores could account for more of the variation in the edaphic attributes of soils than soil depth. This suggests substantial spatial variation in the input and availability of nutrients to support microbial metabolism in these environments, despite their close spatial proximity. Nonetheless, the availability of oxygen at depth in each of the three vertical soil profiles was low relative to atmospheric conditions, suggesting that biological communities inhabiting deeper sediments are consuming oxygen and are likely adapted to lower oxygen concentrations (i.e. sub-oxic conditions). Indeed, phenotypic assays indicate that heterotrophic oxidation of organic compounds by soil communities occurred under sub-oxic conditions. Like previous studies (Herbold et al., 2014a), sequencing of 16S rRNA genes from one of the three soil profiles revealed a community that harbored unique bacterial populations, including sequences affiliated with the GAL35 class of the candidate division OP1 as well as Chlorflexi, Meiothermus, and other unclassifiable sequences. In summary, studies of EV at Tramway Ridge have shown the presence of a microbial habitat that is globally unique among studied hydrothermal systems with unusual qualities including:

- Steam as the primary source of water supporting microbial communities (Broady, 1984)

- Volatiles are the primary source of chemical energy and nutrients supporting chemosynthetic communities in higher temperature $\left(>60^{\circ} \mathrm{C}\right)$ thermal transects (Vickers et al., 2016)(Hudson \& Daniel, 1988)

- The presence of deeply branching archaeal and bacterial populations that are apparently endemic to this hydrothermal system (Herbold et al., 2014a)(Vickers et al., 2016). Further work is needed to determine if this unique biodiversity is the consequence of geographic isolation from other thermal areas or if it is due to the unusual physical and chemical conditions at Tramway Ridge.

While most microbiologically focused studies conducted to date on Erebus have focused on geothermally heated soils in surface environments, Tebo et al. (2015) recently reported on microbial diversity from three fumarolic ice caves near the summit. These caves are formed by volcanic heat and gas melting overlying ice and snow. Meltwaters can then percolate through the regolith, becoming heated and turning into steam, which, in turn, can be infused by volcanic gases. Over time, these processes can culminate into a cave-like system that provides a moist and 
relatively warm $\left(>0^{\circ} \mathrm{C}\right)$ habitat for microbial life, compared to the cold and dry external Antarctic environment (Curtis \& Kyle, 2011). Importantly, the overriding ice and snow restrict input of light, thereby forcing microbial communities to use chemosynthesis to support microbial metabolism. Like fumarolic soils, chemical energy to support microbial metabolism likely comes in the form of disequilibrium in oxidation-reduction reactions generated through mixing of reduced volcanic gas emissions, which have been shown to contain carbon monoxide (CO) and other reduced gases (Moussallam et al., 2012; Oppenheimer \& Kyle, 2008b), with oxidized atmospheric gases.

The three ice caves examined by Tebo et al. (2015) included Warren Cave, Harry's Dream, and Hubert's Nightmare. Sediments collected from these three caves had temperatures that ranged from $0.1^{\circ} \mathrm{C}$ in Hubert's Nightmare to $18.5^{\circ} \mathrm{C}$ in Warren Cave, whereas the $\mathrm{pH}$ of sediments varied only slightly from 5.2 to 5.9. Like soils from fumaroles on Tramway Ridge (Vickers et al., 2016), the organic carbon contents of sediments collected from the ice caves were low $\left(<126 \mu \mathrm{g} \mathrm{g} \mathrm{sediment}^{-1}\right)$, pointing to the nutrient-limited (termed oligotrophic) nature of these isolated habitats. Nevertheless, the abundance of bacterial 16S rRNA gene templates (a proxy for cell abundance) ranged from $1.6-40 \times 10^{6} \mathrm{~g}$ sediment $^{-1}$, which is similar to the abundances of templates and transcripts (indicative of activity) identified in other hydrothermal habitats including a variety of springs in Yellowstone National Park (Lindsay et al., 2018; Colman et al., 2016; Colman et al., 2018).

The abundance of bacterial cells in sediments from nutrient-limited ice caves prompted additional sequencing of 16S rRNA genes and of the large subunit of the ribulose 1,5bisphosphate carboxylase/oxygenase gene ( $c b b L)$ involved in the Calvin Cycle of carbon fixation (Tebo et al., 2015). Harry's Dream Cave harbored the most diverse bacterial 16S rRNA gene assemblages (archaeal 16S rRNA genes were not detected), including a variety of cyanobacterial phylotypes. This is consistent with the observation that light is only partially excluded from this particular ice cave system, as compared to the other two ice cave habitats, which are completely dark. Surprisingly, however, sediments in Harry's Dream Cave were more limited in total organic carbon than sediments from dark cave systems, the latter of which would preclude input of photosynthetic carbon. Other abundant sequences in Harry's Dream Cave were affiliated with 
putative hydrogen oxidizers and a variety of novel Chloroflexi and Acidobacteria; similar novel sequences dominated sediment bacterial communities from Warren Cave. Sediments from Hubert's Nightmare Cave, despite being only $50 \mathrm{~m}$ from Warren Cave, but with significantly colder temperatures than Warren Cave $\left(0.1^{\circ} \mathrm{C}\right.$ versus $\left.18.5^{\circ} \mathrm{C}\right)$, harbored a taxonomically distinct bacterial community that was dominated by a novel member of the Sphingobacteriales bacterial order.

The taxonomic composition of $c b b L$ genes (encode the large subunit of the primary enzyme involved in the Calvin Cycle of $\mathrm{CO}_{2}$ fixation) recovered from these three environments largely mirrored the taxonomic composition of 16S rRNA genes (Tebo et al., 2015). Cyanobacterial and Chloroflexi-affiliated genes dominated sediment $c b b L$ libraries from Harry's Dream, whereas Warren Cave sediment libraries were dominated by Chloroflexi and Acidobacteria-affiliated $c b b L$ genes. $c b b L$ libraries from Hubert's Nightmare were dominated by sequences affiliated with Acidobacteria and Bacteroidetes. Similarity in the taxonomic composition of dominant $16 \mathrm{~S}$ rRNA genes and $c b b L$ genes in sediment communities point to the importance of autotrophic carbon fixation and lithogenic energy in supporting microbial communities in dark sub-ice caves on EV.

Volcanic environments have been suggested to represent refugia for organisms, both microbial and macrobial, during periods of extensive glaciation (Fraser et al., 2014). The isolated nature of $\mathrm{EV}$, in particular the geothermally impacted caves and soils, makes these latter useful environments for the study of this potential phenomenon. A recent study of ice caves and fumarolic soils near the crater and Tramway Ridge, respectively, focused on the detection and identification of plant and animal DNA using molecular approaches (Fraser et al., 2018). This included an examination of recovered 28S rRNA and intragenic spacer region gene sequences from sediments from Warren Cave and Harry's Dream, in addition to a cave termed " 22 Blue". From this study, a variety of eukaryotic sequences were identified, including those affiliated with mosses, animals, and algae. At "22 Blue", a variety of non-human associated algal and arthropod sequences without representation in current databases were recovered. At Warren Cave, nonhuman associated sequences affiliated with a variety of algae and oligochaetes (Earth worms) were recovered, whereas algae were the dominant non-human associated sequences recovered 
from environmental DNA at Harry's Dream. It remains unclear if these environments served as refugia for these organisms or if this DNA was exogenously introduced into the system. In support of the former possibility, several of the algal sequences recovered have been previously identified in exposed geothermal sites on other volcanoes and in soils at EV (Broady, 1984; Skotnicki et al., 2004). In support of the latter possibility, a number of 28S rRNA and intragenic spacer region gene sequences affiliated with potential human-derived contaminants in Warren Cave sediments were identified, including those affiliated with common wheat and soybean. Further work will be needed to determine the extent to which EV's geothermal habitats have served as refugia during periods of extensive glaciation. Past studies have revealed several unique aspects of EVs ice cave system, including:

- An isolated, diverse, and comparatively abundant microbial community that is supported by chemoautotrophic metabolism. This is confirmed by the recovery of a diverse array of genes involved in the Calvin Cycle of $\mathrm{CO}_{2}$ fixation (Tebo et al., 2015). Key questions remain regarding the source of the $\mathrm{CO}_{2}$ that supports these organisms (volcanic or atmospheric) and what the source of chemical energy is that drives $\mathrm{CO}_{2}$ fixation. Potential sources include hydrogen and $\mathrm{CO}$, among others.

- EV ice caves are useful analogs to develop life detection techniques for application to extraterrestrial life detection missions and for understanding the geobiochemical processes that sustained life during periods of glacial advance. 


\subsection{Driving Forces, Magmatic Evolution, Eruptive Behavior, and Potential Hazards of Mt Erebus Volcano.}

\subsection{The HIMU-like Isotopic Signature of Erebus Volcano is a Well-Established, Important Source Characteristic.}

3.1.1 How do current geophysical and geochemical measurements inform about the origin of Erebus Volcano's unique HIMU-like source and the underlying causes and driving forces behind the volcanism at Erebus Volcano and Ross Island?

\subsubsection{Hypotheses to Explain the Erebus HIMU Isotopic Signature}

The HIMU-like isotopic signature (Figure 12) observed to be ubiquitous at Ross Island and across West Antarctica and the greater southwest Pacific (e.g., Sun and Hanson, 1975; Hart, 1988; Rocholl et al., 1995; Hart et al., 1995; 1997; Panter et al., 2000; 2006; Rocchi et al., 2002; Finn et al., 2005; Sims and Hart, 2006; Sims et al., 2008a) has been explained in different ways.

1) Ross Island is the manifestation of a localized thermal anomaly in the mantle centered beneath EV (Kyle et al., 1992; Storey et al., 1999). Noting the large volume of magma erupted over a short period of time $\left(\sim 4,520 \mathrm{~km}^{3}\right.$ during only $\sim 4 \mathrm{Ma}$; Esser et al., 2004$)$ and the observation that the volcanic rocks at Ross Island exhibit HIMU-like isotopic signatures akin to St. Helena and Tubuai ocean island basalts (OIB), Sun and Hansen (1975) and Kyle et al. (1992) suggested that Ross Island in general, and EV in particular, are manifestations of an upwelling mantle plume.

2) Noting further the widespread nature of the HIMU-like isotopic signature in the Antarctic and southwest Pacific (Figures 11-12), Hart et al. (1997) proposed that a large deep plume with a HIMU signature impinged on the base of the Gondwana lithosphere prior to its breakup at $\sim 85 \mathrm{Ma}$ and that this large plume head could have been associated with the Ferrar Large Igneous Province at 185 Ma.

3) The diffuse alkaline magmatic province (DAMP) model of Finn et al. (2005) posits that the widespread regional HIMU isotopic signature can be explained alternatively, not by a mantle plume, but by melting of a metasomatized lithospheric source. This metasomatism is proposed to have resulted from a sustained Gondwana subduction regime throughout the Paleozoic and into the Mesozoic. Interpretations suggest that slab detachment in the late 
Cretaceous caused a change in mantle flow. This change in mantle flow was the cause of the onset of Cenezoic magmatism in the region at $~ 55 \mathrm{Ma}$ with the metasomatized lithospheric source melting at low melt fractions. Similarly, Panter et al. (2006) advocated for widespread metasomatized lithosphere as the primary source for the HIMU signature found in basalts from the Antipodes, Campbell, and Chatham Islands.

\subsubsection{Arguments in Support of Asthenospheric Upwelling Beneath Ross Island as the HIMU} Source

The combination of isotopic and trace element constraints together with tomographic imaging strongly indicate that the HIMU source component beneath Antarctica is old (i.e. Archean or early Proterozoic) and deriving from deep mantle upwelling (Phillips et al., 2018).

\section{Isotope Systematics Require the HIMU Source Component to be Archean to Paleoproterozoic:}

The third hypothesis, the DAMP model (Finn et al., 2005), is readily eliminated for the EV lavas as it is based on the argument that the lithosphere was extensively metasomatized between $\sim 100$ and $\sim 500$ Ma within a subduction regime along the margin of Gondwana and that this young metasomatized lithosphere later became the source for the HIMU-like signature (Finn et al., 2005; Panter et al., 2006). As noted by Sims et al. (2008a) and again by Phillips et al. (2018), the DAMP model only considered ${ }^{206} \mathrm{~Pb} /{ }^{204} \mathrm{~Pb}$. U-enrichment during subduction in the Paleozoic could easily have produced the observed HIMU-like ${ }^{206} \mathrm{~Pb} /{ }^{204} \mathrm{~Pb}$ signature. The observation that all of the radiogenic isotope systems look HIMU-like, however, particularly ${ }^{143} \mathrm{Nd} /{ }^{144} \mathrm{Nd},{ }^{176} \mathrm{Hf} /{ }^{177} \mathrm{Hf}$, and ${ }^{207} \mathrm{~Pb} /{ }^{204} \mathrm{~Pb}$, places explicit temporal constraints on the age of the source. Specifically it dictates that the $<500$ m.y. timescale invoked by DAMP is too short to grow in the HIMU-like $\mathrm{Nd}$ and $\mathrm{Hf}$ isotopic signatures, as the half-lives of ${ }^{147} \mathrm{Sm}$ (parent of ${ }^{143} \mathrm{Nd}$ ) and ${ }^{176} \mathrm{Lu}$ (parent of ${ }^{176} \mathrm{Hf}$ ) are $1.06 \times 10^{11} \mathrm{yr}$ and $3.71 \times 10^{10} \mathrm{yr}$, respectively. Furthermore, ${ }^{207} \mathrm{~Pb} /{ }^{204} \mathrm{~Pb}$ would not be significantly influenced in $<500 \mathrm{~m}$.y. because of the low abundance of ${ }^{235} \mathrm{U}$ relative to ${ }^{238} \mathrm{U}$ on the modern Earth, and as such would not be high if the cause were metasomatism.

Given the relatively recent time window since the proposed metasomatism ( $<500$ m.y.), the long half-lives of the $\mathrm{Sm}-\mathrm{Nd}$ and $\mathrm{Lu}-\mathrm{Hf}$ isotope systems, and the fact that all four isotope 
systems ( $\mathrm{Sr}, \mathrm{Nd}, \mathrm{Hf}$ and $\mathrm{Pb})$ are similar to the St. Helena HIMU end-member, we argue that it is improbable that the HIMU characteristics of Ross Island represent melting of a relatively young (<500 m.y.) metasomatically altered lithosphere. Rather, the HIMU mantle end-member is consistent with an ancient (Archean to early Proterozoic) recycled source component that was isolated in the lower mantle (Hanyu et al., 2011; Weiss et al., 2016), thus allowing the development of the characteristic HIMU isotopic signature. Hence, we infer that the Ross Island lavas are derived from a deep-seated, long-lived mantle component that is delivered to the shallow mantle by an upwelling plume.

\section{Ross Island Trace Element and Isotope Systematics are not Arc-like:}

Phillips et al. (2018) presented several lines of evidence that show that the chemical and isotopic compositions of the lavas and tephras from EV and the other Ross Island volcanoes are not arc-like.

1) Trace element abundances and patterns of the Ross Island volcanics are not consistent with derivation of these lavas from a metasomatized lithospheric source altered by fluids from subduction processes. In subduction regimes, high-field-strength elements (HFSE) are retained in downgoing slabs (Kelemen et al., 1993), whereas fluid mobile elements, such as La, are enriched and thus subcontinental lithosphere is expected to be depleted in HFSE (e.g., $\mathrm{Nb}$ ) relative to other incompatible elements. As such, ratios like $\mathrm{Nb} / \mathrm{La}$ are important discriminants of slab-derived fluids related to subduction processes. In arcs, $\mathrm{Nb} / \mathrm{La}$ is universally $<0.5$ (Gill, 1981). However, as noted in Phillips et al. (2018), the Ross Island lavas and tephras, including those from $\mathrm{EV}$, have $\mathrm{Nb} / \mathrm{La}>1.25$, indicating little involvement of a subduction-metasomatized lithospheric component (Figures 10 and 27). In contrast to the Ross Island samples, the Mount Somers Volcanic Group (Tappenden, 2003), which is often considered the end-member composition for Zealandia magmas generated from subduction-related metasomatically altered lithosphere (Timm et al. 2010), and the Schirmacher Oasis minettes from East Antarctica (Hoch et al., 2001), all have $\mathrm{Nb} / \mathrm{La}<0.5$, suggesting they are either sourced from or have assimilated significant amounts of metasomatized lithospheric mantle (Figure 27). Accordingly, the $\mathrm{Nb} / \mathrm{La}>>0.5$ of the Ross Island volcanics were interpreted as a contraindication of their being derived by melting or assimilation of a lithospheric source altered by subduction processes 
(Phillips et al., 2018). It was also noted that the Ross Island samples from Mt. Bird, Mt. Terror, and Hut Point Peninsula lie on a mixing curve between DMM and HIMU (Figure 27), consistent with trends also observed for $\mathrm{Sr}, \mathrm{Nd}, \mathrm{Hf}$, and $\mathrm{Pb}$ isotopes (Figures 11 and 12). An interesting feature of the Erebus samples is their high $\mathrm{Nb} / \mathrm{La}$ relative to lavas from its peripheral volcanoes. Phillips et al. (2018) interpreted this increasing Erebus $\mathrm{Nb} / \mathrm{La}$ as a function of variable extents of apatite fractionation, a phase that is present in EV lavas at $\sim 0.5 \%$ modal abundance (Kyle, 1981b; Kyle et al., 1992).

2) Long-lived radiogenic isotope compositions $(\mathrm{Sr}, \mathrm{Nd}, \mathrm{Hf}$, and $\mathrm{Pb}$ ) of the Ross Island lavas and tephras do not resemble what would be expected for a recently metasomatically enriched subcontinental lithospheric source (Phillips et al, 2018). Lavas interpreted as lithospheric melts usually have more enriched isotopic signatures (lower $\varepsilon_{\mathrm{Nd}}$ and $\varepsilon_{\mathrm{Hf}}$ ) than those measured at Ross Island (e.g., Daley and DePaolo, 1992; Leat et al., 2005).

Metasomatic enrichment will typically decrease $\mathrm{Sm} / \mathrm{Nd}$ and $\mathrm{Lu} / \mathrm{Hf}$, leading to lower timeintegrated values of $\varepsilon_{\mathrm{Nd}}$ and $\varepsilon_{\mathrm{Hf}}$ (Reid et al., 2012). In this regard, the older Antarctic samples, such as the minettes of the Schirmacher Oasis ( 455 Ma; Hoch et al., 2001) and the Ferrar Group ( 177 Ma; Fleming et al., 1995), show much more enriched and variable isotopic signatures (Figure 28), consistent with melting of metasomatized lithosphere during Paleozoic subduction. It is essential to note that the Ross Island lavas and tephras are similar to the St. Helena HIMU mantle source, which is interpreted to be derived from a mid-Atlantic deep mantle plume.

3) The absence of an arc-related metasomatic signature is not only seen in the isotopic and trace element data, but also in the ${ }^{238} \mathrm{U}_{-}{ }^{230} \mathrm{Th}$ systematics from EV. Arc-related metasomatism would likely enrich U over Th (e.g., Reubi et al., 2014 and references therein) resulting in high ${ }^{238} \mathrm{U} /{ }^{232} \mathrm{Th}$ and high ${ }^{230} \mathrm{Th} /{ }^{232} \mathrm{Th}$ values as a result of the decay of ${ }^{238} \mathrm{U}$ to ${ }^{230} \mathrm{Th}$ (over $\sim 500$ k.y.). Young EV phonolites have relatively low ${ }^{230} \mathrm{Th} /{ }^{232} \mathrm{Th}$ compared to global data compilations of MORB and OIB (Sims and Hart, 2006; Sims et al., 2013a), and show ${ }^{238} \mathrm{U} /{ }^{232}$ Th similar to the HIMU end-member (Sims and Hart, 2006), both observations indicating that the parental basanites were not derived from a source that has been enriched in $\mathrm{U}$ relative to $\mathrm{Th}$, as would be expected from arc-related metasomatism. 
4) Finally, the major element compositions of the volcanic rocks from Ross Island - Mt Erebus, Mt Terror, Mt Bird, and Hut Point Peninsula - are neither arc-like nor do they exhibit the anomalous chemistry attributed to melting of a metasomatically altered source. The compositions of Ross Island lavas and tephras are basanitic, or differentiates of parental basanites (e.g., phonolites), and these have long been interpreted to represent small-degree partial melts of mantle peridotite (Green and Ringwood 1967; Green, 1973; see section 3.2.1); whereas metasomatic signatures are typically manifest in unusual alkaline lavas such as lamprophyres or minettes (e.g., the minettes of the Schirmacher Oasis in East Antarctica (Hoch et al., 2001)).

\section{He isotopes for Ross Island are also similar to the St Helena end member HIMU Source}

${ }^{3} \mathrm{He} /{ }^{4} \mathrm{He}$ measured in eleven olivine phenocrysts from hyaloclastites from the DVDP core at Ross Island have $\mathrm{R} / \mathrm{R}_{\mathrm{a}}$ values with an error-weighted mean of 6.91 (Parmelee et al., 2015). These values are similar to St. Helena (with $\mathrm{R} / \mathrm{R}_{\mathrm{a}}$ of 5.24 to 5.97; Hanyu et al., 2014). While high ${ }^{3} \mathrm{He} /{ }^{4} \mathrm{He}$ is thought to reflect an undegassed primitive mantle source because of the primordial nature of ${ }^{3} \mathrm{He}$, lavas that represent the HIMU mantle end-member at plumes, such as St. Helena, have low ${ }^{3} \mathrm{He} /{ }^{4} \mathrm{He}$ because of the presence of radiogenic ${ }^{4} \mathrm{He}$ in the recycled materials that presumably form the deep HIMU mantle reservoir (Graham et al., 1992; Parai et al., 2009; Hanyu et al., 2014; Phillips et al., 2018).

The Mantle Shows a Deep Low-Velocity Zone Beneath Erebus Volcano and Ross Island: Regional seismic data collected across Antarctica reveal a prominent low-velocity zone in the upper mantle beneath Ross Island (Ritzwoller et al., 2001; Watson et al., 2006; Zhao, 2007; Gupta et al., 2009; Heeszel et al., 2016; Phillips et al., 2018) and WARS, implying elevated temperatures (Figure 29) which further support the plume hypothesis. The regional tomographic body wave inversion of Hansen et al. (2014) indicates extensive low velocities within the upper $\sim 200-300 \mathrm{~km}$ of the mantle. However, this model has insufficient spatial resolution to image low velocities at greater depths. Global-scale tomographic modeling using finite-frequency kernels (Montelli et al., 2006) and full-waveform inversion (Bozdă̆ et al., 2016; see French and Romanowicz, 2015) have a coarser resolution, but strongly indicate a sub-mantle transition-zone, low-shear wave seismic velocity anomaly that extends to $\sim 1200 \mathrm{~km}$ depth 
beneath Ross Island, with linked features that extend eastward beneath the WARS and below the Marie Byrd Land volcanic province and also along the Australian-Antarctic Ridge (Park et al., 2019). Low-velocity sub-transition zone structures are also verified by models such as SGLOBErani (Chang et al., 2015), GyPSuM (Simmons et al., 2010), and the composite model SMEAN2 (Becker and Boschi, 2002; Simmons et al., 2010; Ritsema et al., 2011; Auer et al., 2014). These global images, which, as discussed in section 2.4 , benefit from vastly expanded recent seismographic data recorded in Antarctica (e.g., Anthony et al., 2015), are consistent with the hypothesis that a disrupted deep mantle thermal feature continues to drive melting beneath EV and Ross Island.

A similar deep HIMU-like component farther afield at the Australian-Antarctic Ridge creates a geographic problem

As recently noted by Park et al. (2019), there is isotopic coherence among the KR-1 and KR-2 segments of the Australian-Antarctic Ridge (AAR), the Ross Island volcanics, and the Hikurangi Seamounts, which is consistent with the mixing of ambient mantle with an enriched component with radiogenic $\mathrm{Pb}, \mathrm{Nd}, \mathrm{Hf}$, and $\mathrm{Sr}$ isotopic compositions akin to HIMU. Given the geographic setting of the AAR and Hikurangi Seamounts, there are two reasons why this isotopic signature cannot be reasonably explained by a model in which the enriched HIMU component comes from a metasomatically enriched lithospheric mantle resulting from Paleozoic subduction along the Gondwana margin (Finn et al., 2005; Panter et al., 2006). First, the Hikurangi Seamounts were erupted on the oceanic lithosphere subducting along the former Gondwana margin, and as such, the influence of sub-continental material on the compositions of the Hikurangi volcanics would be minimal. Second, it is physically implausible that this enriched lithospheric material could be influencing mid-ocean ridge volcanism at the AAR, which is 800 $\mathrm{km}$ away from both the Zealandia and Antarctica continents. In addition, the influence of any pre-existing lithospheric component would have been eliminated by thermal erosion.

\subsection{Mt Erebus is a Rare, Active Alkaline Volcano that Provides an Important Window into Mantle Melting Processes}

3.2.1 What does Erebus Geochemistry Indicate About the Depth of Melting and Lithology of its Mantle Source? 
Key questions remain regarding the petrogenesis of the alkaline lavas of EV and Ross Island. Namely, 1) what is the lithology of the mantle source, peridotite versus pyroxenite, and how these lithologies and their different fusibilities influence the elemental and isotopic composition of the EV primitive magmas (Sims et al., 2013b); and, 2) what role do volatiles such as $\mathrm{H}_{2} \mathrm{O}$ and $\mathrm{CO}_{2}$ play in the petrogenesis and evolution of the EV magmas?

Proposed source lithologies for alkaline lavas include: garnet lherzolite (e.g., Green and Ringwood, 1967, Takahashi and Kushiro, 1983), carbonated garnet lherzolite (e.g., Hirose, 1997, Green and Falloon, 1998, Dasgupta, et al., 2007), garnet pyroxenite (e.g., Hirschmann, et al., 2003, Kogiso, et al., 2003), carbonated eclogite (e.g, Dasgupta, et al., 2006), eclogite-lherzolite mixtures (e.g., Kogiso, et al., 1998), and metasomatic veins (Pilet et al., 2008). Depletion in heavy compared to middle REE in lavas and tephras from EV and Ross Island (mean $\mathrm{Dy}_{\mathrm{N}} / \mathrm{Yb}_{\mathrm{N}} \cong$ 1.4; Figure 10) and the observation that ${ }^{230} \mathrm{Th} /{ }^{238} \mathrm{U}>1$ in Erebus lineage lavas (Figure 13) require melting in the presence of residual garnet (Sun and Hanson, 1976; Sims and Hart, 2006; Sims et al., 2013a).

Dasgupta et al. (2007) argued, on the basis of results from partial melting experiments carried out at $30 \mathrm{kbar}$, that basanites can be generated by up to $6 \%$ partial melting of a carbonated fertile peridotite. The importance of volatiles to the generation and evolution of Erebus volcanic province magmas is also strongly indicated by the presence of up to $\sim 7300 \mathrm{ppm}$ $\mathrm{CO}_{2}$ in olivine-hosted melt inclusions from 2 DVDP basanites (Oppenheimer et al., 2011) and up to $\sim 1.8 \mathrm{wt} \% \mathrm{CO}_{2}$, after correction for bubbles, in basanites from Mt. Terror (Rasmussen, et al., 2017). These values are enriched by a factor of $\sim 30$ relative to nominally undegassed MORB melt inclusions from the Siqueiros fracture zone (Saal et al., 2002). In addition to elevated $\mathrm{CO}_{2}$, DVDP and Mt. Terror basanite melt inclusions contain up to $\sim 2 \mathrm{wt} \% \mathrm{H}_{2} \mathrm{O}$, enriched by a factor of $\sim 13$ relative to those of Siqueiros MORB. The common occurrence of kaersutite in DVDP lineage lavas is also a strong indication that Erebus volcanic province lavas are generated and evolve under the influence of $\mathrm{H}_{2} \mathrm{O}$. Conversely, the extremely low values of $\mathrm{CO}_{2}$ and $\mathrm{H}_{2} \mathrm{O}$ in the Erebus pyroxene and anorthoclase melt inclusions and the lack of kaersutite in Erebus lineage lavas suggest that these lavas may have been generated from a relatively $\mathrm{H}_{2} \mathrm{O}$-poor source that may have been hotter than that which produced the DVDP lineage lavas (Kyle et al., 1992; 
Iacavino et al., 2016). Perhaps a more likely explanation, as discussed previously, is that EV magmas degassed at shallow depths relative to the basanites from the DVDP lineage.

The simplest interpretation of the EV and Ross Island elemental and isotopic geochemistry (Phillips et al., 2018) is that the Erebus magmas were derived by low-degree partial melting of a source containing residual garnet (i.e. below the garnet-spinel transition zone, $\sim 80 \mathrm{~km}$ depth) and high $\mathrm{CO}_{2}$. Combined geophysics and geochemistry suggest that the source of these melts is the asthenospheric mantle (Phillips et al., 2018).

The subsequent evolution from basanite to phonolite is recorded in the compositions of lavas and melt inclusions from both the DVDP and EL lavas (Kyle, 1977; 1992; Kelly 2008b; Oppenheimer, 2011). The liquid-line of descent in these lineages have been experimentally investigated (Moussallam et al., 2013; Iacavino et al., 2016) and thermodynamically modeled (Iacavino, 2015). There is also evidence of gases from the basanitic part of the system streaming through to the phonolite magma to be degassed both passively and explosively from the lava lake (Oppenheimer et al., 2008b; 2011; Iacavino, 2015).

An important first-order constraint on the recent and current EV magma system comes from the seemingly steady-state composition of its eruptive products, which, as represented in the dated lava flows and historic bombs, have been uniformly phonolitic over several millennia. This observation begs several questions: 1) How much magma is driving the active lava lake at the surface? 2) Is heat (and mass) input from depth (i.e. the mantle) episodic or continuous? 3) Where (i.e. at what depth) does differentiation from primitive basanite to evolved phonolite occur? 4) Which processes control the uniform nature of Mt Erebus phonolitic magmas and where is that uniform character set (at shallow depth, $>5 \mathrm{~km}$, or deeper)?

\subsection{Erebus volcano Hosts a Unique, Long-Lived Lava Lake that Provides an Open- conduit, Alkaline Magma System Natural Laboratory}

Given the persistent summit lava lake and open magma conduit at EV and the imaged near-summit magma body, two end-member models for the Mt Erebus magmatic system are: 1) 
full connectivity from a mantle source to the shallow system that feeds the lava lake; and 2) episodic buoyant rise of discrete bodies of mantle-derived basanitic melt, which establish transient pre-eruptive crustal reservoirs.

Determining the geometry and physical state of the magmatic plumbing system is essential to understanding how the EV lava lake has remained near its liquidus temperature for decades, likely even millennia, while erupting nearly compositionally uniform magmas over the same timescales. In the following section, we examine geophysical and geochemical constraints on the geometry and processes occurring within the Erebus magma system.

\subsubsection{What Constraints do Geophysical Measurements Place on the Geometry of the Erebus Magmatic Plumbing System from the Lava Lake Vent to the Lower Crust?}

Geophysical imaging of the internal structure of EV provides constraints on models of magma formation, staging, evolution, and degassing. A qualitative and quantitative combination of all of these techniques can robustly determine characteristics of the deep system and explain its past and possible future evolution. In the following we examine the constraints geophysical imaging is providing on the subsurface structure of EV, including its shallow magma conduit system.

\subsubsection{Shallow subsurface structure of the upper cone}

The surface morphology and geology of the summit cone at EV, as well as its crater walls, indicate spatial and temporal variability in the processes forming the upper volcanic edifice. Evidence includes an uneven distribution of fumaroles and lava flows, a significantly off-center crater and vent system, and interleaved lava flow, pyroclastic, and ice deposits. Temporary dense array seismic observations of high-frequency scattered waves ( $\sim 1$ to $15 \mathrm{~Hz}$ ) from regional icequakes, ice borehole shots, and eruptions show that this eruptive and morphological heterogeneity is strongly reflected in the seismic wave field (Chaput et al., 2014, 2015a,b).

3.3.1.2 Shallow Magma Conduit System (Lava lake to $1.5 \mathrm{~km}$ below the surface) 
Below the surface expression of the lava lake, the assimilated $\mathrm{P}$ wave tomography and coda-derived autocorrelation scattering imaging (Zandomeneghi et al., 2013) confirm the absence of a large centralized vertical conduit below the lava lake (Figures 21 and 22). Instead, imaged areas with low P-wave velocities and high scattering suggest that a near-summit magmatic storage zone exists several hundred meters to the NW of the lava lake at a depth of several hundred meters below the Tramway Ridge warm ground and other well-pronounced hydrothermal features of that sector of the summit plateau. This near-summit magma body (NSMB) resides $500-1000 \mathrm{~m} \mathrm{NW}$ of the lava lake and extends to depths in excess of $500 \mathrm{~m}$ below the surface.

The terminal conduit (i.e., its uppermost few hundred meters above the NSMB) has not been resolved by tomographic study, which indicates that it is likely narrower than approximately 10 meters in its uppermost few hundred meters. If the conduit extends to the nearest edge of the NSMB, connecting near the VLP source region, then it would have an inclination of approximately $60^{\circ}$ and a length of approximately 500 meters, although there is no reason to assume a simple upper conduit geometry. Indeed, the presence of additional sporadically active vents within the inner crater implies a branching or otherwise complex terminal geometry in at least the uppermost few 100's of meters below the inner crater. This varying near-summit-conduit diameter is also reflected in physical studies of gas slug disruption during lava lake eruptions (Gerst et al., 2013). Although the terminal conduit is evidently too narrow to be resolved in existing tomographic models, it is a source of very-long-period seismic signal generation (Aster et al., 2003), and an average diameter of less than about $10 \mathrm{~m}$ is consistent with variations in the timing of these very-long-period signals with respect to surface explosions (Knox et al., 2018). Broadband observations of the lava lake eruptive process have been particularly valuable in quantifying and understanding both the explosive decomposition signal of the emerging overpressured gas slug and the subsequent minutes-long response of the magmatic conduit as it re-establishes equilibrium during system refill. A remarkable feature of these events is that the system is nearly reset after this process concludes, so that the next lava lake eruption may generate nearly identical seismograms and infrasonograms. This quasirepeating elastic radiation from the EV lava lake explosions reflects the non-destructive and selfreconstructing nature of the erupting and refilling lava lake system. 
Variable terminal conduit size is also reflected in video and geophysical studies of gas slug disruption during lava lake eruptions (Gerst et al., 2013). Broadband observations of the lava lake eruptive process have been particularly valuable in quantifying and understanding both the explosive decomposition signal of the emerging overpressured gas slug and the subsequent minutes-long response of the magmatic conduit as it re-establishes equilibrium during system refill.

Finally, moment-tensor inversions and spectral analyses of very-long-period seismic signals associated with lava lake eruptions demonstrate the existence of significant single force components in the VLP source region that are consistent with reaction forces generated during post-eruptive lava lake refill magmatic and gas transport within the shallow conduit system. The predominant single force component dips northwest, providing additional evidence for an inclined conduit with this general orientation (Aster et al., 2003; Aster et al., 2008).

Together, these observations suggest that the shallowest (upper few hundred meters to 1.5 $\mathrm{km}$ ) elements of the conduit system have significantly nonvertical, nonplanar geometries, and that a significant feature of this system extends from the lava lake to the VLP source region and NSMB (Figure 23). The presence of less persistent vents (an intermittent ash vent near the south margin of the inner crater and an intermittent small secondary vent west of the lava lake) furthermore suggests that this system has a multithreaded geometry across at least the uppermost several hundred meters to support sporadic activity at these secondary vents.

\subsubsection{Magma conduit system deeper than $1.5 \mathrm{~km}$}

Geophysical investigations on Mt Erebus have focused primarily on imaging the uppermost magma plumbing system $(<1.5 \mathrm{~km}$ depth), in particular the shallow conduit, but the continuation of the shallow conduit system to greater depth is so far poorly constrained by existing geophysical and geochemical/petrologic data sets. Recent reprocessing of dense seismograph deployment data from the Tomo Erebus data set (Zandomeneghi et al., 2013) by Blodel et al. (2018) using advanced scattering matrix and adaptive confocal filtering methods has extended seismic imaging to depths near $2.5 \mathrm{~km}$ and suggests additional reservoirs near and 
below sea level. This model is also consistent with the predominant near-summit magma storage zone (the NSMB also imaged in Chaput et al. (2012) and Zandomeneghi et al. (2013)) lying northwest of the lava lake and indicates an inclined conduit system that extends east-northeast to depths of near $2000 \mathrm{~m}$ below sea level with an average dip near 60 degrees. At still greater crustal depths, scattering regions that may represent deeper elements of the magmatic system are visible with a general westward inclination to depths near $6000 \mathrm{~m}$ below sea level. This westdipping deeper trend is also generally consistent with recent, as yet unpublished, magnetotelluric imaging, which shows a generally inclined conduit system below $10 \mathrm{~km}$ towards the west and south (Hill et al., 2017; P. Wannamaker, pers. comm.).

\subsubsection{How do Surface Gas Measurements Inform Our Knowledge of Subsurface Processes of Magma Differentiation and Degassing Occurring Within the Volcanic Conduit?}

The parental lavas of EV are $\mathrm{CO}_{2}$-rich, silica-undersaturated basanitic magmas, which subsequently evolve via fractional crystallization into intermediate and then phonolitic melts. Simultaneously, as this $\mathrm{CO}_{2}$-rich silicate melt is evolving from basanite to phonolite, a coexisting $\mathrm{C}-\mathrm{O}-\mathrm{H}-\mathrm{S}$ fluid evolves (and is eventually released as gas at the surface). The composition of the fluid is a function of T, $\mathrm{P}, f \mathrm{O}_{2}$, and the concentrations of volatiles dissolved in the melt. A discussion and evaluation of relevant solubility parameters for volatiles in basanitic and phonolitic melts can be found in Burgisser et al. (2012) and Iacovino (2016).

EV's open conduit provides a pathway along which the alkaline magma differentiates and volatiles are exsolved and potentially segregated from the magma. Because the composition of the measured surface gas is the summation of all subsurface processes involving gas exsolution and exchange, deconvolving possible signatures of gasses derived from various depths within the EV system is an important goal that is just beginning to be realized (Iacovino, 2015).

Surface gas compositions from the EV lava lake are $\mathrm{CO}_{2}$ rich $\left(35-40 \mathrm{~mol} \% \mathrm{CO}_{2}\right)$ and exhibit a bimodal behavior linked to eruptive activity. Ambient passive degassing is punctuated by explosive Strombolian degassing associated with large bubble bursts in the lava lake. During these Strombolian eruptions, both $\mathrm{CO}_{2} / \mathrm{H}_{2} \mathrm{O}$ and $\mathrm{CO}_{2} / \mathrm{CO}$ increase significantly compared to the ambient passive degassing signal. Physically, these Strombolian events are interpreted as 
eruptions of deeper gas slugs that have accumulated in a shallow magma reservoir and then moved to the surface through the tilted narrow conduit (Aster et al., 2003; Aster et al., 2008; Gerst et al., 2013; Ilanko et al., 2015).

The $\mathrm{CO}_{2}$-rich nature of gases released by ambient passive degassing at $\mathrm{EV}$ have been variably explained by 1) the complete degassing of a parental basanite melt at $\sim 400 \mathrm{MPa}$ (Oppenheimer and Kyle, 2008b); 2) differential degassing of a shallow phonolite melt within the lava lake at near-surface pressure (Burgisser et al., 2012); or 3) a mixture of both shallow (phonolite) and deep (basanite, 500-800 MPa) degassing (Iacovino et al., 2013; Oppenheimer et al., 2011; Iacovino, 2016).

Modeling the sources of measured magmatic gases depends on knowing several thermodynamic parameters, including the solubilities of the various gases in the different magma compositions, ranging from basanite to phonolite. Experimental studies have placed tight constraints on the $\mathrm{P}-\mathrm{T}-f \mathrm{O}_{2}-\mathrm{XH}_{2} \mathrm{O}$ conditions of magma differentiation, storage, and degassing at various depths throughout the EV plumbing system (Iacovino et al., 2013, 2016; Moussallam et al., 2013). As a result of poor knowledge of all the required parameters, the solubility models used to calculate the composition of $\mathrm{C}-\mathrm{O}-\mathrm{H}-\mathrm{S}$ fluids in equilibrium with sampled silicate melts have come up with very different implications for the EV conduit system.

The highly distinct signatures from explosive degassing (e.g. Figure 16) are also variably interpreted to 1) be sourced from deep parental basanite magma (Oppenheimer et al., 2009; 2011) or 2) be due to different processes occurring entirely with the evolved phonolite (Burgisser et al., 2012).

In the third scenario, which is an outgrowth of ideas from the first scenario, the ratio of $\mathrm{CO}_{2} / \mathrm{CO}$ tracks redox conditions (Oppenheimer et al., 2011), whereas the ratio of $\mathrm{CO}_{2} / \mathrm{H}_{2} \mathrm{O}$ relates to the source depth of degassing. In this case, the measured differences in these ratios between quiescent and explosive gas signatures are due to the decompression of two deep, volatile-saturated sources that mixed to various degrees (phonolite at 100-300 MPa and basanite at 500-800 MPa with the basanitic gas signature dominating the explosive signal). The 
implication for the EV system is that both the deep (mafic) and shallow (phonolitic) portions of the plumbing system are actively degassing (Figure 30 ).

In the starkly contrasting second scenario, Burgisser et al. (2012) examined whether the difference in the $\mathrm{CO}_{2} / \mathrm{CO}$ and $\mathrm{CO}_{2} / \mathrm{H}_{2} \mathrm{O}$ ratios between explosive and quiescent degassing can be explained entirely by variations in the adiabatic (isentropic) expansion of the gas bubbles, accompanied by cooling and immediate re-equilibration (Figure 16). Burgisser et al. (2012) interpreted the observed difference in these ratios, particularly the $\mathrm{CO}_{2} / \mathrm{CO}$, as indicating that the explosive gases are not from a deep basanitic source but rather represent gas slugs from the shallow phonolitic source. Essentially, they posit that adiabatic expansion and differences in rates of ascent compared to rates of volatile diffusion between melt and gas are the cause of the observed range of $\mathrm{H}_{2} \mathrm{O} / \mathrm{CO}_{2}$ and $\mathrm{CO}_{2} / \mathrm{CO}$ ratios. Their results suggest that the gas slug last equilibrated at temperatures of up to $300^{\circ} \mathrm{C}$ cooler than those estimated for the lava lake, due to rapid gas expansion just prior to burst. In both scenarios, the sporadic periodicity of the explosions is caused by the gas slug migrating through the narrow conduit to the surface.

More recently, Iacovino (2015) again argued for degassing of volatiles from the deeper basanitic magma system. Using measurements of dissolved volatiles recorded in melt inclusions (Oppenheimer et al., 2011), a forward thermodynamic model that computes the composition of a $\mathrm{C}-\mathrm{O}-\mathrm{H}-\mathrm{S}$ fluid in equilibrium with melts of different depths (considering the parameters $\mathrm{T}, \mathrm{P}$, $f \mathrm{O}_{2}, f \mathrm{H}_{2}$ or $f \mathrm{~S}_{2}$, and $\mathrm{CO}_{2}$ ), and then a mixing model which "finds all possible mixtures of subsurface fluid that match the chemistry of surface gas within \pm 2.0 mol\%" Iacovino (2016) interprets the EV lake surface gas emissions to be a mixture dominated by degassing from the deep basanite (at $\sim 450 \mathrm{MPa}$ ) with a lesser, but still substantial contribution from near-surface fluid in the lava lake.

While the compositions and the ratios of the gases provide important constraints on the source of exsolved EV gases, simple petrological calculations show that the magnitude of $\mathrm{CO}_{2}$ gas discharge from the EV lava lake can easily be accounted for by gases streaming from deep. Using a $\mathrm{CO}_{2}$ emission rate of $1000 \mathrm{Mg} /$ day ( 1300 Mg d-1; Oppenheimer and Kyle, 2008b) and an initial $\mathrm{CO}_{2}$ content of $0.6 \mathrm{wt} \%$ as measured in melt inclusions $\left(\mathrm{CO}_{2}: 690 \pm 125 \mathrm{ppm}\right.$; 
Oppenheimer et al., 2011), the $\mathrm{CO}_{2}$ flux can be accounted for by complete degassing of $\sim 1 \mathrm{~m}^{3}$ $\mathrm{s}^{-1}$ of parental basanite magma (Oppenheimer et al., 2011). Further, as noted by Oppenheimer et al. (2011), a declining magma flux towards the surface is required to explain the observed $\mathrm{CO}_{2}$ and $\mathrm{H}_{2} \mathrm{O}$ fluxes (Oppenheimer and Kyle, 2008b). Given the solubilities and initial concentrations of $\mathrm{H}_{2} \mathrm{O}$ and $\mathrm{CO}_{2}$ in the melt, if all the magma reached very shallow levels in the conduit, then the water flux should be significantly higher than observed.

Finally, the suggestion that $\mathrm{CO}_{2}$ must be streaming up from a deep storage zone of mafic magma in order to explain $\mathrm{CO}_{2}$-rich surface gas compositions makes physical sense, because the gas phase would be buoyant relative to magma, and would help maintain thermal output from the EV system. Such a process of gas streaming is often invoked in active intra-plate volcanoes from across the globe, including Nyiragongo volcano (Democratic Republic of Congo) whose alkaline (nephelinite) lava lake emits $\mathrm{CO}_{2}$ in quantities beyond those that could be sustained by the erupted lava (Sawyer et al., 2008), Etna (Aiuppa et al., 2006), and Yellowstone (Lowenstern and Hurwitz, 2008)

Accordingly, a consensus model of the EV system includes 1) an open conduit, manifest in the surface lava lake, which has connectivity from deep basanite to the shallow phonolite magmas; and 2) deep basanitic melts, which are the most volatile-rich and likely make up the largest portion of melt in the system by mass, and thus provide both heat and volatiles to maintain EV's shallow, more evolved magma. That being said, the above arguments based on gas measurements are highly dependent on 1) our knowledge of the solubilities of the various gaseous species as a function of temperature, pressure, and melt composition; and 2) the assumption of equilibrium.

\subsubsection{What is Known About the Timescales of Magma Evolution, Crystallization, and Magma Degassing in the Erebus Magma System?}

\subsubsection{Growth Rates of Anorthoclase Megacrystals}

Determining the growth rates of anorthoclase megacrystals in the Erebus phonolites provides an opportunity for constraining the magma residence time in the upper phonolitic system. To date, three main approaches have been used to establish the growth rates of Erebus 
anorthoclase megacrystals: 1) crystal size distributions; 2) crystal speedometry; and 3) U-series measurements.

\section{Crystal Size Distributions:}

Crystal size distributions of Erebus anorthoclase megacrystals (Dunbar et al., 1994) suggest initial low nucleation rates followed by rapid growth in two or more stages. The initial growth stage produced spongy inclusion-rich cores, which were overgrown by finely laminated rims. The composition of melt inclusions in the anorthoclase is very similar to that of the glass matrix of the samples, indicating that the anorthoclase crystals formed in a fully evolved phonolitic melt. Anorthoclase megacrystal size distributions in Erebus bombs show a linear relationship between the natural logarithm of the crystal number density (as a function of linear crystal size) and crystal width, with no accumulation in the larger size classes. This linear relationship suggests that crystallization has been temporally continuous and that accumulation of anorthoclase crystals has not been an important factor (Dunbar et al., 1994). Finally, Dunbar et al. (1994) find that the age of an average EV anorthoclase crystal is 100-300 years. As a caveat, it is critical to note that the presence of resorption/dissolution within some anorthoclase megacrystals suggests that a simple size distribution-age calculation may underestimate the true crystal age.

\section{Diffusion Chronometry}

The first study using oscillatory zoning of anorthoclase feldspar megacrystals erupted from the lava lake of EV was in an unpublished M.S. thesis (Sumner, 2007), who measured Sr and Ba profiles by electron microprobe and laser ablation ICP-MS in five anorthoclase crystals from phonolite bombs, yielding an average growth rate of $1.4 \times 10^{-9} \mathrm{~cm} \mathrm{~s}^{-1}$. We note, however, that this calculation is significantly influenced by a single outlier, which, when removed, decreases the growth rate to $2.1 \times 10^{-10} \mathrm{~cm} \mathrm{~s}^{-1}$.

Moussallam et al. (2015) evaluated the origin of the oscillatory zoning in the anorthoclase megacrystals using what they describe as a "perspective of phase equilibrium, solubility experiments and an analysis of melt inclusion data." Their general conclusions are consistent with other studies, namely that the oscillatory zoning seen in the anorthoclase megacrysts is a 
manifestation of the convective overturn of the upper phonolitic lava system. This vigorous convection is essential for maintaining geochemical homogeneity in the EV magmatic system as indicated by the absence of chemical and isotopic changes in lavas erupted at Erebus over the last 20 ka (Kelly et al., 2008; Sims et al., 2008a)

Moussallam et al.'s (2015) model calculations, which do not consider magma recharge, use experimentally-determined growth rates of synthetic feldspar to estimate 'maximum' growth rates of anorthoclase crystals as a function of pressure and temperature. Fixing the EV melt temperature at $962^{\circ} \mathrm{C}$, they convert zone widths to timescales to calculated vertical speeds within the magma chamber of about 0.3 to $1 \mathrm{mms}^{-1}$ and a Raleigh number of $10^{17}$ (using an ascent speed of $0.5 \mathrm{mms}-1$ and a 1-km-deep chamber). Based upon this growth rate model they conclude that crystal ages must exceed a few years for the smallest crystals and range up to hundreds of years for the largest ones. However, these crystal age estimates neglect resorption episodes, which are evident in the anorthoclase megacrystals (Figure 7). This lack of constraints on the duration(s) of episodic resorption requires that these calculated crystal ages are minimum ages.

\section{$U$ - and Th-Decay Series Constraints:}

Sims et al. (2013) investigated the time scales of magma genesis, melt evolution, crystal growth rates, and magma degassing in the EV magmatic system using measurements of ${ }^{238} \mathrm{U}$ ${ }^{230} \mathrm{Th}^{2}{ }^{226} \mathrm{Ra}-{ }^{210} \mathrm{~Pb}-{ }^{210} \mathrm{Po},{ }^{232} \mathrm{Th}^{228}{ }^{2} \mathrm{Ra}^{228} \mathrm{Th}$ and ${ }^{235} \mathrm{U}-{ }^{231} \mathrm{~Pa}-{ }^{227} \mathrm{Ac}$. These different nuclides have starkly contrasting chemistries resulting in significant elemental fractionations during a variety of magmatic processes, and their different half-lives allow the investigation of time scales ranging from less than 1 year to $10^{5}$ years.

The Sims et al. (2013) measurements of ${ }^{238} \mathrm{U}-{ }^{230} \mathrm{Th},{ }^{230} \mathrm{Th}-{ }^{226} \mathrm{Ra},{ }^{226} \mathrm{Ra}-{ }^{210} \mathrm{~Pb}$ and ${ }^{232} \mathrm{Th}-$ ${ }^{228} \mathrm{Ra}^{228} \mathrm{Th}$ disequilibria provide four important observations pertinent to both anorthoclase crystal growth rates and magma residence times in the shallow EV system.

1) On a $\left({ }^{230} \mathrm{Th} /{ }^{232} \mathrm{Th}\right)$ vs $\left({ }^{238} \mathrm{U} /{ }^{232} \mathrm{Th}\right)$ isochron diagram, both the anorthoclase and phonolite glass show significant $\left({ }^{230} \mathrm{Th} /{ }^{238} \mathrm{U}\right)$ disequilibria and cluster tightly in two distinct groups forming horizontal two-point isochrons (Figure 13). 
2) On a $\left({ }^{226} \mathrm{Ra}\right) / \mathrm{Ba}$ versus $\left({ }^{230} \mathrm{Th}\right) / \mathrm{Ba}$ isochron diagram, the anorthoclase and glass lie on opposite sides of the 'equiline' forming steeply inclined two-point isochrons (see Figure 9 in Sims et al., 2013a).

3) $\left.{ }^{210} \mathrm{~Pb} /{ }^{226} \mathrm{Ra}\right)$ values are within error of equilibrium for both the anorthoclase and phonolite glass (see Figure 6 in Sims et al., 2013a).

4) $\left({ }^{228} \mathrm{Ra} /{ }^{232} \mathrm{Th}\right)$ values are within error of equilibrium in the phonolite glasses but $\left({ }^{228} \mathrm{Ra} /{ }^{232} \mathrm{Th}\right)>1$ for the anorthoclase (Figure 14).

Instantaneous crystal formation and chemical isolation with a magma residence time of $10^{2}-10^{3}$ years is consistent with the first three of these four constraints. The ${ }^{238} \mathrm{U}-{ }^{230} \mathrm{Th}$ data form horizontal "zero-age" isochrons with an age resolution of 5-10 ky; ${ }^{230} \mathrm{Th}-{ }^{226} \mathrm{Ra}$ data form inclined two-point isochrons giving ages of $\sim 2500$ years for $\mathrm{D}_{\mathrm{Ra}} / \mathrm{D}_{\mathrm{Ba}}=1$, down to 100 's of years for $D_{R a} / D_{B a}=0.1$ (see Figure 10 in Sims et al., 2013a); and the anorthoclase and glass separates both have equilibrium $\left({ }^{226} \mathrm{Ra} /{ }^{210} \mathrm{~Pb}\right)$ values suggesting they are older than 100 years. The equilibrium $\left.{ }^{227} \mathrm{Ac} /{ }^{231} \mathrm{~Pa}\right)$ in the phonolite glasses is also consistent with a magma residence time greater than 100 years, but without measurements of these nuclides in the anorthoclase, these isotopic data have no direct bearing on the timescales of anorthoclase crystallization.

The observation that $\left({ }^{228} \mathrm{Ra} /{ }^{232} \mathrm{Th}\right)$ significantly exceeds unity in several young anorthoclase separates (1984, 1988- Reagan et al., 1992; 2005- Sims et al., 2013a), however, is inconsistent with simple instantaneous crystal growth and requires some portion of the crystal to have grown less than 25 years prior to eruption. This is not surprising as numerous petrographic observations, in situ measurements, and determinations of crystal size distributions (e.g. Dunbar et al., 1994; Sumner, 2007; Kelley et al., 2008b) suggest that anorthoclase crystal growth was episodic and probably continued until eruption. Additionally, there is considerable data indicating that crystallization of magmas occurs over significant periods of time (10s to 1000s of years) as heat is transferred away from the magma/wall-rock interface (see e.g. Charlier and Zellmer, 2000; Vasquez and Reid, 2002; Turner et al., 2003; Hawksworth et al., 2004; Sims et al., 2007; Reagan et al., 2003; 2008; Cooper et al., 2016; Reubi et al., 2017). In light of these observations, it is essential to explicitly consider the timescales of magma differentiation processes in the context of the half-lives of the shorter-lived $\mathrm{U}$ and Th decay series nuclides (e.g. ${ }^{226} \mathrm{Ra},{ }^{210} \mathrm{~Pb},{ }^{210} \mathrm{Po},{ }^{222} \mathrm{Rn}$, 
${ }^{227} \mathrm{Ac},{ }^{228} \mathrm{Ra},{ }^{228} \mathrm{Th}$, etc.). In other words, when the timescale of crystallization is comparable to the half-life of the daughter nuclide of interest (e.g., ${ }^{226} \mathrm{Ra}$ ), caution is warranted and a multi-proxy approach to establishing crystal ages is required.

To account for the abundances of all of the short-lived nuclides in the ${ }^{238} \mathrm{U}$ - and ${ }^{232} \mathrm{Th}$ decay series, including the very short-lived ${ }^{232} \mathrm{Th}-{ }^{228} \mathrm{Ra}$ system, in a manner consistent with known mineral abundances, partition coefficients, and geochemical variations in the EV system, Sims et al. (2013) developed a finite-element, continuous-crystallization model that incorporates ingrowth and decay of the different nuclides in the continuously growing anorthoclase crystals and associated phonolitic melt. This model was used to interrogate a variety of crystallization scenarios including: 1) closed-system continuous crystallization; 2) variable-rate crystallization; 3) dissolution; and 4) dissolution and recrystallization in open systems with magma recharge (Figure 31).

The only way Sims et al. (2013) could replicate the observed Ba and Th concentrations and ${ }^{238} \mathrm{U}_{-},{ }^{235} \mathrm{U}$-, and ${ }^{232} \mathrm{Th}$ - decay series data was to incorporate magma recharge into the shallow system. Accordingly, the recharge rate had to exceed the crystallization rate. These high recharge rates and degrees of crystallization are close to the values required for steady-state compositions to be attained even for incompatible elements such as Th, implying that the young anorthoclase phonolites from EV have major and trace element compositions that are close to those of a steadystate system (Sims et al., 2013a). The modeled high recharge rates also imply that the volume of phonolite in the shallow magma chamber and lava lake system at EV has been growing, which makes sense from a heat-balance point of view, as it explains how a lava lake and shallow magma reservoir can remain liquid (Calkins et al., 2008). The result that the shallow magma reservoir within EV is still growing, has important implications for hazard assessment (see below).

\subsubsection{U-series Constraints on the Timescales of Magma Degassing}

U-series systematics of the glasses also place constraints on the timescales of magma degassing (Reagan et al., 2006; Sims et al., 2013a; Reubi et al., 2014). The observation that 
$\left({ }^{210} \mathrm{~Pb} /{ }^{226} \mathrm{Ra}\right)$ and $\left({ }^{227} \mathrm{Ac} /{ }^{231} \mathrm{~Pa}\right)$ are in radioactive equilibrium suggests that the residence time of the phonolitic magma is $>100$ years, consistent with the above calculations based on anorthoclase ages. When the effect of ${ }^{222} \mathrm{Rn}$ degassing on ${ }^{210} \mathrm{~Pb} /{ }^{226} \mathrm{Ra}$ is considered, the isotopic data indicate that the majority of magma degassing for the phonolitic magma occurred deep and long before eruption. Additionally, for the 2005 lava bomb, whose eruption date (12/16/05) is known explicitly, ${ }^{210} \mathrm{Po}$ was not completely degassed from the lava at the time of eruption. Incomplete degassing of ${ }^{210} \mathrm{Po}$ is atypical for subaerially erupted lavas (Reagan et al., 2006; Sims et al., 2008b) and suggests the EV shallow magma degasses about $1 \%$ of its Po per day.

\subsection{The Erebus Ice Tower Fumaroles and Hot Ground Host a Unique Community of Chemotrophic Life in Antarctica}

\subsubsection{What is the Relationship Between EV's Magmatic System, Hydrothermal System, and its Biosphere?}

The near-summit $\mathrm{P}$ wave tomography model of Zandomeneghi et al. (2013) describes several prominent features interpreted to represent regions of fumarolic ice cave hydrothermal systems, a prominent radial dike, and a near-summit magma body (NSMB) located 500 - 1000 $\mathrm{m} \mathrm{NW}$ of the lava lake and extending to depths in excess of $500 \mathrm{~m}$ below the surface. The NSMB underlies the prominent Tramway Ridge warm ground region of the summit plateau, which is an area of high surface temperatures and gas emissions (Figure 32). Tramway Ridge is also an area that hosts biodiverse and, in some locations, apparently endemic microbial communities (Herbold et al., 2014 a,b) that can comprise thermophilic Archaea, Bacteria, and Eukarya supported by a variety of metabolic functionalities. The habitability (Shock and Holland, 2007; Hoehler, 2007) of these environments appears to be a direct consequence of volcanic activity, in particular the role that this process has in generating steam, the predominant source of water supporting microbial activity and growth (Broady, 1984). Moreover, the energy metabolism of resident populations is likely to be primarily supported by volatiles generated by volcanic degassing and ensuing interactions between condensed steam, these gases, and subsurface minerals.

Further work studying the 'geohydrobiology' of the shallow hydrothermal systems on the summit flanks of EV is necessary to establish the explicit connections between heat and volatile 
mass transfer from the magma system and their collective role in supporting EV's unique microbiological ecosystem. Such an assessment requires an interdisciplinary approach - shallow geophysical imaging to determine fluid and gas pathways and reservoirs; isotope and elemental geochemistry to determine fluid sources and timescales of water-rock-gas interaction; and, cultivation-dependent and cultivation-independent techniques to deduce the redox reactions that support the energy metabolism of the microbial communities. The fumarolic fields on Tramway Ridge and the various fumarolic ice caves present on Erebus provide a unique field laboratory to make direct connections between subsurface processes extending to the mantle and how these integrated processes manifest to generate geochemical conditions conducive to supporting diverse microbial communities. In particular, given the geophysical imaging that links the NSMB and Tramway Ridge, this warm, biologically rich ground could serve as a unique and important site for a long-term ecological study. Clearly heat and mass transfer from the magma system are strongly coupled to the development and evolution of this microbial community. As such, this connection begs an important question - Do changes in volcanic activity (eruptive style, intensity, gas flux) produce changes in the hydrothermal system (across a variety of timescales, from minutes, associated with abrupt pore pressure changes, to months, associated with long-term changes in volcanic activity), which are then manifest in the microbiological community? If so, monitoring changes in the Tramway Ridge microbial communities (and elsewhere on Mt Erebus) could possibly serve as "biosensors" or "bioindicators" of changing volcanic activity.

\subsection{Erebus Volcano's Location Makes it a Threat to Both US and International Antarctic}

\section{Science Programs and Personnel}

Erebus volcano is currently active and sits inspiringly above and 35 miles north of McMurdo Station emitting a gaseous plume that often trails into the horizon (Figures 1-5). McMurdo Station is essential to the US Antarctica program, and also provides logistical and backup support to many other International Programs (e.g., New Zealand, Italy, and Australia).

\subsubsection{How do the Observed Patterns and Changes in Magmatic and Volcanic Activity Over} Both Long- and Short-Timescales Inform About Potential Future Eruptive Behavior and Help in the Assessment of EV's Hazards? 
Most of EV's persistent activity consists of frequent Strombolian eruptions. There has been variability in the extent and magnitude of EV's Strombolian eruptions through time. The largest and most significant Strombolian activity observed in recent decades occurred in September 1984 through January 1985, when ashy clouds were visible to altitudes near 6,000 m (approximately $2 \mathrm{~km}$ above the summit) and ejecta were estimated to reach heights of $600 \mathrm{~m}$ above the summit (e.g., Smithsonian Institution Global Volcanism Program summary). Events like those occurring in 1984-1985, while not likely to disrupt activity in McMurdo, are dangerous and thus would inhibit scientists working on the flanks of Mt. Erebus. Variations in the intensity of EV's Strombolian activity could be a function of geometry or roughness of the vent/conduit system, which allows intermittent trapping of larger gas slugs. Volcanic gas data show strong periodicities in fluxes of species that degas from magma at low pressures $\left(\mathrm{H}_{2} \mathrm{O}\right.$ and $\mathrm{SO}_{2}$ ), consistent with recharge of the lake by intermittent pulses of magma from shallow depths (Ilanko et al., 2015). Cyclic changes in proportions of other gas species suggest a background gas flux that is decoupled from this very shallow magma degassing. These interpretations are consistent with geometric complexity in the uppermost conduit system as inferred from seismic and infrasonic studies (Figure 30) As such, inclination and/or cross-sectional area changes within the shallow magma/gas pathways of EV may play a controlling role in the growth, storage, and eruption size and rate of the large gas slugs driving the current style of lava lake Strombolian eruptive activity. Alternatively, shallow magma crystallization and/or degassing processes may influence convection and release of gas to a greater degree, although petrological evidence to date does not support this suggestion. Finally, another possibility is that eruption style is dominated by changes in gas/magma supply from the deep system (e.g., through the size and flux of $\mathrm{CO}_{2}$ slugs from depth), with conduit processes playing a subordinate role in controlling the timing and intensity of each explosive event.

The potential for large accumulated gas slug or even phreatic (ice) or phreatomagmatic eruptions at EV also exists. On 19 October 1993, two substantial gas explosions near the rim of the inner crater created a new sub-crater approximately $80 \mathrm{~m}$ in diameter and ejected substantial debris over the crater rim. Thus, a near-term and more likely hazard is a phreatic or phreatomagmatic eruption, similar or larger than the one which occurred in 1993. Such an eruption could be extremely dangerous for anyone working on the volcano's summit or flanks, 
and could even potentially disrupt air traffic, which is critical for the USAP science support and safety of life operations.

The geologic record also indicates numerous periods of more intense activity. Evidence of episodes of greater activity at EV include: 1) an EV edifice that is mantled by numerous lava flows ranging in age from $22 \mathrm{ka}$ to $2 \mathrm{ka}$ (Supplemental Table); 2) the morphology of the EV edifice which shows evidence of two crater rims inferred to be associated with large eruptions; and 3) englacial tephra layers that have been recognized at a number of locations around Ross Island (Harpel et al., 2008; Harpel et al., 2004; Iverson et al., 2014) as well as several hundred kilometers away from Ross Island in the blue ice of the Transantarctic Mountains (Harpel et al., 2004). Geochemical investigation of these distal tephras reveal that most are compositionally indistinguishable from the modern EV phonolite, suggesting that they are derived from EV's past explosive activity (Harpel et al., 2008; Harpel et al., 2004; Iverson et al., 2014).

The probability of a Plinian eruption from the summit, or even an effusive flank eruption, is relatively small. Nevertheless, both geophysical and gas measurements show that the EV magmatic system is likely maintained by a mafic magmatic system at depth. Modeled high recharge rates from Sims et al. (2013) imply that the volume of phonolite in the shallow magma chamber and lava lake system at EV has been growing. This makes sense from a heat-balance point of view because it explains how a lava lake and shallow magma reservoir can remain liquid (cf. Calkins et al., 2008). Sims et al.'s (2013) modeled duration of reservoir growth is approximately 2000 years, which coincides, within error, with the ages of the two youngest lavas from the flanks of EV (the Northwest and Upper Ice Tower Ridge flows; Harpel et al., 2004). This observation has important implications for hazard assessment and permits speculation that the EV summit magma chamber system began to grow after these eruptive events and is presently amassing magma in advance of another significant lava eruption from a flank vent. Whatever the short- and long-term hazards, given the nearby proximity of EV to McMurdo Station and its potential to interrupt essential air-traffic, understanding volcanic patterns, monitoring signals indicative of the state of volcanic unrest (seismic, deformation, degassing, heat flow, etc.), and forecasting EV's eruptive behavior is essential. 


\subsubsection{What Information and Monitoring are Needed to Best Forecast Short- And Long-Term}

Volcanic Hazards at Erebus Volcano and Ross Island?

Two timescales of information are required to best assess volcanic hazard: 1) long timescales to understand how Erebus volcano has evolved in order to establish patterns of magmatic cyclicity and thus to constrain the potential types of eruptions that could occur; and 2) active and remote volcanic monitoring and interpretation.

\subsubsection{Long-Term Hazard Mapping}

In volcanology, the past is the key to the future. Establishing magmatic cyclicity is important for understanding the petrogenesis and evolution of a volcano as well as forecasting its eruption probability. While numerous volcanological and chronological studies have been conducted on the upper flanks of Mt Erebus, there is still significant work to be done for a proper assessment of the long-term volcanic hazards associated with EV, including:

- Better determination of the full dynamic range of EV's eruptive behavior over time. The assessment of EV's eruptive drivers and styles will require a comprehensive review and characterization of volcanic materials from the proto-Erebus shield and proto-Erebus cone building phases to modern deposits.

- Critical evaluation of the inferred link that more explosive periods in EV's history are directly linked to caldera collapse events. This will require additional high-precision geochronology coupled with stratigraphic, petrologic, petrographic, and granulometric analyses of EV's edifice rocks as well as distal tephra deposits.

- Assessment of whether the overall driving mechanisms and long-term changes in volcanic activity (e.g., Strombolian versus Plinian or caldera forming) are largely determined by the geometry of the deeper magmatic plumbing system, and how this controls magmatic/chemical processing (stagnation, cooling, convection, differentiation, degassing, gas accumulation, etc.) within the system. In this regard, imaging (and periodically reimaging) the mid- to upper-crustal magma plumbing system could greatly enhance our understanding of EV's eruption dynamics. Additionally, comparison of EV's crustal structure using seismic, MT, and EP techniques may help separate fluid and magma domains and thus clarify where longer-range fluid/melt pathways exist. 
- Finally, systematic geochronological assessment of the entirety of Ross Island volcanism is necessary to better constrain the regional volcanic history and potential hazard, as there is clearly young volcanism on Hut Point Peninsula, the recurrence of which would be extremely problematic for operations and personnel at McMurdo Station.

\subsubsection{Revitalize MEVO: A New Monitoring Program}

Monitoring of volcanoes is important for hazard assessment and impact mitigation. For several decades MEVO was led by Phil Kyle at NM Tech. Its observational system functioned until late 2016, when the instruments were removed from the mountain at the conclusion of funding.

At the time of writing (early 2019), the US Antarctic Program (USAP) has contracted a small temporary network of seismographs, installed and maintained by the IRIS consortium, to maintain some continuity of data collection on the volcano. USAP is presently considering the installation of a multi-year network of IRIS-supported seismographs and infrasonic sensors to ensure monitoring, and is potentially receptive to science and/or monitoring proposals that can provide a new level of reporting and research on the volcano.

EV continues to be an attractive target for improved monitoring and the development and application of volcanic studies to further understanding of this remarkable volcano, and as a proving ground for techniques and insights that are generally applicable to active volcanoes. Advances in low-maintenance and high signal-to-noise seismic, infrasonic, structure-frommotion, radar, video, geodetic, and other robust low-power and high-capability instrumentation, recent progress in seismic and magnetotelluric imaging of the magmatic system of the volcano to sea level and deeper depths, and the continued repetitive seismic illumination of the volcano by quasi-repeating lava lake eruptions all facilitate the improved monitoring and continued scientific potential of EV. As discussed above, we believe that appropriate and sustained volcano monitoring is essential to ensure the viability and continued safe operation of McMurdo Station for the US as well as for leveraging future international research support and collaboration.

\subsection{Summary: From Mantle to Microbe}


Erebus volcano is a rare example of an active, intraplate alkaline volcano with an open conduit system that provides a unique opportunity to study a volcano from its deep source to its surface, or "from mantle to microbe." Accordingly, given that this is a review paper, it seems appropriate to conclude by summarizing, as simply as possible, what is currently known about EV and Ross Island, starting from the mantle and moving upward toward the surface.

\subsection{Mantle Source and Mantle Melting}

- The Erebus lineage is a spectacular alkaline sequence, ranging from basanite to phonolite, that can be modeled by simple crystal fractionation. (Kyle et al., 1981b; 1992).

- The parental basanite is derived by low degrees of melting from deep in the mantle. Its mantle source is carbon-rich, as indicated by high $\mathrm{CO}_{2}$ in olivine-hosted melt inclusions, with garnet being residual during melting, as indicated by heavy REE depletions and $\left({ }^{230} \mathrm{Th} /{ }^{238} \mathrm{U}\right)>1$ in EV lavas (Sun and Hansen, 1975; 1976; Sims and Hart, 2006; Sims et al., 2013a; Phillips et al., 2018).

- The Erebus lineage lavas, as well as other Ross Island volcanics, have high ${ }^{206} \mathrm{~Pb} /{ }^{204} \mathrm{~Pb}$ and mix toward the HIMU mantle end-member represented by St. Helena (Sun and Hansen, 1975; 1976; Sims and Hart, 2006; Sims et al., 2008a; Phillips et al., 2018).

- The other long-lived radiogenic isotope systems also mix toward the St. Helena HIMU end-member. Because of the long half-lives of ${ }^{147} \mathrm{Sm}\left(\mathrm{t}_{1 / 2}=108 \mathrm{Gyr}\right)$ and ${ }^{176} \mathrm{Lu}\left(\mathrm{t}_{1 / 2}=\right.$ $37.1 \mathrm{Gyr}$ ), which are the parents of, respectively, ${ }^{143} \mathrm{Nd}$ and ${ }^{176} \mathrm{Hf}$, this isotopic coherency requires the age of the HIMU component of the EV and other Ross Island rocks to be old (Archean or early Proterozoic).

- The EV and Ross Island basanitic lavas have trace element characteristics consistent with their being derived in part from a source whose HIMU-like signature is similar to St. Helena (Phillips et al., 2018). These same characteristics are incompatible with the Erebus and Ross Island volcanics originating from a recently (Paleozoic) metasomatized lithospheric source related to subduction along the margins of Gondwana.

- A resolvable low-velocity zone, as deep as 1200 km, exists beneath Ross Island, suggesting that a deep, upwelling plume is connected to the shallow, lithosphere-scale magmatic system (Phillips et al., 2018). 


\subsection{Open System Magma Conduit}

- Seismic methods (P-wave tomography and coda-derived autocorrelation scattering imaging) show no indication of a large centralized vertical conduit below the lava lake (Zandomeneghi et al., 2013). This inability to resolve the EV terminal conduit in tomographic studies, post-eruptive observation of the lava lake system (e.g., Aster et al., 2003), terminal splitting of eruptive gas slugs (Gerst et al., 2013), and seismogram analyis as indicative of small-scale terminal conduit evolution (Knox et al., 2018) consistently indicate that it is likely narrower than $\sim 10 \mathrm{~m}$, and is geometrically complex and inclined in its uppermost few hundred meters below the lava lake.

- Very low P-wave velocities and high short-period seismic scattering indicate a nearsummit magmatic storage zone. This near-summit magma body (NSMB) resides $500-$ $1000 \mathrm{~m} \mathrm{NW}$ of the lava lake and has a top that is less than $\sim 500 \mathrm{~m}$ below the surface. The NSMB is located below the Tramway Ridge warm ground and other well-pronounced hydrothermal features in this sector of the summit plateau.

- Geochemically, EV's open conduit and internal geometry provide pathways along which its alkaline magma differentiates and volatiles exsolve and are released to the atmosphere.

- The EV magma system has been uniformly phonolitic over several millennia, as demonstrated by measurements of its dated lava flows and historic bombs from the summit lava lake (Kelly et al., 2008b; Sims et al., 2008a).

- Combined ${ }^{238} \mathrm{U}$ - and ${ }^{232} \mathrm{Th}$-decay series data indicate that pyroclasts ejected by Strombolian eruptions at EV have compositions expected for a near-steady-state system, reflecting inmixing of degassed magmas, crystal fractionation, and aging (Sims et al., 2013a).

- Gas measurements of $\mathrm{CO}_{2}, \mathrm{CO}, \mathrm{H}_{2} \mathrm{O}$, and $\mathrm{SO}_{2}$ taken during both passive degassing and Strombolian eruptions, together with melt inclusion studies, yield a general consensus model for the EV system that includes the following features: 1) an open conduit that has gas connectivity from the deep basanitic reservoir to the shallow phonolitic lava lake; and 2) deep basanitic melts, which are the most volatile-rich and likely make up the largest portion of melt in the system by mass and provide the heat and volatiles needed to 
maintain the shallow, more evolved phonolitic lava (Oppenheimer et al., 2011; Iacavino, 2015).

\subsection{Surface Expression of Magmatic Activity}

- The most obvious surface manifestation of EV and Ross Island magmatism is its edifice morphology developed as a result of numerous eruptive episodes, which have both deposited lava flows and tephras, and also created large crater rims from past explosive phases (Figures 1-4). In total, about $4,520 \mathrm{~km}^{3}$ of volcanic material has been erupted on Ross Island over the last $\sim 4$ Ma (Esser et al., 2004). Currently, the summit of EV is covered with phonolitic lava flows and tephra from lava bombs.

- EV's persistent degassing produces an ever-present volcanic gas plume that represents a potentially important point source of chemical species to the Antarctic atmosphere and subsequent glacio-chemical records (Zoller et al., 1974; Chuan et al. (1986); Chuan, 1994; Meeker et al., 1991; Zreda-Gostynska et al., 1997; Ilyinskaya et al., 2010).

○ The average $\mathrm{SO}_{2}$ emission rates of $61 \mathrm{Mg} \mathrm{d}^{-1}$ (Sweeney et al., 2008) of the $\mathrm{EV}$ plume is low compared to those of other persistently active volcanoes (Andres and Kasgnoc, 1998).

- The EV gas plume is rich in halogens $(\mathrm{Cl}, \mathrm{Fl}$, etc.) with some of the highest halogen/ $/ \mathrm{SO}_{2}$ ratios for volcanoes globally (Kyle et al, 1990c; Pyle and Mather, 2009; Ilyinskaya et al., 2010).

○ The EV plume is enriched in trace metals of $\mathrm{In}, \mathrm{As}, \mathrm{Hg}, \mathrm{Zn}, \mathrm{Au}, \mathrm{Se}, \mathrm{Co}, \mathrm{W}$, $\mathrm{Cs}, \mathrm{Mo}, \mathrm{Rb}, \mathrm{Cu}, \mathrm{Na}$, and $\mathrm{K}$.

- The final surface manifestation of the EV system is that it hosts biodiverse and endemic microbial communities (Herbold et al., 2014a,b) that can comprise thermophilic Archaea, Bacteria, and Eukarya supported by a variety of metabolic functionalities. The habitability of these environments for supporting microbial activity and growth appears to be a direct consequence of EV's sustained thermal and eruptive activity as demonstrated by the spectacular link between the imaged nearsurface magma system and the warm hydrothermally active ground and the thriving microbial community at Tramway Ridge. 


\section{Figure Captions}

Figure 1: Mt Erebus Volcano (3794 m elevation). Looking north from Castle Rock. (Photo: Sylvain Pichat)

Figure 2: Satellite Image of Mt Erebus (Image created by Jeff Dishbrow, Polar Geospatial Center).

Figure 3: "Conquest of Mt Erebus". Photos taken during the first ascent of Mt Erebus on March 10, 1908, by a party from Shackleton's Nimrod Expedition (from Shackleton et al., 1909).

Figure 4: Map of Mt Erebus showing the location of Mt. Erebus and the location and ${ }^{40} \mathrm{Ar} /{ }^{39} \mathrm{Ar}$ ages of its lavas. Map modified from Kelly et al. (2008a) and Sims et al. (2008a). Data taken from Harpel et al. (2004), Esser et al. (2004), and Kelly et al. (2008a).

Figure 5: Erebus Summit Geography. Modified from Harpel et al. (2004) and Kelly et al. (2008a).

Figure 6: The Erebus Hut looking southwest toward Erebus summit. Erebus Crater from Dante Launch site.

Figure 7: (a) Molten lava bomb. Ice Axe for Scale. (b) Phonolitic lava flow (Scale Bar is $4 \mathrm{~cm}$ ). (c) Separated anorthoclase megacrystals. D) Back-scattered electron (BSE) image and Ca element map of a single anorthoclase crystal. The darkest areas in the BSE image are the anorthoclase host crystal. The abundant irregular areas, slightly brighter than the anorthoclase, are melt inclusions. Other included phases are pyroxene (light grey phase on Ca map), apatite (next brightest on BSE, highlighted in red on Ca map) and magnetite (brightest in BSE, dark on Ca map). The size of the apatite crystals has been slightly increased in order to improve visibility. SEM Image from Sims et al. (2013). 
Figure 8: Ice Tower showing passive degassing on Mt Erebus summit flank. Tower is approximately 3 meters tall; circular tube is collapsed section of tower that remained intact (Photo: K.W.W. Sims).

Figure 9: Total alkalis (wt\%) vs. silica (wt\%) diagram for Ross Island volcanics. Most samples from the peripheral volcanic centers examined in Phillips et al. (2018) are basanites. The Mt. Terror, Mt. Bird, and Hut Point Peninsula samples contain $\mathrm{SiO}_{2}$ ranging from 40.9 to 56.8 wt.\%, $\mathrm{Na}_{2} \mathrm{O}+\mathrm{K}_{2} \mathrm{O}$ ranging from 3.74 to $14.7 \mathrm{wt} . \%$, and $\mathrm{MgO}$ ranging from 0.12 to $12.7 \mathrm{wt} . \%$, with an average of $6.43 \mathrm{wt} . \%$. All samples with $\mathrm{MgO}$ less than $1 \mathrm{wt} . \%$ are either phonolites or plot close to the phonolite-tephriphonolite divide. Major and trace element data for these samples, including both whole-rock analyses and matrix glass analyses, are reported in Kyle et al. (1992), Kelly et al. (2008b), and Phillips et al. (2018). Modified from Phillips et al. (2018).

Figure 10: Primitive mantle-normalized trace element diagram, showing light REE enrichments in Mt. Terror, Mt. Bird, and Hut Point Peninsula samples, with primitive mantle-normalized $\mathrm{La} / \mathrm{Yb}$ ranging from 14.5 to 26.2. Trace element patterns for the highest $\mathrm{Mg \#}$ samples from the three peripheral volcanic centers are very similar to each other as well as to the HIMU mantle end-member, with negative $\mathrm{K}$ and $\mathrm{Pb}$ anomalies. HIMU is the mean of 12 samples from St. Helena (Willbold and Stracke, 2006). Averages for Erebus volcano are for samples reported in Sims et al. (2008a). Major and trace element concentrations for these Erebus samples are reported in Kelly et al. (2008b) and Kyle et al. (1992). Historical Erebus lineage (EL) lavas from Kelly et al. (2008b) are for matrix glass and older Erebus lineage lavas from Kelly et al. (2008b) and Kyle et al. (1992) are for whole-rock samples. Primitive mantle values are from McDonough and Sun (1995). The highest and lowest Mg\# samples from Mt. Terror, Mt. Bird, and Hut Point are indicated. Modified from Phillips et al. (2018).

Figure 11: Isotope plots showing Ross Island rocks in a global context on the left-hand side, including MORB in green and OIB in gray, illustrating the similarity of Ross Island lavas and tephras to OIB and the HIMU mantle end-member. Plots on the right-hand side show Ross Island volcanic samples in detail and display the overall greater variability of the peripheral volcanic centers compared to Erebus volcano as well as the general clustering of isotope compositions 
within each volcanic center. Erebus lineage samples from Sims et al. (2008a) exclude enriched iron series samples, which show clear signs of crustal contamination. (a) ${ }^{87} \mathrm{Sr} /{ }^{86} \mathrm{Sr}$ versus $\varepsilon_{\mathrm{Nd}}$. Mantle end-members are shown with yellow symbols; depleted MORB mantle (DMM) from Hart et al. (1992; circle), Salters and Stracke (2004; square), and Workman and Hart (2005; triangle); HIMU and enriched mantle 1 (EM1) from Hart et al. (1992); enriched mantle 2 (EM2) from Hart et al. (1992; circle) and Workman et al. (2004; triangle). (b) $\varepsilon_{\mathrm{Nd}}$ versus $\varepsilon_{\mathrm{Hf}}$. Mantle end-members, shown with yellow circles, are inferred for $\mathrm{Hf}$ isotope compositions from their $\mathrm{Nd}$ isotope compositions in Hart et al. (1992). (c) ${ }^{206} \mathrm{~Pb} /{ }^{204} \mathrm{~Pb}$ versus ${ }^{208} \mathrm{~Pb} /{ }^{204} \mathrm{~Pb}$. Mantle endmembers are shown with yellow symbols; DMM, HIMU, and EM1 are from Hart et al. (1992; circles); EM2 are from Hart et al. (1992; circle) and Workman et al. (2004; triangle). After Phillips et al. (2018).

Figure 12: (a) ${ }^{206} \mathrm{~Pb} /{ }^{204} \mathrm{~Pb}$ versus ${ }^{87} \mathrm{Sr} /{ }^{86} \mathrm{Sr}$ showing the similarity of Ross Island lavas and tephras to those from the West Antarctic Rift and the greater southwest Pacific (data from Sun and Hanson, 1975; Hart, 1988 [Balleny]; Hart et al., 1995, 1997; Rocholl et al., 1995; Hoernle et al., 2006, 2010 [Hikurangi]; Panter et al., 2000, 2006; Timm et al., 2010; see also Finn et al., 2005). Ross Island volcanics fall on a mixing line between the DMM and HIMU mantle endmembers, possibly with a small contribution from an EM component. Mantle end-members are shown with yellow symbols; depleted MORB mantle (DMM) from Hart et al. (1992; circle) and Workman and Hart (2005; triangle); HIMU and enriched mantle 1 (EM1) from Hart et al. (1992); enriched mantle 2 (EM2) from Hart et al. (1992; circle) and Workman et al. (2004; triangle). (b) Close-up of (a) showing Ross Island samples in detail. After Phillips et al. (2018).

Figure 13: (a) ${ }^{30} \mathrm{Th} /{ }^{232} \mathrm{Th}$ versus ${ }^{238} \mathrm{U} /{ }^{232} \mathrm{Th}$ isochron plot showing Erebus samples compared with the global database for MORB and OIB. (b) Erebus data enlarged. The shift of anorthoclase megacrystals to lower U/Th exceeds what would be predicted from experimental uncertainties and is interpreted to be due to apatite inclusions (see text for discussion). After Sims et al., 2013a.

Figure 14: (a) Time-series data for $\left({ }^{226} \mathrm{Ra} /{ }^{230} \mathrm{Th}\right)$ over the 34-year historical record from 1972 to 2005. Time is since 2012. (b) Time-series data for ${ }^{228} \mathrm{Ra}$ over the 34 -year historical record from 
1972 to 2005 . Time is since $2012 .{ }^{*}\left({ }^{228} \mathrm{Ra} /{ }^{232} \mathrm{Th}\right)$ was determined using ${ }^{228} \mathrm{Th} /{ }^{232} \mathrm{Th}$ measured by alpha spectroscopy as a proxy, as indicated by the asterisk. The half-life of ${ }^{228} \mathrm{Th}$ is 1.9 years, so for this 2005 sample (measured in 2008$)$ the $\left({ }^{228} \mathrm{Ra} /{ }^{232} \mathrm{Th}\right)$ inferred from $\left({ }^{228} \mathrm{Th} /{ }^{232} \mathrm{Th}\right)$ is a minimum value as the system had not yet attained full equilibrium. Reagan et al. (1992) data are shown for comparison. After Sims et al. (2013).

Figure 15: Histogram of $\mathrm{SO}_{2}$ emission rates measured between 1992 and 2005. The average is $61 \pm 27 \mathrm{Mg} \mathrm{d}-1\left(0.7 \pm 0.3 \mathrm{~kg} \mathrm{~s}^{-1} ; \mathrm{N}=8064\right)$. The Gaussian curve has a peak at $60 \mathrm{Mg} \mathrm{d}^{-1}(0.7 \mathrm{~kg}$ $\mathrm{s}^{-1}$ ). Modified from Sweeney et al. (2008).

Figure 16: Example of retrieved $\mathrm{CO}_{2}$ versus $\mathrm{CO}$ immediately following a large Strombolian explosion at 16:57 UT on 13 December 2005 (red triangles) and a smaller explosion just over a minute later (green triangles) compared with the signature of passive degassing through the lava lake (yellow circles) over the subsequent $2.5 \mathrm{~h}$. Note the much higher $\mathrm{CO}_{2} / \mathrm{CO}$ ratio for the explosively released gas but the differing $\mathrm{CO}_{2} / \mathrm{CO}$ ratios of the two explosions. Modified from Burgisser et al. (2012).

Figure 17: (a) Characteristic vertical-component broadband seismograms of a lava lake explosion observed at summit seismic stations recorded at distances ranging from 0.7 to $2.4 \mathrm{~km}$ from the lava lake. (b) Seismograms from Figure A, prefiltered with a 30-s corner, high-pass, zero-phase, four-pole filter and integrated to displacement. Displacement seismograms are dominated by a VLP signal that begins several seconds prior to the eruption. After Aster et al. (2003).

Figure 18: Shaded relief image (Csatho et al., 2008) of the summit region of Erebus volcano with $100 \mathrm{~m}$ contours showing the geometry of the TOMO Erebus near-summit imaging experiment. Blue circles: locations of seismic stations; red stars: seismic shot points; red circles: locations of fumarolic ice caves [Curtis and Kyle, 2011]; white star: lava lake location. Yellow curves: exposed older, outer (80 - $24 \mathrm{ka}$ ) and younger, inner (11-9 ka) caldera rims [Harpel et al., 2004]. After Zandomeneghi et al. (2013). 
Figure 19: Eruptive energy budget and estimated bubble overpressure with time for "Type I" Erebus lava lake eruptions. After Gerst et al. (2013).

Figure 20: Self-scaled vertical component velocity seismogram (high-pass filtered above 0.5 $\mathrm{Hz}$ ) record section from a shot at Fang Glacier recorded during the TOMO Erebus experiment. Note the rapid development of an extended signal coda (within a few $\mathrm{km}$ from the source) and the diminishment of the first ( $\mathrm{P}$ wave) arrival amplitude. This reflects the high internal heterogeneity and resultant high frequency seismic scattering. After Zandomeneghi et al. (2013).

Figure 21: Very long period (VLP) and short-period (SP) displacement spectra from lava lake explosions, sorted into event size bins, showing direct and nearly identical event size spectral scaling of both signals, and comparison with background noise. (1) Empirical background noise level, dominated by the oceanic microseism. (2) Global low noise model of Peterson (1993). After Aster et al. (2003).

Figure 22: Four depth slices showing the P-wave velocity model (left panels) and scattering intensity (Chaput et al., 2012). Each pair of images is referenced to its depth below the lava lake (bll). Grey contour: crater rim; white star: lava lake location. Labeling indicates near-summit features discussed in Zandomeneghi et al. (2013). Of particular note is the high scattering and very low velocity region (b) centered approximately $1.25 \mathrm{~km}$ northwest of the crater (indicated by the black contour), which is interpreted as a near-summit magma body (NSMB). The lack of low velocities directly below the crater supports the hypothesis of a thin, inclined or otherwise tortuous, summit conduit that connects the lava lake to the NSMB. After Zandomeneghi et al. (2013).

Figure 23: Isosurfaces showing regions of very low $\mathrm{P}$ wave velocity (top, left) and high scattering coefficient (top, right). The intersection of these regions is interpreted as a shallow magma body with a center $\sim 1 \mathrm{~km} \mathrm{NW}$ of the crater and lying beneath the Tramway Ridge warm ground region of the summit plateau. White star: lava lake location; red sphere: location of the VLP moment tensor centroid from Aster et al. (2008). The joint (intersection) volume is shown in the lower panels in cross section and plan view. After Zandomeneghi et al. (2013). 
Figure 24: Temporally progressive VLP-SP lag variations in vertical-component lava lake eruption seismograms between 2003 and 2011 at near-summit station E1S. A) Correlationaligned SP signals (1-8 Hz). B) Identically aligned VLP signals $(0.03-0.2 \mathrm{~Hz})$ showing systematic timing variations of approximately \pm 1 s. After Knox et al. (2018).

Figure 25: VLP-SP lag variations with time across the summit broadband network with respect to time (top) and by event number for high signal-to-noise station E1S. Corresponding time periods of change are represented by the numbered black bars. The lower figure shows VLP-SP lag variation estimated by peak (max) tracking of the VLP signal and via cross-correlation. Outlier lags represent low signal-to-noise events, commonly arising from the strong oceanic microseism signal, which overlaps with the VLP band. After Knox et al. (2018).

Figure 26: Conceptualization of lava lake eruptions and the terminal Erebus conduit system (after Knox et al., 2018), based on tomographic results and eruption seismogram interpretation. Eruptive events $(1-6)$ are shown referenced to the SP and VLP seismograms below. (1) Seismically unobserved pre-eruptive storage in, or transport of, eruptive gas slugs to the NSMB (depicted at lower left); (2) buoyant ascent of the gas slug into and through the (inclined, and possibly geometrically complex) conduit; (3) gas slug emergence into and bulging of the lava lake; pre-eruptive VLP signal; (4) surface explosion, mass ejection, and SP signal origin; (5) elastic communication of surface mass removal back into the conduit system; (6) post-eruptive and prolonged VLP signal (source region indicated) due to oscillatory conduit recharge. Because both the surface (SP) explosion and deeper (VLP) seismic processes and seismograms are similar, correlation or peak tracking produces robust measures of the communication time in process (5). Lengthened communication time is interpreted as indicating increasing construction of the conduit due to internal (i.e. spalling, freezing, or thawing of the conduit wall) or external (i.e. collapse of the inner crater) processes.

Figure 27: $\mathrm{Nb} / \mathrm{La}$ versus (a) $\left({ }^{206} \mathrm{~Pb} /{ }^{204} \mathrm{~Pb}\right)$ and (b) $\varepsilon \mathrm{Hf}$, showing the difference between Ross Island volcanic samples (Mt Erebus, Mt Terror, Mt Bird, and Hut Point), the Mount Somers Volcanic Group (MSVG; Tappenden, 2003), and the Schirmacher Oasis minettes (Hoch et al., 
2001). Ross Island lavas and tephras lie on a mixing line between the HIMU and DMM mantle end-members. Left-hand side panels show Ross Island lavas and tephras in a global context. St. Helena (yellow HIMU circle; Willbold and Stracke, 2006), represents the HIMU mantle endmember, and Depleted MORB Mantle (yellow DMM circle; Workman and Hart, 2005). Also shown is the mixing compositions, with marked increments, between the HIMU and DMM sources. The blue shaded region $(\mathrm{Nb} / \mathrm{La}<0.5)$ represents $\mathrm{Nb} / \mathrm{La}$ ratios that represent arc-related processes (Gill, 1981). Right-hand side panels are close-ups showing the Ross Island samples in detail. Timm et al. (2010) use the MSVG as a possible composition for Zealandia lithosphere enriched by subduction. MSVG's dissimilarity to Ross Island volcanics indicates a lack of influence from metasomatized subcontinental lithospheric mantle at Ross Island. After Phillips et al. (2018).

Figure 28: ${ }^{87} \mathrm{Sr} /{ }^{86} \mathrm{Sr}$ versus ${ }^{143} \mathrm{Nd} /{ }^{144} \mathrm{Nd}$ comparing Ross Island lavas and tephras to volcanic rocks from the greater Antarctic and southwest Pacific region. The highly enriched isotopic signature of the older Mount Somers Volcanic Group (data from Tappenden, 2003), the Ferrar Group (Fleming et al., 1995), and the Schirmacher Oasis minettes of East Antarctica (Hoch et al., 2001). West Antarctic and southwest Pacific/Zealandia data from Futa et al. (1983), Hart (1988; Balleny), Hart et al. (1995; 1997), Rocholl et al. (1995), Hoernle et al. (2006; 2010 [Hikurangi]), Panter et al. (2000; 2006), Rocchi et al. (2002), and Timm et al. (2010) is more typical of metasomatic influence. Ross Island data include samples from Phillips et al. (2018) and from Sims et al. (2008a), excluding enriched iron series samples. After Phillips et al. (2018).

Figure 29: Seismic tomography transects through Ross Island for three azimuths (upper left) displaying the isotropically averaged seismic shear wave velocity anomaly from the crust to the core-mantle boundary in global velocity model SEMUCB-WM1 (French and Romanowicz, 2015). This and other recent tomography models of the region indicate a low seismic shear wave velocity anomaly that extends below the mantle transition zone to near $1200 \mathrm{~km}$ depth beneath Ross Island, with linked features that extend eastward beneath the West Antarctic Rift System into the volcanic province of Marie Byrd Land. The color scale indicates the relative perturbation of shear wave velocity compared to the corresponding model 1-dimensional depth average. SEMUCB-WM1 was calculated using full-waveform inversion of a large data set of long period 
body (> $32 \mathrm{~s}$ ) and surface (> $60 \mathrm{~s}$ ) wave global seismograms. Comparable lower mantle features are also present in the full waveform inversion model GLAD-M15 of Bozdağ et al. (2016) and in other global models (see Supplement F in Phillips et al., 2018). After Phillips et al. (2018).

Figure 30: Schematic image showing how processes and sources of passive and erupting degassing result in significantly different $\mathrm{CO}_{2} / \mathrm{H}_{2} \mathrm{O}$ (by mass) as determined by Oppenheimer et al. (2011).

Figure 31: (a) Schematic of the Erebus shallow magmatic system, detailing compositional constraints, model parameters, and assumptions. (b) Results of finite-element, continuous crystallization model developed to account for all of the abundances of short-lived nuclides in the ${ }^{238} \mathrm{U}$ - and ${ }^{232} \mathrm{Th}$-decay series in a manner consistent with our understanding of mineral abundances, partition coefficients, and geochemical variations in the Erebus system. After Sims et al. (2013).

Figure 32. Cross-sectional diagram of Erebus Volcano across a 6-km long transect that strikes $\mathrm{NW}-\mathrm{SE}\left(135^{\circ} \mathrm{E}\right.$ of $\left.\mathrm{N}\right)$ and goes through the center of the inner crater, and the inferred magma body center (see upper right for transect). The purple volume corresponds to an isosurface characterized by very low P-wave velocities from ray path seismic tomography $(\Delta \mathrm{Vp}<1 \mathrm{~km} / \mathrm{s})$ from travel-time tomography and a high scattering coefficient $(\mathrm{S}>46)$ from scattering tomography (Chaput et al., 2012). This geophysically constrained volume is interpreted to delineate a near-summit magma body that approaches to within $\sim 400 \mathrm{~m}$ of the surface in the northwest sector of the summit plateau and may contribute to sustaining the Tramway Ridge geothermal system (Zandomeneghi et al., 2013). The Erebus volcanic system is thought to supply steam, carbon dioxide $\left(\mathrm{CO}_{2}\right)$, and volatiles as a source of reductant (e.g., $\left.\mathrm{H}_{2} \mathrm{~S}\right)$ to nearsurface microbial communities. Mixing of these fluids with atmosphere (source of $\mathrm{O}_{2}$ ) generates chemical disequilibria that can serve as a source of electrons and energy to drive chemosynthetic $\mathrm{CO}_{2}$ fixation reactions, resulting in the formation of biomass (represented generically as $\mathrm{CH}_{2} \mathrm{O}$ ). As such, microbial communities form an interface between the subsurface volcanic and hydrothermal system and the surface environment. Microbial communities sampled from active fumaroles are distinct from those sampled from passive or inactive fumaroles, as determined by 
16S rRNA gene sequencing and analysis. For example, sequences affiliated with a novel thaumarchaeota lineage were shown to dominate communities inhabiting active fumarolic systems on Tramway Ridge (top left pie chart) whereas those from passive fumaroles from the same location were dominated by sequences affiliated with Meiothermus (Herbold et al., 2014). Importantly, sequences affiliated with known thermophiles were more abundant in the active fumarole community. Data adapted from Herbold et al., 2014. The thin and inclined conduit geometry connecting the near-summit magma body to the lava lake is consistent with that inferred from temporally varying very-long-period and short-period eruptive seismic signals by Knox et al. (2018). Image created by Jeff Dishbrow Polar Geospatial Center and Cole Messa and Lisa Kant, University of Wyoming High Precision Isotope Laboratory using Reference Elevation Model of Antarctica (Howat et al. 2019).

Supplemental Table 1: Average major and trace elements compositions of lavas from Erebus lineage.

Supplemental Table 2: Ages of dated flows on Erebus Volcano

\section{Acknowledgements:}

This work was supported by NSF grants OPP -0126269, OPP-1141167 and OPP- 1644013 to KWWS; OPP-0229305, ANT-0538414, ANT-0838817, and ANT-1142083 to RA; OPP 1644013 to GG; OPP- 1644013 to PW, and EAR-1820658 to ESB. ESB also acknowledges support from NASA grant NNA15BB02A. We thank UNAVCO and the IRIS PASSCAL Instrument Center at New Mexico Tech for facility support and field assistance. Seismic and infrasound data are archived and available at the IRIS Consortium Data Management Center. The facilities of the IRIS Consortium are supported by the National Science Foundation under Cooperative Agreement EAR-1261681, the NSF Office of Polar Programs, and the DOE National Nuclear Security Administration. Geospatial support for this work provided by the Polar Geospatial Center under NSF-OPP awards 1043681 and 1559691. DEMs provided by the Byrd Polar and Climate Research Center and the Polar Geospatial Center under NSF-OPP awards 1543501, 1810976, 1542736, 1559691, 1043681, 1541332, 0753663, 1548562, 1238993 and NASA award NNX10AN61G. Computer time provided through a Blue Waters Innovation Initiative. DEMs produced using data from DigitalGlobe, Inc. We thank the many individuals and groups at McMurdo and within USAP who make field work possible. Ken Sims and Rick Aster also thank Phil Kyle for introducing us to Mt Erebus volcano. Jake Lowenstern and an anonymous reviewer improved the quality of the manuscript. Cole 
Messa and Lisa Kant assisted with figures. Finally, we thank the effective and professional editorial handling of Editors John Smellie and Adelina Geyer. 


\section{REFERENCES}

Aiuppa, A., Federico, C. et al. 2006. Rates of carbon dioxide plume degassing from Mount Etna volcano. Journal of Geophysical Research, 111, B09207, https://doi.org/10.1029/2006JB004307

Amend, J.P. and Shock, E.L. 2001. Energetics of overall metabolic reactions of thermophilic and hyperthermophilic Archaea and bacteria. FEMS Microbiological Reviews, 25, 175-243, https://doi.org/10.1111/j.1574-6976.2001.tb00576.x

Andersen, D.J., Lindsley, D.H. and Davidson, P.M. 1993. QUILF: A pascal program to assess equilibria among Fe-Mg-Mn-Ti oxides, pyroxenes, olivine, and quartz. Computers \& Geosciences, 19, 1333-1350, https://doi.org/10.1016/0098-3004(93)90033-2

Andres, R.J. and Kasgnoc, A.D. 1998. A time-averaged inventory of subaerial volcanic sulfur emissions. Journal of Geophysical Research, 103, 25251-25262, https://doi.org/10.1029/98JD02091

Anthony, R.E., Aster, R.C. et al. 2015. The seismic noise environment of Antarctica. Seismological Research Letters, 86, 89-100, https://doi.org/10.1785/0220140109

Aster, R., Mah, S. et al. 2003. Very long period oscillations of Mount Erebus Volcano. Journal of Geophysical Research-Solid Earth, 108(B11), 2522, https://doi.org/10.1029/2002JB002101

Aster, R., McIntosh, W. et al. 2004. Real-Time Data Received from Mount Erebus Volcano, Antarctica. EOS, 85(10), 97-104, https://doi.org/10.1029/2004EO100001

Aster, R., Beaudoin, B., Hole, J., Fouch, M.J., Fowler, J. and James, D. 2005. IRIS PASSCAL program marks 20 years of scientific discovery. EOS, 86, https://doi.org/10.1029/2004EO100001

Aster, R., Zandomeneghi, D., Mah, S., McNamara, S., Henderson, D.B., Knox, H. and Jones, K. 2008. Moment tensor inversion of very long period seismic signals from Strombolian eruptions of Erebus Volcano. Journal of Volcanology and Geothermal Research, 177(3), 635-647, https://doi.org/10.1016/j.jvolgeores.2008.08.013

Auer, L., Boschi, L., Becker, T.W., Nissen-Meyer, T. and Giardini, D. 2014. Savani: a variableresolution whole-mantle model of anisotropic shear-velocity variations based on multiple datasets. Journal of Geophysical Research, 119, 3006-3034, https://doi.org/10.1002/2013JB010773

Bannister, S., Yu, J., Leitner, B. and Kennett, B.L.N. 2003. Variations in crustal structure across the transition from West to East Antarctica, Southern Victoria Land. Geophysical Journal International, 155, 870-884, https://doi.org/10.1111/j.1365-246X.2003.02094.x

Bateman, H. 1910. The solution of a system of differential equations occurring in the theory of radioactive transformations. In: Proc. Cambridge Philos. Soc. Vol. 15, No. pt V, pp. 423 427.

Becker, T.W. and Boschi, L. 2002. A comparison of tomographic and geodynamic mantle models. Geochemistry, Geophysics, Geosystems, 3, https://doi.org/10.1029/2001GC000168

Behrendt, J.C. 1999. Crustal and lithospheric structure of the West Antarctic Rift System from geophysical investigations - a review. Global and Planetary Change, 23(1-4), 25-44, https://doi.org/10.1016/S0921-8181(99)00049-1

Belly, R.T. and Brock, T.D. 1974. Widespread occurrence of acidophilic strains of Bacillus coagulans in hot springs. Journal of Applied Bacteriology, 37, 175-177, https://doi.org/10.1111/j.1365-2672.1974.tb00427.x 
Boichu, M., Oppenheimer, C., Roberts, T.J., Tsanev, V. and Kyle, P. 2011. On bromine, nitrogen oxides and ozone depletion in the tropospheric plume of Erebus volcano (Antarctica). Atmospheric Environment, 45, 3856-3866, https://doi.org/10.1016/j.atmosenv.2011.03.027

Boichu, M., Oppenheimer, C., Tsanev, V.I. and Kyle, P.R. 2010. High temporal resolution $\mathrm{SO}_{2}$ flux measurements at Erebus volcano, Antarctica. Journal of Volcanology and Geothermal Research, 190, 325-336, https://doi.org/10.1016/j.jvolgeores.2009.11.020

Boyd, E., Hamilton, T., Wang, J., He, L. and Zhang, C. 2013. The role of tetraether lipid composition in the adaptation of thermophilic Archaea to acidity. Frontiers in Microbiology, 4, https://doi.org/10.3389/fmicb.2013.00062

Boyd, E.S., Fecteau, K.M., Havig, J.R., Shock, E.L. and Peters, J.W. 2012. Modeling the habitat range of phototrophs in yellowstone national park: Toward the development of a comprehensive fitness landscape. Frontiers in Microbiology, 3, 221-221, https://doi.org/10.3389/fmicb.2012.00221

Boyd, E.S., Hamilton, T.L., Spear, J.R., Lavin, M. and Peters, J.W. 2010. [FeFe]-hydrogenase in Yellowstone National Park: Evidence for dispersal limitation and phylogenetic niche conservatism. ISME Journal, 4, 1485-1495, https://doi.org/10.1038/ismej.2010.76

Boyd, E.S., King, S., Tomberlin, J.K., Nordstrom, D.K., Krabbenhoft, D.P., Barkay, T. and Geesey, G.G. 2009. Methylmercury enters an aquatic food web through acidophilic microbial mats in Yellowstone National Park, Wyoming. Environmental Microbiology, 11, 950-959, https://doi.org/10.1111/j.1462-2920.2008.01820.x

Bozdă̆ E., Peter D. et al. 2016. Global adjoint tomography: first-generation model. Geophysical Journal International, 207, 1739-1766, https://doi.org/10.1093/gji/ggw356

Broady, P.A. 1984. Taxonomic and ecological investigations of algae on steam-warmed soil on Mt Erebus, Ross Island, Antarctica. Phycologia, 23, 257-271, https://doi.org/10.2216/i0031-8884-23-3-257.1

Brock, T.D. 1967. Micro-organisms adapted to high temperatures. Nature, 214, 882-885, https://doi.org/10.1038/214882a0

Brock, T.D. 1973. Lower pH limit for the existence of blue-green algae: Evolutionary and ecological implications. Science, 179, 480-483, https://doi.org/10.1126/science.179.4072.480

Brock, T.D. and Brock, M.L. 1969. Effect of light intensity on photosynthesis by thermal algae adapted to natural and reduced sunlight. Limnology and Oceanography, 14, 334-341, https://doi.org/10.4319/lo.1969.14.3.0334

Bucholz, C.E., Gaetani, G.A., Behn, M.D. and Shimizu, N. 2013. Post-entrapment modification of volatiles and oxygen fugacity in olivine-hosted melt inclusions. Earth and Planetary Science Letters, 374, 145-155, https://doi.org/10.1016/j.epsl.2013.05.033

Burgisser, A., Oppenheimer, C., Alletti, M., Kyle, P.R., Scaillet, B. and Carroll, M.R. 2012. Backward tracking of gas chemistry measurements at Erebus volcano. Geochemistry, Geophysics, Geosystems, 13, Q11010, https://doi.org/10.1029/2012GC004243

Caldwell, D. and Kyle, P.R. 1994. Mineralogy and geochemistry of ejecta erupted from Mount Erebus, Antarctica between 1972 and 1986. In: Kyle, P.R. (ed) Volcanological and Environmental Studies of Mount Erebus, Antarctica. Antarctic Research Series, 66, American Geophysical Union, Washington, D.C., 147-162, https://doi.org/10.1029/AR066p0147 
Calkins, J.A., Oppenheimer, C. and Kyle, P.R. 2008. Ground-based thermal imaging of lava lakes at Mount Erebus Volcano, Antarctica in December 2004. Journal of Volcanology and Geothermal Research, 177, 695-704, https://doi.org/10.1016/j.jvolgeores.2008.02.002

Caltabiano, T., Romano, R., and Budetta, G. 1994. $\mathrm{SO}_{2}$ flux measurements at Mount Etna, Sicily. Journal of Geophysical Research, 99, 12809-12819, https://doi.org/10.1029/94JD00224

Caltabiano, T., Burton, M., Giammanco, S., Allard, P., Bruno, N., Murè, F. and Romano, R. 2004. Volcanic gas emissions from the summit craters and flanks of Mt. Etna,1987-2000. Mt. Etna: Volcano Laboratory. AGU Geophysical Monograph Series, vol. 143, pp. 111128, https://doi.org/10.1029/143GM08

Castenholz, R.W. 1969. Thermophilic blue-green algae and the thermal environment. Bacteriological Reviews, 33, 476-504, https://doi.org/10.1128/MMBR.33.4.476-504.1969

Chang, S.-J., Ferreira, A.M.G., Ritsema, J., van Heijst, H.J. and Woodhouse, J.H. 2015. Joint inversion for global isotropic and radially anisotropic mantle structure including crustal thickness perturbations. Journal of Geophysical Research, 120, 4278-4300, https://doi.org/10.1002/2014JB011824

Chaput, J., Aster, R. et al. 2014. The Crustal Thickness of West Antarctica. Journal of Geophysical Research, 119, 1-18, https://doi.org/10.1002/2013JB010642

Chaput, J., Zandomeneghi, D., Aster, R., Knox, H. and Kyle, P. 2012. Imaging of Erebus volcano using body wave seismic interferometry of Strombolian eruption coda. Geophysical Research Letters, 39, L07304, https://doi.org/10.1029/2012GL050956

Chaput, J., Campillo, M., Aster, R., Roux, P., Kyle, P., Knox, H. and Czoski, P. 2015a. Multiple scattering from icequakes at Erebus volcano, Antarctica: Implications for imaging at glaciated volcanoes. Journal of Geophysical Research, 120, https://doi.org/10.1002/2014JB011278

Chaput, J., Clerc, V., Campillo, M., Roux, P. and Knox, H. 2015b. On the practical convergence of coda-based correlations: A window optimization approach. Geophysical Journal International, 204, 736-747, https://doi.org/10.1093/gji/ggv476

Charlier, B.L.A. and Zellmer, G.F. 2000. Some remarks on U-Th mineral ages from igneous rocks with prolonged crystallisation histories. Earth and Planetary Science Letters, 183, 457-469, https://doi.org/10.1016/S0012-821X(00)00298-3

Chen, Y., Provost, A., Schiano, P. and Cluzel, N. 2011. The rate of water loss from olivinehosted melt inclusions. Contributions to Mineralogy and Petrology, 162, 625-636, https://doi.org/10.1007/s00410-011-0616-5

Chen, Y., Provost, A., Schiano, P. and Cluzel, N. 2013. Magma ascent rate and initial water concentration inferred from diffusive water loss from olivine-hosted melt inclusions. Contributions to Mineralogy and Petrology, 165, 525-541, https://doi.org/10.1007/s00410-012-0821-x

Chuan, R.L. 1994. Dispersal of volcanic-derived particles from Mount Erebus in the Antarctic atmosphere. In: Kyle, P.R. (ed) Volcanological and Environmental Studies of Mount Erebus, Antarctica. Antarctic Research Series, 66, American Geophysical Union, Washington, D.C., 97-102, https://doi.org/10.1029/AR066p0097

Chuan, R.L., Palais, J.M., Rose, W.I. and Kyle, P.R. 1986. Fluxes, size, morphology and composition of particles in the Mt. Erebus volcanic plume, December 1983. Journal of Atmospheric Chemistry, 4, 467-477, https://doi.org/10.1007/BF00053846 
Colman, D.R., Feyhl-Buska, J., Robinson, K.J., Fecteau, K.M., Xu, H., Shock, E.L. and Boyd, E.S. 2016. Ecological differentiation in planktonic and sediment-associated chemotrophic microbial populations in Yellowstone hot springs. FEMS Microbial Ecology, 92 , https://doi.org/10.1093/femsec/fiw137

Colman, D.R., Lindsay, M.R. and Boyd, E.S. 2019. Mixing of end-member fluids supports hyperdiverse chemosynthetic hydrothermal communities. Nature Communications, 10, https://doi.org/10.1038/s41467-019-08499-1

Colman, D.R., Poudel, S., Hamilton, T.L., Havig, J.R., Selensky, M.J., Shock, E.L. and Boyd, E.S. 2018. Geobiological feedbacks and the evolution of thermoacidophiles. ISME Journal, 12, 225-236, https://doi.org/10.1038/ismej.2017.162

Colman, D.R., Lindsay, M.R., Amenabar, M.J. and Boyd, E.S. 2019. The intersection of geology, geochemistry, and microbiology in continental hydrothermal systems. Astrobiology, 19, https://doi.org/10.1089/ast.2018.2016

Cooper, K., Sims, K.W.W., Eiler, J.M. and Banerjee, N. 2016. Time scales of storage and recycling of crystal mush at Krafla Volcano, Iceland. Contributions to Mineralogy and Petrology, 171, 6, 54, https://doi.org/10.1007/s00410-016-1267-3

Cox, A., Shock, E.L. and Havig, J.R. 2011. The transition to microbial photosynthesis in hot spring ecosystems. Chemical Geology, 280, 344-351, https://doi.org/10.1016/j.chemgeo.2010.11.022

Csatho, B., Schenk, T., Kyle, P., Wilson, T. and Krabill, W.B. 2008. Airborne laser swath mapping of the summit of Erebus volcano, Antarctica: Applications to geological mapping of a volcano. Journal of Volcanology and Geothermal Research, 177, 531-548, https://doi.org/10.1016/j.jvolgeores.2008.08.016

Curtis, A. and Kyle, P. 2011. Geothermal point sources identified in a fumarolic ice cave on Erebus volcano, Antarctica using fiber optic distributed temperature sensing. Geophysical Research Letters, 38(16), https://doi.org/10.1029/2011GL048272

Dabrowa, A., Green, D.N., Johnson, J.B., Phillips, J.C. and Rust, A.C. 2014. Comparing nearregional and local measurements of infrasound from Mount Erebus, Antarctica: Implications for monitoring. Journal of Volcanology and Geothermal Research, 288, 4661, https://doi.org/10.1016/j.jvolgeores.2014.10.001

Daley E.E. and DePaolo D.J. 1992. Isotopic evidence for lithospheric thinning during extension: Southeastern Great Basin. Geology, 20, 104-108, https://doi.org/10.1130/00917613(1992)020<0104:IEFLTD>2.3.CO;2

Dasgupta, R., Hirschmann, M. and Smith, N. 2007. Partial melting experiments of peridotite + $\mathrm{CO}_{2}$ at $3 \mathrm{GPa}$ and genesis of alkalic ocean island basalts. Journal of Petrology, 48, 20932124, https://doi.org/10.1093/petrology/egm053

Dasgupta, R., Hirschmann, M. and Stalker, K. 2006. Immiscible transition from carbonate-rich to silicate-rich melts in the $3 \mathrm{GPa}$ melting interval of eclogite plus $\mathrm{CO}_{2}$ and genesis of silicaundersaturated ocean island lavas. Journal of Petrology, 47, 647-671, https://doi.org/10.1093/petrology/egi088

de Moor, J.M., Fischer, T.P. et al. 2013. Sulfur degassing at Erta Ale (Ethiopia) and Masaya (Nicaragua) volcanoes: Implications for degassing processes and oxygen fugacities of basaltic systems. Geochemistry, Geophysics, Geosystems, https://doi.org/10.1002/ggge.20255 
Dibble, R.R., Kienle, J., Kyle, P.R. and Shibuya, K. 1984. Geophysical studies of Erebus volcano, Antarctica, from 1974-1981. New Zealand Journal of Geology and Geophysics, 27, 425-455, https://doi.org/10.1080/00288306.1984.10422264

Dibble, R.R., Kyle, P.R. and Rowe, C. 2008. Video and seismic observations of Strombolian eruptions at Erebus volcano, Antarctica. Journal of Volcanology and Geothermal Research, 177, 619-634, https://doi.org/10.1016/j.jvolgeores.2008.07.020

Doemel, W.N. and Brock, T.D. 1970. The upper temperature limit of Cyanidium caldarium. Archiv für Mikrobiologie, 72, 326-332.

Dunbar, N.W., Cashman, K. and Dupre, R. 1994. Crystallization processes of anorthoclase phenocrysts in the Mount Erebus magmatic system: evidence from crystal composition, crystal size distributions and volatile contents of melt inclusions. In: Kyle, P.R. (ed) Volcanological and Environmental Studies of Mount Erebus, Antarctica. Antarctic Research Series, 66, American Geophysical Union, Washington, D.C., 129-146, https://doi.org/10.1029/AR066p0129

Eschenbacher, A.J. 1999. Open-system degassing of a fractionating, alkaline magma, Mount Erebus, Ross Island, Antarctica. M.S. Thesis, N.M. Institute of Mining and Technology.

Esser, R.P., Kyle, P.R. and McIntosh, W.C. $2004 .{ }^{40} \mathrm{Ar} /{ }^{39} \mathrm{Ar}$ dating of the eruptive history of Mount Erebus, Antarctica: Volcano evolution. Bulletin of Volcanology, 66, 671-686, https://doi.org/10.1007/s00445-004-0354-X

Farman, J.C., Gardiner, B.G. and Shanklin, J.D. 1985. Large losses of total ozone in Antarctica reveal seasonal ClOx/NOx interaction. Nature, 315, 207-210, https://doi.org/10.1038/315207a0

Finn, C.A., Muller, R.D. and Panter, K.S. 2005. A Cenozoic diffuse alkaline magmatic province (DAMP) in the southwest Pacific without rift or plume origin. Geochemistry, Geophysics, Geosystems, 6, https://doi.org/10.1029/2004GC000723

Finotello, M., Nyblade, A., Julia, J., Wiens, D. and Anandakrishnan, S. 2011. Crustal Vp-Vs ratios and thickness for Ross Island and the Transantarctic Mountain front, Antarctica. Geophysical Journal International, 185, 85-92, https://doi.org/10.1111/j.1365246X.2011.04946.x

Fischer, T.P., Curtis, A.G., Kyle, P.R. and Sano, Y. 2013. Gas discharges in fumarolic ice caves of Erebus volcano, Antarctica. AGU Fall Meeting Abstracts.

Fleming, T.H., Foland, K.A. and Elliot, D.H. 1995. Isotopic and chemical constraints on the crustal evolution and source signature of Ferrar magmas, north Victoria Land, Antarctica. Contributions to Mineralogy and Petrology, 121, 217-236, https://doi.org/10.1007/BF02688238

Fraser, C.I., Connell, L., Lee, C.K. and Cary, S.C. 2018. Evidence of plant and animal communities at exposed and subglacial (cave) geothermal sites in Antarctica. Polar Biology, 41, 417-421, https://doi.org/10.1007/s00300-017-2198-9

Fraser, C.I., Terauds, A., Smellie, J., Convey, P. and Chown, S.L. 2014. Geothermal activity helps life survive glacial cycles. Proceedings of the National Academy of Sciences, 111, 5634-5639, https://doi.org/10.1073/pnas.1321437111

French, S.W. and Romanowicz, B. 2015. Broad plumes rooted at the base of the Earth's mantle beneath major hotspots. Nature, 525, 95-99, https://doi.org/10.1038/nature14876

Friedrich, C.G., Rother, D., Bardischewsky, F., Quentmeier, A. and Fischer, J. 2001. Oxidation of reduced inorganic sulfur compounds by Bacteria: Emergence of a common mechanism? 
Applied and Environmental Microbiology, 67, 2873-2882,

https://doi.org/10.1128/AEM.67.7.2873-2882.2001

Futa, K. and Le Masurier, W.E. 1983. Nd and Sr Isotopic Studies on Cenozoic Mafic Lavas from West Antarctica: Another Source for Continental Alkali Basalts. Contributions to Mineralogy and Petrology, 83, 38-44, https://doi.org/10.1007/BF00373077

Gaetani, G.A., O'Leary, J.A., Shimizu, N., Bucholz, C.E. and Newville, M. 2012. Rapid reequilibration of $\mathrm{H}_{2} \mathrm{O}$ and oxygen fugacity in olivine-hosted melt inclusions. Geology, 40, 915-918, https://doi.org/10.1130/G32992.1

Gerst, A., Hort, M., Kyle, P.R. and Voge, M. 2008. 4D velocity of Strombolian eruptions and man-made explosions derived from multiple Doppler radar instruments. Journal of Volcanology and Geothermal Research, 177, 648-660, https://doi.org/10.1016/j.jvolgeores.2008.05.022

Gerst, A., Hort, M., Aster, R.C., Johnson, J.B. and Kyle, P.R. 2013. The first second of volcanic eruptions from the Erebus volcano lava lake, Antarctica-Energies, pressures, seismology, and infrasound. Journal of Geophysical Research-Solid Earth, 118(7), 3318-3340, https://doi.org/10.1002/jgrb.50234

Ghiorso, M.S. and Gualda, G.A.R. 2015. An $\mathrm{H}_{2} \mathrm{O}-\mathrm{CO}_{2}$ mixed fluid saturation model compatible with rhyolite-MELTS. Contributions to Mineralogy and Petrology, 169, https://doi.org/10.1007/s00410-015-1141-8

Giggenbach, W.F., Kyle, P.R. and Lyon, G. 1973. Present volcanic activity on Mt. Erebus, Ross Island, Antarctica. Geology, 1, 135-136, https://doi.org/10.1130/00917613(1973)1<135:PVAOME>2.0.CO;2

Gill, J. 1981. Orogenic Andesites and Plate Tectonics. Springer-Verlag, Berlin, https://doi.org/10.1007/978-3-642-68012-0

Graham D.W., Humphris S.E., Jenkins W.J. and Kurz M.D. 1992. Helium isotope geochemistry of some volcanic rocks from Saint Helena. Earth and Planetary Science Letters, 121-131, https://doi.org/10.1016/0012-821X(92)90043-U

Green, D.H. and Falloon, T.J. 1998. Pyrolite: A Ringwood concept and its current expression. In: Jackson, I. (ed) The Earth's Mantle: Composition, Structure, and Evolution. Cambridge University Press, Cambridge, U.K., 311-378.

Green, D.H. and Ringwood, A.E. 1967. The genesis of basaltic magmas. Contributions to Mineralogy and Petrology, 15, 103-190, https://doi.org/10.1007/BF00372052

Green, D.H. 1973. Experimental melting studies on a model upper mantle composition at high pressure under water-saturated and water-undersaturated conditions. Earth and Planetary Science Letters, 19(1), 37-53, https://doi.org/10.1016/0012-821X(73)90176-3

Gupta, S., Zhao, D. and Rai, S.S. 2009. Seismic imaging of the upper mantle under the Erebus hotspot in Antarctica. Gondwana Research, 16, 109-118, https://doi.org/10.1016/j.gr.2009.01.004

Hamilton, T.L., Vogl, K., Bryant, D.A., Boyd, E.S. and Peters, J.W. 2012. Environmental constraints defining the distribution, composition, and evolution of chlorophototrophs in thermal features of Yellowstone National Park. Geobiology, 10, 236-249, https://doi.org/10.1111/j.1472-4669.2011.00296.x

Hansen, S.E., Graw, J.H. et al. 2014. Imaging the Antarctic mantle using adaptively parameterized P-wave tomography: Evidence for heterogeneous structure beneath West Antarctica. Earth and Planetary Science Letters, 408, 66-78, https://doi.org/10.1016/j.eps1.2014.09.043 
Hanyu T., Kawabata H. et al. 2014. Isotope evolution in the HIMU reservoir beneath St. Helena: Implications for the mantle recycling of $\mathrm{U}$ and Th. Geochimica et Cosmochimica Acta, 143, 232-252, https://doi.org/10.1016/j.gca.2014.03.016

Hanyu T., Tatsumi Y. et al. 2011. Geochemical characteristics and origin of the HIMU reservoir: A possible mantle plume source in the lower mantle. Geochemistry, Geophysics, Geosystems, 12, https://doi.org/10.1029/2010GC003252

Harpel, C.J., Kyle, P.R., Esser, R.P., McIntosh, W.C. and Caldwell, D.A. $2004 .{ }^{40} \mathrm{Ar} /{ }^{39} \mathrm{Ar}$ dating of the eruptive history of Mount Erebus, Antarctica: summit flows, tephra, and caldera collapse. Bulletin of Volcanology, 66(8), 687-702, https://doi.org/10.1007/s00445-0040349-7

Harpel, C.J., Kyle, P.R. and Dunbar, N.W. 2008. Englacial tephrostratigraphy of Erebus volcano, Antarctica. Journal of Volcanology and Geothermal Research, 177, 549-568, https://doi.org/10.1016/j.jvolgeores.2008.06.001

Hart, S.R., Blusztajn, J., LeMasurier, W.E. and Rex, D.C. 1997. Hobbs Coast Cenozoic volcanism: implications for the West Antarctic rift system. Chemical Geology, 139, 223 248, https://doi.org/10.1016/S0009-2541(97)00037-5

Hart, S., Blusztajn, J. and Craddock, C. 1995. Cenozoic volcanism in Antarctica; Jones Mountains and Peter I Island. Geochimica et Cosmochimica Acta, 59, 3379-3388, https://doi.org/10.1016/0016-7037(95)00212-I

Hart, S.R., Hauri, E.H., Oschmann, L.A. and Whitehead, J.A. 1992. Mantle plumes and entrainment: isotopic evidence. Science, 256, 517-520, https://doi.org/10.1126/science.256.5056.517

Hart S.R. 1988. Heterogeneous mantle domains: signatures, genesis and mixing chronologies. Earth and Planetary Science Letters, 90, 273-296, https://doi.org/10.1016/0012821X(88)90131-8

Hartley, M.E., Maclennan, J., Edmonds, M. and Thordarson, T. 2014. Reconstructing the deep $\mathrm{CO}_{2}$ degassing behaviour of large basaltic fissure eruptions. Earth and Planetary Science Letters, 393, 120-131, https://doi.org/10.1016/j.epsl.2014.02.031

Hawkesworth, C., George, R., Turner, S. and Zellmer, G. 2004. Timescales of magmatic processes. Earth and Planetary Science Letters, 218, 1-16, https://doi.org/10.1016/S0012821X(03)00634-4

Heeszel D.S., Wiens D. et al. 2016. Upper mantle structure of central and West Antarctica from array analysis of Rayleigh wave phase velocities. Journal of Geophysical Research-Solid Earth, 1-23, https://doi.org/10.1002/2015JB012616

Herbold, C.W., Lee, C.K., Mcdonald, I.R. and Cary, S.C. 2014a. Evidence of global-scale aeolian dispersal and endemism in isolated geothermal microbial communities of Antarctica. Nature Communications, 5, 3875, https://doi.org/10.1038/ncomms4875

Herbold, C.W., Mcdonald, I.R. and Cary, S.C. 2014b. Microbial Ecology of Geothermal Habitats in Antarctica. In: Cowan, D.A. (ed) Antarctic Terrestrial Microbiology: Physical and Biological Properties of Antarctic Soils. Springer, Berlin, Heidelberg, 181-215, https://doi.org/10.1007/978-3-642-45213-0_10

Hill, G., Wannamaker, P.E. et al. 2017. Imaging the Magmatic System of Erebus Volcano, Antarctica using the Magnetotelluric Method. AGU Fall Meeting.

Hirose, K. 1997. Partial melt compositions of carbonated peridotite at $3 \mathrm{GPa}$ and role of $\mathrm{CO}_{2}$ in alkali-basalt magma generation. Geophysical Research Letters, 24, 2837-2840, https://doi.org/10.1029/97GL02956 
Hirschmann, M., Kogiso, T., Baker, M.B. and Stolper, E.M. 2003. Alkalic magmas generated by partial melting of garnet pyroxenite. Geology, 31, 481-484, https://doi.org/10.1130/00917613(2003)031<0481:AMGBPM>2.0.CO;2

Hoch, M., Rehkämper, M. and Tobschall, H.J. 2001. Sr, Nd, Pb and O Isotopes of Minettes from Schirmacher Oasis, East Antarctica: a Case of Mantle Metasomatism involving Subducted Continental Material. Journal of Petrology, 42, 1387-1400, https://doi.org/10.1093/petrology/42.7.1387

Hoernle, K., White, J.D.L. et al. 2006. Cenozoic intraplate volcanism on New Zealand: Upwelling induced by lithospheric removal. Earth and Planetary Science Letters, 248, 350-367, https://doi.org/10.1016/j.epsl.2006.06.001

Hoernle, K., Hauff, F. et al. 2010. Age and geochemistry of volcanic rocks from the Hikurangi and Manihiki oceanic Plateaus. Geochimica et Cosmochimica Acta, 74, 7196-7219, https://doi.org/10.1016/j.gca.2010.09.030

Howat, I.M., Porter, C., Smith, B.E., Noh, M.-J. and Morin, P. 2019. The Reference Elevation Model of Antarctica. The Cryosphere, 13, 665-674, https://doi.org/10.5194/tc-13-6652019

Hudson, A.J., Daniel, R.M. and Morgan, H.W. 1989. Acidophilic and thermophilic Bacillus strains from geothermally heated Antarctic soil. FEMS Microbiology Letters, 60, 279-282, https://doi.org/10.1111/j.1574-6968.1989.tb03486.x

Hudson, J.A. and Daniel, R.M. 1988. Enumeration of thermophilic heterotrophs in geothermally heated soils from Mount Erebus, Ross Island, Antarctica. Applied and Environmental Microbiology, 54, 622-624, https://doi.org/10.1128/AEM.54.2.622-624.1988

Hudson, J.A., Daniel, R.M. and Morgan, H.W. 1988. Isolation of a strain of Bacillus schlegelii from geothermally heated Antarctic soil. FEMS Microbiology Letters, 51, 57-60, https://doi.org/10.1111/j.1574-6968.1988.tb02968.x

Iacovino, K. 2015. Linking subsurface to surface degassing at active volcanoes: A thermodynamic model with applications to Erebus volcano. Earth and Planetary Science Letters, 431, 59-74, https://doi.org/10.1016/j.eps1.2015.09.016

Iacovino, K., Oppenheimer, C., Scaillet, B. and Kyle, P. 2016. Storage and evolution of mafic and intermediate alkaline magmas beneath Ross Island. Antarctica. Journal of Petrology, 57, 93-117, https://doi.org/10.1093/petrology/egv083

Iacovino, K., Moore, G., Roggensack, K., Oppenheimer, C. and Kyle, P. 2013. $\mathrm{H}_{2} \mathrm{O}-\mathrm{CO}_{2}$ solubility in mafic alkaline magma: applications to volatile sources and degassing behavior at Erebus volcano, Antarctica. Contributions to Mineralogy and Petrology, 166, 845-860, https://doi.org/10.1007/s00410-013-0877-2

Iacovino, K., Oppenheimer, C., Scaillet, B. and Kyle, P. 2016. Storage and Evolution of Mafic and Intermediate Alkaline Magmas beneath Ross Island, Antarctica. Journal of Petrology, 57, 93-118, https://doi.org/10.1093/petrology/egv083

Ilanko, T., Oppenheimer, C., Burgisser, A. and Kyle, P.R. 2015. Cyclic degassing of Erebus volcano, Antarctica. Bulletin of Volcanology, 77:56, https://doi.org/10.1007/s00445-0150941-z

Ilyinskaya, E., Oppenheimer, C., Mather, T.A., Martin, R.S. and Kyle, P.R. 2010. Size-resolved chemical composition of aerosol emitted by Erebus volcano, Antarctica. Geochemistry, Geophysics, Geosystems, 11, Q03017, https://doi.org/10.1029/2009GC002855

Iverson, N.A., Kyle, P.R., Dunbar, N.W., McIntosh, W.C. and Pearce, N.J.G. 2014. Eruptive history and magmatic stability of Erebus volcano, Antarctica: Insights from englacial 
tephra. Geochemistry, Geophysics, Geosystems, 15, 4180-4202,

https://doi.org/10.1002/2014GC005435

Johnson, J.B., Aster, R.C., Ruiz, M.C., Malone, S.D., McChesney, P.J., Lees, J.M. and Kyle,

P.R. 2003. Interpretation and utility of infrasonic records from erupting volcanoes.

Journal of Volcanology and Geothermal Research, 121(1-2), 15-63, https://doi.org/10.1016/S0377-0273(02)00409-2

Johnson, J.B., Aster, R.C. and Kyle, P.R. 2004. Volcanic eruptions observed with infrasound. Geophysical Research Letters, 31(14), L14604, https://doi.org/10.1029/2004GL020020

Johnson, J. and Aster, R. 2005. Relative partitioning of acoustic and seismic energy during Strombolian eruptions. Journal of Volcanology and Geothermal Research, 148(3-4), 334354, https://doi.org/10.1016/j.jvolgeores.2005.05.002

Johnson, J., Aster, R., Jones, K.R., Kyle, P. and McIntosh, W. 2008. Acoustic source characterization of impulsive Strombolian eruptions from the Mount Erebus lava lake. Journal of Volcanology and Geothermal Research, 177(3), 673-686, https://doi.org/10.1016/j.jvolgeores.2008.06.028

Jones, K.R., Johnson, J.B., Aster, R., Kyle, P.R. and McIntosh, W.C. 2008. Infrasonic tracking of large bubble bursts and ash venting at Erebus Volcano, Antarctica. Journal of Volcanology and Geothermal Research, 177(3), 661-672, https://doi.org/10.1016/j.jvolgeores.2008.02.001

Kelemen, P.B., Shimizu, N. and Dunn, T. 1993. Relative depletion of niobium in some arc magmas and the continental crust: partitioning of $\mathrm{K}, \mathrm{Nb}$, La, and Ce during melt/rock reaction in the upper mantle. Earth and Planetary Science Letters, 120, 111-134, https://doi.org/10.1016/0012-821X(93)90234-Z

Kelly, P.J., Dunbar, N.W., Kyle, P.R. and McIntosh, W.C. 2008a. Refinement of the late Quaternary geologic history of Erebus volcano, Antarctica using ${ }^{40} \mathrm{Ar} /{ }^{39} \mathrm{Ar}$ and ${ }^{36} \mathrm{Cl}$ age determinations. Journal of Volcanology and Geothermal Research, 177, 569-577, https://doi.org/10.1016/j.jvolgeores.2008.07.018

Kelly, P.J., Kyle, P.R., Dunbar, N.W. and Sims, K.W.W. 2008b. Geochemistry and mineralogy of the phonolite lava lake, Erebus volcano, Antarctica: 1972 - 2004 and comparison with older lavas. Journal of Volcanology and Geothermal Research, 177, 589-605, https://doi.org/10.1016/j.jvolgeores.2007.11.025

Knox, H.A., Chaput, J.A., Aster, R.C. and Kyle, P.R. 2018. Multi-year shallow conduit changes observed with lava lake eruption seismograms at Erebus volcano, Antarctica. Journal of Geophysical Research-Solid Earth, 123, 3178-3196, https://doi.org/10.1002/2017JB015045

Kogiso, T., Hirose, K. and Takahashi, E. 1998. Melting experiments on homogeneous mixtures of peridotite and basalt: application to the genesis of ocean island basalts. Earth and Planetary Science Letters, 162, 45-61, https://doi.org/10.1016/S0012-821X(98)00156-3

Kogiso, T., Hirschmann, M.M. and Frost, D.J. 2003. High-pressure partial melting of garnet pyroxenite: possible mafic lithologies in the source of ocean island basalts. Earth and Planetary Science Letters, 216, 603-617, https://doi.org/10.1016/S0012-821X(03)00538-7

Kyle, P.R. 1977. Mineralogy and glass chemistry of volcanic ejecta, from Mt. Erebus, Antarctica. New Zealand Journal of Geology and Geophysics, 20(6), 1123-1146, https://doi.org/10.1080/00288306.1977.10420699 
Kyle, P.R. 1981a. The geological history of Hut Point Peninsula as indicated by Dry Valley Drilling Project holes 1, 2 and 3. Antarctic Research Series, 33, American Geophysical Union, 427-445, https://doi.org/10.1029/AR033p0427

Kyle, P.R. 1981b. Evolution of a basanite phonolite sequence, Hut Point Peninsula, Antarctica Evidence from Dry Valley Drilling Project Drillholes 1, 2 and 3. Journal of Petrology, 22, 451-500, https://doi.org/10.1093/petrology/22.4.451

Kyle, P.R. and McIntosh, W.C. 1989. Automation of a correlation spectrometer for measuring $\mathrm{SO}_{2}$ emissions. New Mexico Bureau of Mines and Mineral Resources Bulletin, 131, 7.

Kyle, P.R. 1990a. McMurdo Volcanic Group Western Ross Embayment: Introduction. In: LeMasurier, W. and Thompson, J. (eds) Volcanoes of the Antarctic Plate and Southern Oceans. Antarctic Research Series, 48, American Geophysical Union, 18-25.

Kyle, P.R. 1990b. Erebus volcanic Province: Summary. In: LeMasurier, W. and Thompson, J. (eds) Volcanoes of the Antarctic Plate and Southern Oceans. Antarctic Research Series, 48, American Geophysical Union, 81-88.

Kyle, P.R., Meeker, K. and Finnegan, D. 1990c. Emission rates of sulfur dioxide trace gases and metals from Mount Erebus Antarctica. Geophysical Research Letters, 17, 2125-2128, https://doi.org/10.1029/GL017i012p02125

Kyle, P., Dibble, R., Giggenbach, W. and Keys, J. 1982. Volcanic activity associated with the anorthoclase phonolite lava lake, Mt. Erebus, Antarctica. In: Craddock, C. (ed) Antarctic Geosciences. University Wisconsin Press, Madison, 735-745.

Kyle, P.R., Moore, J.A. and Thirlwall, M.F. 1992. Petrologic evolution of anorthoclase phonolite lavas at Mount Erebus, Ross Island, Antarctica. Journal of Petrology, 33, 849-875, https://doi.org/10.1093/petrology/33.4.849

Kyle, P.R., Sybeldon, L.M., McIntosh, W.C., Meeker, K. and Symonds, R. 1994. Sulfur dioxide emission rates from Mount Erebus, Antarctica. In: Kyle, P.R. (ed) Volcanological and Environmental Studies of Mount Erebus, Antarctica. Antarctic Research Series, 66, American Geophysical Union, Washington, D.C., 69-82, https://doi.org/10.1029/AR066p0069

Leat, P.T., Dean, A.A., Millar, I.L., Kelley, S.P., Vaughan, A.P.M. and Riley, T.R. 2005. Lithospheric mantle domains beneath Antarctica. Geological Society of London, Special Publication 246, 359-380, https://doi.org/10.1144/GSL.SP.2005.246.01.15

Le Losq, C., Neuville, D., Moretti, R., Kyle, P. and Oppenheimer, C. 2015. Rheology of phonolitic magmas - the case of the Erebus lava lake. Earth and Planetary Science Letters, 411, https://doi.org/10.1016/j.epsl.2014.11.042

Lesser, M.P., Barry, T.M. and Banaszak, A.T. 2002. Effects of UV radiation on a chlorophyte alga (Scenedesmus sp.) isolated from the fumarole fields of Mt. Erebus, Antarctica. Journal of Phycology, 38, 473-481, https://doi.org/10.1046/j.1529-8817.2002.01171.x

Lindsay, M.R., Amenabar, M.J. et al. 2018. Subsurface processes influence oxidant availability and chemoautotrophic hydrogen metabolism in Yellowstone hot springs. Geobiology, 16, 674-692, https://doi.org/10.1111/gbi.12308

Lowenstern, J.B. and Hurwitz, S. 2008. Monitoring a supervolcano in repose: Heat and volatile flux at the Yellowstone Caldera. Elements, 4(1), 35-40, https://doi.org/10.2113/GSELEMENTS.4.1.35

MacAyeal, D.R., Okal, E.A., Aster, R.C. and Bassis, J. N. 2008. Seismic and hydroacoustic tremor generated by colliding icebergs. Journal of Geophysical Research-Earth Surface, 113(F3), F03011, https://doi.org/10.1029/2008JF001005 
Martin, S., Drucker, R., Aster, R., Davey, F., Okal, E., Scambos, T. and MacAyeal, D. 2010. Kinematic and seismic analysis of giant tabular iceberg breakup at Cape Adare, Antarctica. Journal of Geophysical Research-Solid Earth, 115, https://doi.org/10.1029/2009JB006700

Martin, R.S., Mather, T.A. et al. 2008. Composition- resolved size distributions of volcanic aerosols in the Mt. Etna plumes. Journal of Geophysical Research, 113, D17211, https://doi.org/10.1029/2007JD009648

Mather, T.A., Allen, A.G., Oppenheimer, C., Pyle, D.M. and McGonigle, A.J.S. 2003. Sizeresolved characterization of soluble ions in the particles in the tropospheric plume of Masaya Volcano, Nicaragua: Origins and plume processing. Journal of Atmospheric Chemistry, 46, 207-237, https://doi.org/10.1023/A:1026327502060

McDonough, W.F. and Sun, S.S. 1995. The Composition of the Earth. Chemical Geology, 120, 223-253, https://doi.org/10.1016/0009-2541(94)00140-4

McGonigle, A.J.S. and Oppenheimer, C. 2003. Optical sensing of volcanic gas and aerosol emissions. In: Oppenheimer, C., Pyle, D.M. and Barclay, J. (eds) Volcanic Degassing. Geological Society, London, 149-168, https://doi.org/10.1144/GSL.SP.2003.213.01.09

Meeker, K.A., Chuan, R.L., Kyle, P.R. and Palais, J.M. 1991. Emission of elemental gold particles from Mount Erebus, Ross Island, Antarctica. Geophysical Research Letters, 18, 1405-1408, https://doi.org/10.1029/91GL01928

Melick, D.R., Broady, P.A. and Rowan, K.S. 1991. Morphological and physiological characteristics of a non-heterocystous strain of the cyanobacterium Mastigocladus laminosus Cohn from fumarolic soil on Mt Erebus, Antarctica. Polar Biology, 11, 81-89, https://doi.org/10.1007/BF00234270

Mickus, K. and Kyle, P. 2013. Preliminary gravity survey of the Erebus Volcano, Antarctica. Geological Society of America Annual Meeting.

Mickus, K. and Kyle, P. 2014. A detailed gravity survey of the Erebus Volcano, Antarctica. Geological Society of America Annual Meeting.

Molina, I., Burgisser, A. and Oppenheimer, C. 2012. Numerical simulations of convection in crystal-bearing magmas: a case study of the magmatic system at Erebus, Antarctica. Journal of Geophysical Research, 117, https://doi.org/10.1029/2011JB008760

Montelli, R., Nolet, G., Dahlen, F.A. and Masters, G. 2006. A catalogue of deep mantle plumes: New results from finite frequency tomography. Geochemistry, Geophysics, Geosystems, 7, https://doi.org/10.1029/2006GC001248

Moore, L.R., Gazel, E. et al. 2015. Bubbles matter: An assessment of the contribution of vapor bubbles to melt inclusion volatile budgets. American Mineralogist, 100, 806-823, https://doi.org/10.2138/am-2015-5036

Moussallam, Y., Oppenheimer, C., Aiuppa, A., Giudice, G. and Moussallam, M. 2012. Hydrogen emissions from Erebus volcano, Antarctica. Bulletin of Volcanology, 74, 2109-2120, https://doi.org/10.1007/s00445-012-0649-2

Moussallam, Y., Oppenheimer, C., Scaillet, B. and Kyle, P.R. 2013. Experimental phaseequilibrium constraints on the phonolite magmatic system of Erebus volcano, Antarctica. Journal of Petrology, 54, 1285-1307, https://doi.org/10.1093/petrology/egt012

Moussallam, Y., Oppenheimer, C. et al. 2014. Tracking the changing oxidation state of Erebus magmas, from mantle to surface, driven by magma ascent and degassing. Earth and Planetary Science Letters, 393, 200-209, https://doi.org/10.1016/j.epsl.2014.02.055 
Moussallam, Y.C., Oppenheimer, B. et al. 2015. Megacrystals track magma convection between reservoir and surface. Earth and Planetary Science Letters, 413, 1-12, https://doi.org/10.1016/j.epsl.2014.12.022

Nicolaus, B., Lama, L., Esposito, E., Bellitti, M.R., Improta, R., Panico, A. and Gambacorta, A. 2000. Extremophiles in Antarctica. Italian Journal of Zoology, 67, 169-174, https://doi.org/10.1080/11250000009356373

Nicolaus, B., Marsiglia, F. et al. 1992. Isolation of extremely halotolerant cocci from Antarctica. FEMS Microbiology Letters, 99, 145-149, https://doi.org/10.1111/j.15746968.1992.tb05557.x

Oppenheimer, C., Kyle, P.R., Tsanev, V.I., McGonigle, A.J.S., Mather, T.A. and Sweeney, D. 2005. Mt. Erebus, the largest point source of $\mathrm{NO}_{2}$ in Antarctica. Atmospheric Environment, 39, 6000-6006, https://doi.org/10.1016/j.atmosenv.2005.06.036

Oppenheimer, C. and Kyle, P. 2008a. Preface: Volcanology of Erebus volcano, Antarctica. Journal of Volcanology and Geothermal Research, 177, v-vii, https://doi.org/10.1016/j.jvolgeores.2008.10.006

Oppenheimer, C. and Kyle, P.R. 2008b. Probing the magma plumbing of Erebus volcano, Antarctica, by open-path FTIR spectroscopy of gas emissions. Journal of Volcanology and Geothermal Research, 177, 743-754, https://doi.org/10.1016/j.jvolgeores.2007.08.022

Oppenheimer, C., Lomakina, A.S., Kyle, P.R., Kingsbury, N.G. and Boichu, M. 2009. Pulsatory magma supply to a phonolite lava lake. Earth and Planetary Science Letters, 284(3-4), 392-398, https://doi.org/10.1016/j.epsl.2009.04.043

Oppenheimer, C., Kyle, P.R. et al. 2010. Atmospheric chemistry of an Antarctic volcanic plume. Journal of Geophysical Research, 115, D04303, https://doi.org/10.1029/2009JD011910

Oppenheimer, C., Moretti, R., Kyle, P.R., Eschenbacher, A., Lowenstern, J.B., Hervig, R.L. and Dunbar, N.W. 2011. Mantle to surface degassing of alkalic magmas at Erebus volcano, Antarctica. Earth and Planetary Science Letters, 306(3-4), 261-271, https://doi.org/10.1016/j.epsl.2011.04.005

Panter, K.S., Hart, S.R., Kyle, P., Blusztanjn, J. and Wilch, T. 2000. Geochemistry of Late Cenozoic basalts from the Crary Mountains: characterization of mantle sources in Marie Byrd Land, Antarctica. Chemical Geology, 165, 215-241, https://doi.org/10.1016/S00092541(99)00171-0

Panter, K.S., Blusztajn, J., Hart, S.R., Kyle, P.R., Esser, R. and McIntosh, W.C. 2006. The Origin of HIMU in the SW Pacific: Evidence from intraplate volcanism in southern New Zealand and Subantarctic Islands. Journal of Petrology, 47, 1673-1704, https://doi.org/10.1093/petrology/eg1024

Parai, R., Mukhopadhyay, S. and Lassiter, J.C. 2009. New constraints on the HIMU mantle from neon and helium isotopic compositions of basalts from the Cook-Austral Islands. Earth and Planetary Science Letters, 277, 253-261, https://doi.org/10.1016/j.epsl.2008.10.014

Park, S-H., Langmuir, C.H. et al. 2019. An isotopically distinct Zealandia-Antarctic mantle domain in the Southern Ocean. Nature Geoscience, 12, 206-214, https://doi.org/10.1038/s41561-018-0292-4

Parmelee, D.E.F., Kyle, P.R., Kurz, M.D., Marrero, S.M., and Phillips, F.M. 2015. A new Holocene eruptive history of Erebus Volcano, Antarctica using cosmogenic ${ }^{3} \mathrm{He}$ and ${ }^{36} \mathrm{Cl}$ exposure ages. Quaternary Geochronology, 30, 114-131, https://doi.org/10.1016/j.quageo.2015.09.001 
Peterson, J. 1993. Observations and Modeling of Seismic Background Noise. USGS Open-File Report 93-322, 94, https://doi.org/10.3133/ofr93322

Phillips, E.H., Sims, K.W.W. et al. 2018. The nature and evolution of mantle upwelling at Ross Island, Antarctica, with implications for the source of HIMU lavas. Earth and Planetary Science Letters, 498, 38-53, https://doi.org/10.1016/j.eps1.2018.05.049

Pilet, S., Baker, M.B. and Stolper, E.M. 2008. Metasomatized lithosphere and the origin of alkaline lavas. Science, 320, 916-919, https://doi.org/10.1126/science.1156563

Portnyagin, M., Hoernle, K., Storm, S., Mironov, N., van den Bogaard, C. and Botcharnikov, R. 2012. $\mathrm{H}_{2} \mathrm{O}$-rich melt inclusions in fayalitic olivine from Hekla volcano: Implications for phase relationships in silicic systems and driving forces of explosive volcanism on Iceland. Earth and Planetary Science Letters, 357-358, 337-346, https://doi.org/10.1016/j.epsl.2012.09.047

Power, J.F., Carere, C.R. et al. 2018. Microbial biogeography of 925 geothermal springs in New Zealand. Nature Communications, 9, 2876, https://doi.org/10.1038/s41467-018-05020-y

Pyle, D.M. and Mather, T.A. 2009. Halogens in igneous processes and their fluxes to the atmosphere and oceans from volcanic activity: a review. Chemical Geology, 263, 110121, https://doi.org/10.1016/j.chemgeo.2008.11.013

Radke, L.F. 1982. Sulphur and sulphate from Mt Erebus. Nature, 299, 710-712, https://doi.org/10.1038/299710a0

Rasmussen, D.J., Kyle, P.R., Wallace, P.J., Sims, K.W.W., Gaetani, G.A. and Phillips, E.H. 2017. Understanding degassing and transport of $\mathrm{CO}_{2}$-rich alkalic magmas at Ross Island, Antarctica using olivine-hosted melt inclusions. Journal of Petrology, 58, 841-861, https://doi.org/10.1093/petrology/egx036

Reagan, M.K., Volpe, A.M. and Cashman, K.V. 1992. ${ }^{238}$ U- and ${ }^{232}$ Th- series chronology of phonolite fractionation at Mt Erebus, Antarctica. Geochimica et Cosmochimica Acta, 56, 1401-1407, https://doi.org/10.1016/0016-7037(92)90071-P

Reagan, M.K., Sims, K.W.W. et al. 2003. Time-scale of differentiation from mafic parents to rhyolite in North American continental arcs. Journal of Petrology, 44, 1703-1726, https://doi.org/10.1093/petrology/egg057

Reagan, M.K., Tepley III, F.J., Gill, J.B., Wortel, M. and Garrison, J. 2006. Timescales of degassing and crystallization implied by ${ }^{210} \mathrm{Po}^{210}{ }^{210}-{ }^{226} \mathrm{Ra}$ disequilibria for andesitic lavas erupted from Arenal volcano. Journal of Volcanology and Geothermal Research, 157, 135-146, https://doi.org/10.1016/j.jvolgeores.2006.03.044

Reagan, M.K., Turner, S., Legg, M.K., Sims K.W.W. and Hards, V.L. 2008. ${ }^{238}$ U and ${ }^{232}$ Th decay series constraints on the timescales of crystal fractionation to produce the phonolite erupted in 2004 near Tristan da Cunha, South Atlantic. Geochimica et Cosmchimica Acta, 72, 4367-4378, https://doi.org/10.1016/j.gca.2008.06.002

Reid, M.R., Bouchet, R.A., Blichert-Toft, J., Levander, A., Liu, K., Miller, M.S. and Ramos, F.C. 2012. Melting under the Colorado Plateau, USA. Geology, 40, 387-390, https://doi.org/10.1130/G32619.1

Reubi, O., Sims, K.W.W. and Bourdon, B. 2014. ${ }^{238}{ }^{2}-{ }^{230}$ Th equilibrium in arc magmas and implications for the time scales of mantle metasomatism. Earth and Planetary Science Letters, 391, 146-158, https://doi.org/10.1016/j.epsl.2014.01.054

Reubi, O. Sims, K.W.W., Varley, N., Reagan, M. and Eikenberg, J. 2015. Timescales of degassing and conduit dynamics inferred from ${ }^{210} \mathrm{~Pb}^{226} \mathrm{Ra}$ disequilibria in Volcan de Colima 1998-2010 andesitic magmas. In: Caricchi, L. and Blundy, J. D. (eds) Chemical, 
Physical and Temporal Evolution of Magmatic Systems. Geological Society, London, Special Publications, 422, https://doi.org/10.1144/SP422.5

Reubi, O., Scott, S.R. and Sims, K.W.W. 2017. Young U-series crystal ages in andesitic magmas from a hyperactive arc volcano. Journal of Petrology, 58(2), 261-276, https://doi.org/10.1093/petrology/egx015

Ritsema, J., van Heijst, H.J., Deuss, A. and Woodhouse, J.H. 2011. S40RTS: a degree-40 shearvelocity model for the mantle from new Rayleigh wave dispersion, teleseismic traveltimes, and normal-mode splitting function measurements. Geophysical Journal International, 184, https://doi.org/10.1111/j.1365-246X.2010.04884.X

Ritzwoller, M.H., Shapiro, N.M., Levshin, A.L. and Leahy, G.M. 2001. Crustal and upper mantle structure beneath Antarctica and surrounding oceans. Journal of Geophysical ResearchSolid Earth, 106, 30645-30670, https://doi.org/10.1029/2001JB000179

Rocholl, A., Stein, M., Molzahn, M., Hart, S.R. and Worner, G. 1995. Geochemical evolution of rift magmas by progressive tapping of a stratified mantle source beneath the Ross Rift, Antarctica. Earth and Planetary Science Letters, 131, 207-224, https://doi.org/10.1016/0012-821X(95)00024-7

Rocchi, S., Arminenti, P., D’Osazio, M., Wijbrans, J. and Di Vincenzo, G. 2002. Cenozoic magmatism in the western Ross Embayment: Role of mantle plume versus plate dynamics in the development of the West Antarctic Rift System. Journal of Geophysical Research, 107, 2195, https://doi.org/10.1029/2001JB000515

Rose, W.I., Chuan, R.L. and Kyle, P.R. 1985. Rate of sulphur dioxide emission from Erebus volcano, Antarctica, December 1983. Nature, 316, 710-712, https://doi.org/10.1038/316710a0

Ross, J.C. 1847. A voyage of discovery and research in the southern Antarctic regions during the years 1839-43. John Murray, London, https://doi.org/10.5962/bhl.title.98449

Rothschild, L.J. and Mancinelli, R.L. 2001. Life in extreme environments. Nature, 409, 1092, https://doi.org/10.1038/35059215

Rowe, C.A., Aster, R.C., Kyle, P.R., Schlue, J.W. and Dibble, R.R. 1998. Broadband recording of Strombolian explosions and associated very-long-period seismic signals on Mount Erebus volcano, Ross Island, Antarctica. Geophysical Research Letters, 25(13), 2297 2300, https://doi.org/10.1029/98GL01622

Rowe, C.A., Aster, R.C., Kyle, P.R., Dibble, R.R. and Schlue, J.W. 2000. Seismic and acoustic observations at Mount Erebus Volcano, Ross Island, Antarctica. 1994-1998. Journal of Volcanology and Geothermal Research, 101(1-2), 105-128, https://doi.org/10.1016/S0377-0273(00)00170-0

Saal, A.E., Hauri, E.H., Langmuir, C.H. and Perfit, M.R. 2002. Vapour undersaturation in primitive mid-ocean-ridge basalt and the volatile content of Earth's upper mantle. Nature, 419, 451-455, https://doi.org/10.1038/nature01073

Saal, A.E., Hart, S.R., Shimizu, N., Hauri, E.H. and Layne, G.D. 1998. Pb isotopic variability in melt inclusions from oceanic island basalts, Polynesia. Science, 282, 1481-1484, https://doi.org/10.1126/science.282.5393.1481

Salters, V.J.M. and Stracke, A. 2004. Composition of the depleted mantle. Geochemistry, Geophysics, Geosystems, 5, https://doi.org/10.1029/2003GC000597

Sawyer, G.M., Carn, S.A., Tsanev, V.I., Oppenheimer, C. and Burton, M. 2008. Investigation into magma degassing at Nyiragongo volcano, Democratic Republic of the Congo. Geochemistry, Geophysics, Geosystems, 9(2), https://doi.org/10.1029/2007GC001829 
Seaman, S.J., Dyar, M.D., Marinkovic, N. and Dunbar, N.W. 2006. An FTIR study of hydrogen in anorthoclase and associated melt inclusions. American Mineralogist, 91, 12-20, https://doi.org/10.2138/am.2006.1765

Shackleton, E.H.S., David, T.W.E.S. and Mill, H.R. 1909. The heart of the Antarctic: being the story of the British Antarctic Expedition 1907-1909. J.B. Lippincott Company, Philadelphia, https://doi.org/10.5962/bhl.title.82322

Shock, E.L. and Holland, M.E. 2007. Quantitative habitability. Astrobiology, 7(6), 839-851, https://doi.org/10.1089/ast.2007.0137

Shock, E.L., Holland, M., Meyer-Dombard, D.A., Amend, J.P., Osburn, G.R. and Fischer, T.P. 2010. Quantifying inorganic sources of geochemical energy in hydrothermal ecosystems, Yellowstone National Park, USA. Geochimica et Cosmochimica Acta, 74, 4005-4043, https://doi.org/10.1016/j.gca.2009.08.036

Simmons, N.A., Forte, A.M., Boschi, L. and Grand, S.P. 2010. GyPSuM: A joint tomographic model of mantle density and seismic wave speeds. Journal of Geophysical Research, 115, https://doi.org/10.1029/2010JB007631

Sims, K.W.W. and Hart, S.R. 2006. Comparison of Th, Sr, Nd and Pb Isotopes in oceanic basalts: Implications for mantle heterogeneity and magma genesis. Earth and Planetary Science Letters, 245, 743-761, https://doi.org/10.1016/j.epsl.2006.02.030

Sims, K.W.W., Ackert, Jr., R.P., Ramos, F., Sohn, R.A., Murrell, M.T. and DePaolo, D.J. 2007. Determining eruption ages and erosion rates of Quaternary basaltic volcanism from combined U-series disequilibria and cosmogenic exposure ages. Geology, 35, 471-474, https://doi.org/10.1130/G23381A.1

Sims, K.W.W., Blichert-Toft, J. et al. 2008a. A Sr, Nd, Hf, and Pb isotope perspective on the genesis and long-term evolution of alkaline magmas from Erebus volcano, Antarctica. Journal of Volcanology and Geothermal Research, 177, 606-618, https://doi.org/10.1016/j.jvolgeores.2007.08.006

Sims, K.W.W., Hart, S.R. et al. 2008b. ${ }^{238} \mathrm{U}_{-}{ }^{230} \mathrm{Th}_{-}{ }^{226} \mathrm{Ra}_{-}{ }^{210} \mathrm{~Pb}_{-}{ }^{210} \mathrm{Po},{ }^{232} \mathrm{Th}^{228}{ }^{22} \mathrm{Ra}$ and ${ }^{235} \mathrm{U}_{-}{ }^{231} \mathrm{~Pa}$ constraints on the ages and petrogenesis of Vailulu and Malumalu Lavas, Samoa. Geochemistry, Geophysics, Geosystems, 9, Q04003, https://doi.org/10.1029/2007GC001651

Sims K.W.W., Pichat S. et al. 2013a. On the time scales of magma genesis, melt evolution, crystal growth rates and magma degassing in the Erebus volcano magmatic system using the ${ }^{238} \mathrm{U},{ }^{235} \mathrm{U}$ and ${ }^{232} \mathrm{Th}$ decay series. Journal of Petrology, 54, 235-271, https://doi.org/10.1093/petrology/egs068

Sims, K.W.W., Maclennan, J., Blichert-Toft, J., Mervine, E.M., Bluzstajn, J. and Grönvold, K. 2013b. Short length scale mantle heterogeneity beneath Iceland probed by glacial modulation of melting. Earth and Planetary Science Letters, 379, 146-157, https://doi.org/10.1016/j.epsl.2013.07.027

Skotnicki, M.L., Selkirk, P.M., Broady, P., Adam, K.D. and Ninham, J.A. 2004. Dispersal of the moss Campylopus pyriformis on geothermal ground near the summits of Mount Erebus and Mount Melbourne, Victoria Land, Antarctica. Antarctic Science, 13, 280-285, https://doi.org/10.1017/S0954102001000396

Soo, R.M., Wood, S.A., Grzymski, J.J., Mcdonald, I.R. and Cary, S.C. 2009. Microbial biodiversity of thermophilic communities in hot mineral soils of Tramway Ridge, Mount Erebus, Antarctica. Environmental Microbiology, 11, 715-728, https://doi.org/10.1111/j.1462-2920.2009.01859.x 
Storey, B.C., Leat, P.T., Weaver, S.D., Pankhurst, R.J., Bradshaw, J.D. and Kelley, S. 1999. Mantle plumes and Antarctica-New Zealand rifting: evidence from mid-Cretaceous mafic dykes. Journal Geological Society of London, 156, 659-671, https://doi.org/10.1144/gsjgs.156.4.0659

Sumner, C.L.K. 2007. Residence time estimates and controls on crystallization patterns for anorthoclase phenocrysts in phonolite magma, Erebus volcano, Antarctica. M.S. thesis, N.M. Institute of Mining and Technology.

Sun, S.-S. and Hanson, G.N. 1975. Origin of Ross Island basanitoids and limitations upon the heterogeneity of mantle sources for alkali basalts and nephelinites. Contributions to Mineralogy and Petrology, 54, 139-55.

Sun, S.-S. and Hanson, G.N. 1976. Rare earth element evidence for differentiation of McMurdo Volcanics, Ross Island, Antarctica. Contributions to Mineralogy and Petrology, 54, 139155, https://doi.org/10.1007/BF00372120

Sweeney, D., Kyle, P.R. and Oppenheimer, C. 2008. Sulfur dioxide emissions and degassing behavior of Erebus volcano, Antarctica. Journal of Volcanology and Geothermal Research, 177, 725-733, https://doi.org/10.1016/j.jvolgeores.2008.01.024

Symonds, R.B., Kyle, P.R. and Rose, W.I. 1985. SO 2 emission rates and the 1984 activity at Mount Erebus Volcano, Antarctica. EOS, Transactions of the American Geophysical Union 66 (18), 417.

Takahashi, E. and Kushiro, I. 1983. Melting of dry peridotite at high pressures and basalt magma genesis. American Mineralogist, 68, 859-879.

Talandier, J., Hyvernaud, O., Reymond, D. and Okal, E.A. 2006. Hydroacoustic signals generated by parked and drifting icebergs in the Southern Indian and Pacific Oceans. Geophysical Journal International, 165(3), 817-834, https://doi.org/10.1111/j.1365246X.2006.02911.x

Tappenden, V.E. 2003. Magmatic response to the evolving New Zealand Margin of Gondwana during the Mid-Late Cretaceous. PhD thesis, University of Canterbury.

Tebo, B.M., Davis, R.E., Anitori, R.P., Connell, L.B., Schiffman, P. and Staudigel, H. 2015. Microbial communities in dark oligotrophic volcanic ice cave ecosystems of Mt. Erebus, Antarctica. Frontiers in Microbiology, 6, 179, https://doi.org/10.3389/fmicb.2015.00179

Timm, C., Hoernle, K. et al. 2010. Temporal and geochemical evolution of the Cenozoic intraplate volcanism of Zealandia. Earth-Science Reviews, 98, 38-64, https://doi.org/10.1016/j.earscirev.2009.10.002

Toomey, D., Solomon, S. and Purdy, G. 1994. Tomographic imaging of the shallow crustal structure of the East Pacific Rise at 9300N. Journal of Geophysical Research, 99(B12), 24135-24157, https://doi.org/10.1029/94JB01942

Turner, S.P., George, R.M.M., Jerram, D.A., Carpenter, N. and Hawkesworth, C.J. 2003. Case studies of plagioclase growth and residence times in island arc lavas from Tonga and the Lesser Antilles, and a model to reconcile discordant age information. Earth and Planetary Science Letters, 214, 279-294, https://doi.org/10.1016/S0012-821X(03)00376-5

Ugolini, F.C. 1967. Soils of Mount Erebus, Antarctica. New Zealand Journal of Geology and Geophysics, 10, 431-442, https://doi.org/10.1080/00288306.1967.10426747

Ugolini, F.C. and Starkey, R.L. 1966. Soils and micro-organisms from Mount Erebus, Antarctica. Nature, 211, 440, https://doi.org/10.1038/211440a0 
Vazquez, J.A. and Reid, M.R. 2002. Time scales of magma storage and differentiation of voluminous high-silica rhyolites at Yellowstone caldera, Wyoming. Contributions to Mineralogy and Petrology, 144, 274-285, https://doi.org/10.1007/s00410-002-0400-7

Vickers, C.J., Herbold, C.W., Cary, S.C. and Mcdonald, I.R. 2016. Insights into the metabolism of the high temperature microbial community of Tramway Ridge, Mount Erebus, Antarctica. Antarctic Science, 28, 241-249, https://doi.org/10.1017/S095410201500067X

Wardell, L.J., Kyle, P.R. and Campbell, A.R. 2003. $\mathrm{CO}_{2}$ emissions from fumarolic ice towers, Mt. Erebus volcano, Antarctica. In: Oppenheimer, C., Barclay, J. and Pyle, D. (eds) Origins, Emissions and Impacts of Volcanic Gases. Geological Society, London, https://doi.org/10.1144/GSL.SP.2003.213.01.14

Wardell, L.J., Kyle, P.R. and Chaffin, C. 2004. Carbon dioxide and carbon monoxide emission rates from an alkaline intra-plate volcano: Mount Erebus, Antarctica. Journal of Volcanology and Geothermal Research, 131, 109-121, https://doi.org/10.1016/S03770273(03)00320-2

Wardell, L.J., Kyle, P.R. and Counce, D. 2008. Volcanic emissions of metals and halogens from White Island (New Zealand) and Erebus volcano (Antarctica) determined using chemical traps. Journal of Volcanology and Geothermal Research, 177, 734-742, https://doi.org/10.1016/j.jvolgeores.2007.07.007

Watson, T., Nyblade, A. et al. 2006. P and S velocity structure of the upper mantle beneath the Transantarctic Mountains, East Antarctic craton, and Ross Sea from travel time tomography. Geochemistry, Geophysics, Geosystems, 7, Q07005, https://doi.org/10.1029/2005GC001238

Weiss, Y., Class, C., Goldstein, S. L. and Hanyu, T. 2016. Key new pieces of the HIMU puzzle from olivines and diamond inclusions. Nature, 537, 666-670, https://doi.org/10.1038/nature19113

Willbold, M. and Stracke, A. 2006. Trace element composition of mantle end-members: Implications for recycling of oceanic and upper and lower continental crust. Geochemistry, Geophysics, Geosystems, 7, https://doi.org/10.1029/2005GC001005

Workman, R.K., Hart, S.R. et al. 2004. Recycled metasomatized lithosphere as the origin of the Enriched Mantle II (EM2) end-member: evidence from the Samoan Volcanic Chain. Geochemistry, Geophysics, Geosystems, 5, https://doi.org/10.1029/2003GC000623

Workman, R.K. and Hart, S.R. 2005. Major and trace element composition of the depleted MORB mantle (DMM). Earth and Planetary Science Letters, 231, 53-72, https://doi.org/10.1016/j.eps1.2004.12.005

Xu, Y., Schoonen, M.A.A., Nordstrom, D.K., Cunningham, K.M. and Ball, J.W. 2000. Sulfur geochemistry of hydrothermal waters in Yellowstone National Park, Wyoming, USA. II. Formation and decomposition of thiosulfate and polythionate in Cinder Pool. Journal of Volcanology and Geothermal Research, 97, 407-423, https://doi.org/10.1016/S03770273(99)00173-0

Zandomeneghi, D., Aster, R., Kyle, P., Barclay, A.H., Chaput, J. and Knox, H. 2013. Internal structure of Erebus volcano, Antarctica imaged by high-resolution active-source seismic tomography and coda interferometry. Journal of Geophysical Research, 118, 1067-1078, https://doi.org/10.1002/jgrb.50073

Zhao, D. 2007. Seismic images under 60 hotspots: search for mantle plumes. Gondwana Research, 12, 335-355, https://doi.org/10.1016/j.gr.2007.03.001 
Zoller, W.H., Gladney, E.S. and Duce, R.A. 1974. Atmospheric concentrations and sources of trace elements at the South Pole. Science, 183, 198-200, https://doi.org/10.1126/science.183.4121.198

Zoller, W.H., Parrington, J.R. and Kotra, J.M.P. 1983. Iridium enrichment in airborne particles from Kilauea volcano. Science, 222, 1118-1121, https://doi.org/10.1126/science.222.4628.1118

Zreda-Gostynska, G., Kyle, P. and Finnegan, D. 1993. Chlorine, fluorine, and sulfur emissions from Mount Erebus, Antarctica and estimated contributions to the Antarctic atmosphere. Geophysical Research Letters, 20, 1959-1962, https://doi.org/10.1029/93GL01879

Zreda-Gostynska, G., Kyle, P.R., Finnegan, D. and Prestbo, K.M. 1997. Volcanic gas emissions from Mount Erebus and their impact on the Antarctic environment. Journal of Geophysical Research, 102(B7), 15,039-15,055, https://doi.org/10.1029/97JB00155 


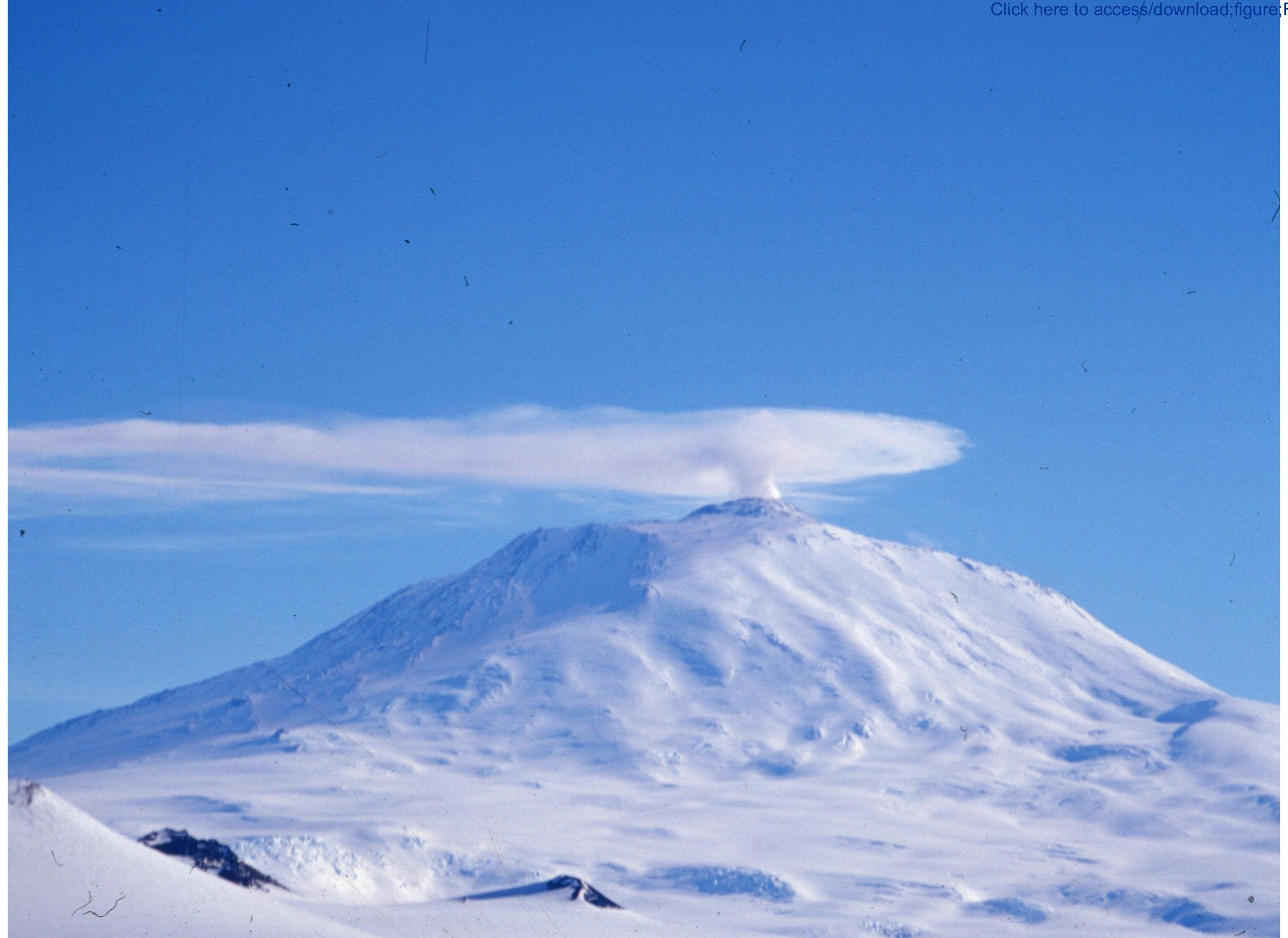




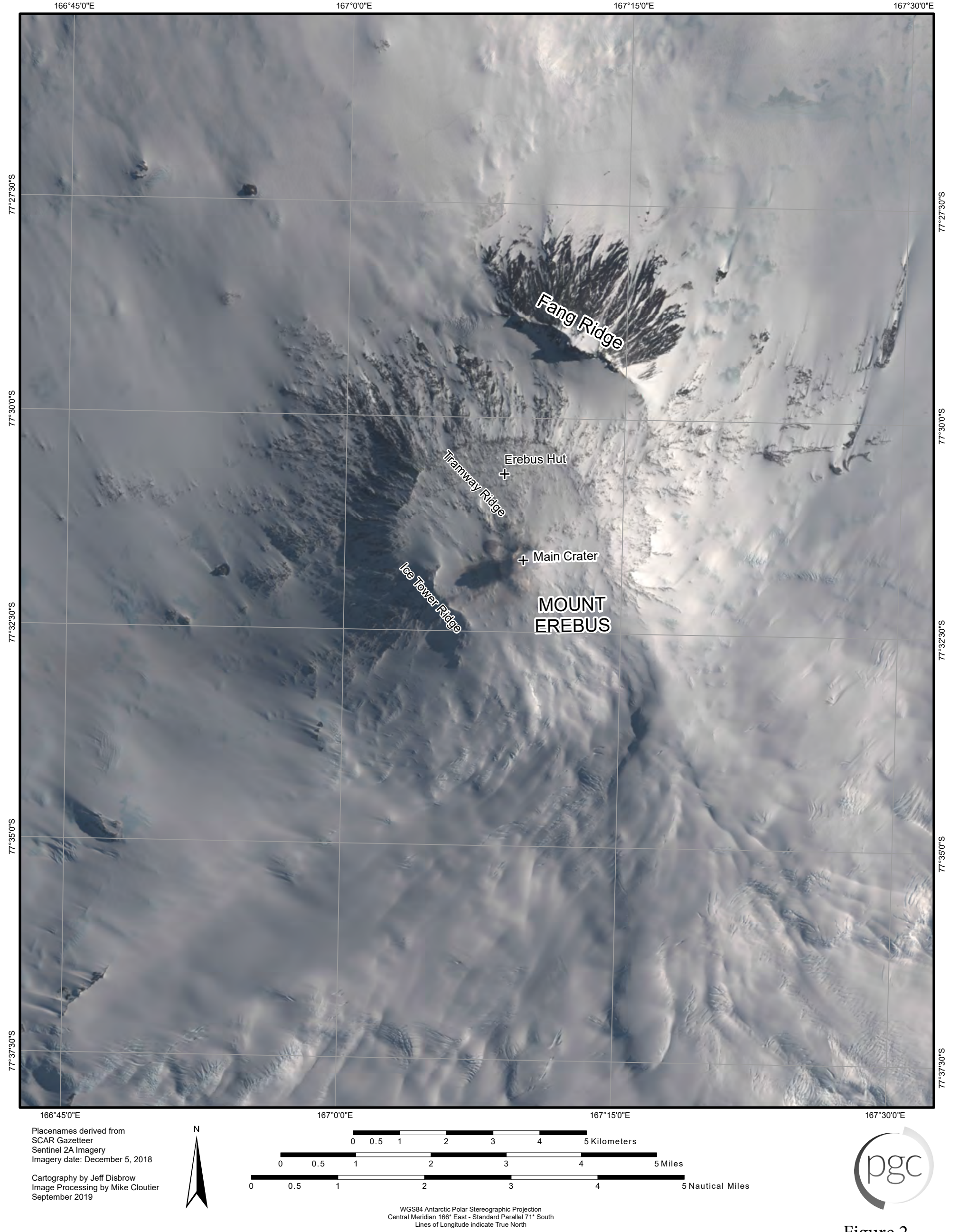

Figure 2 

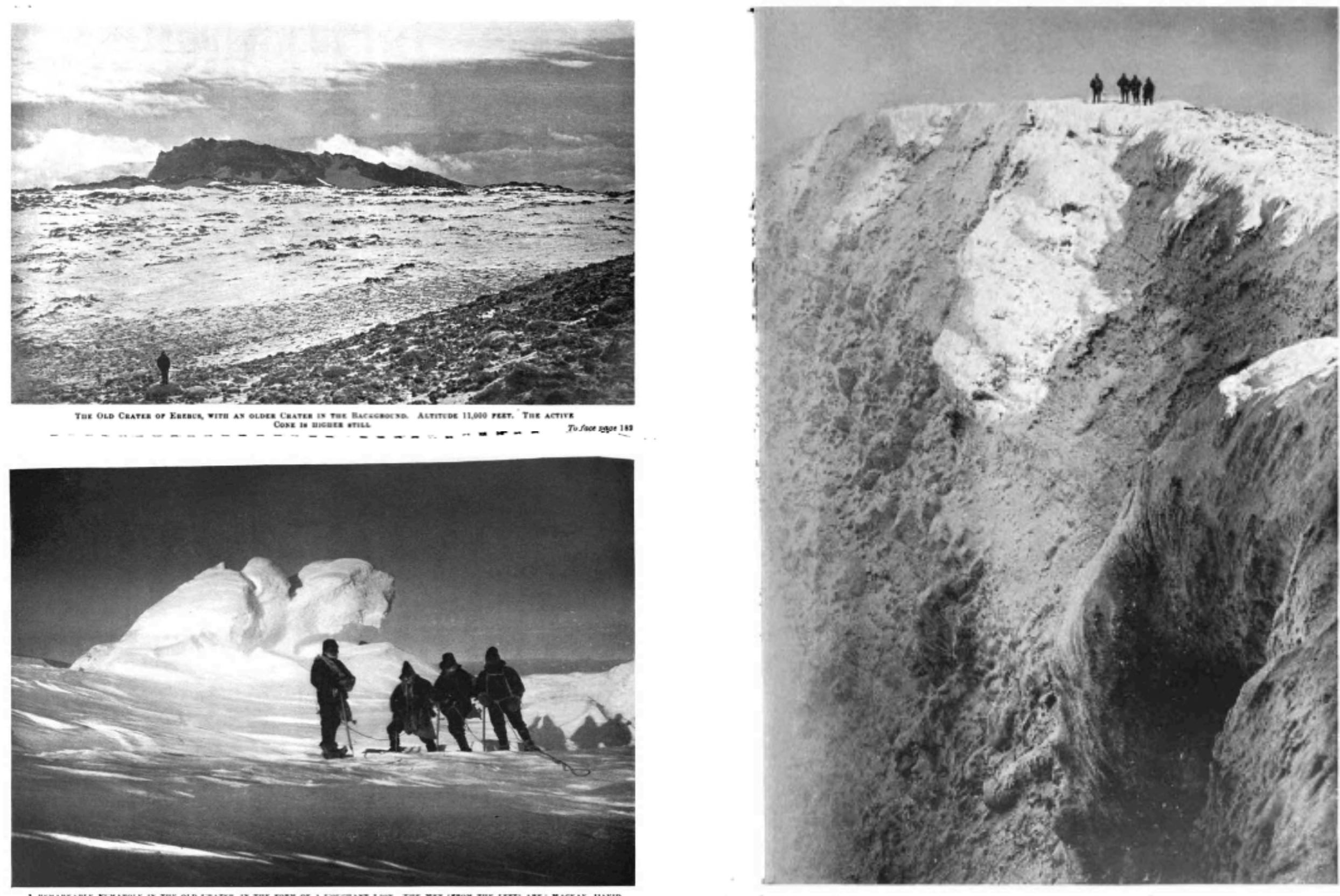

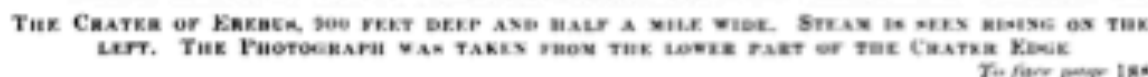




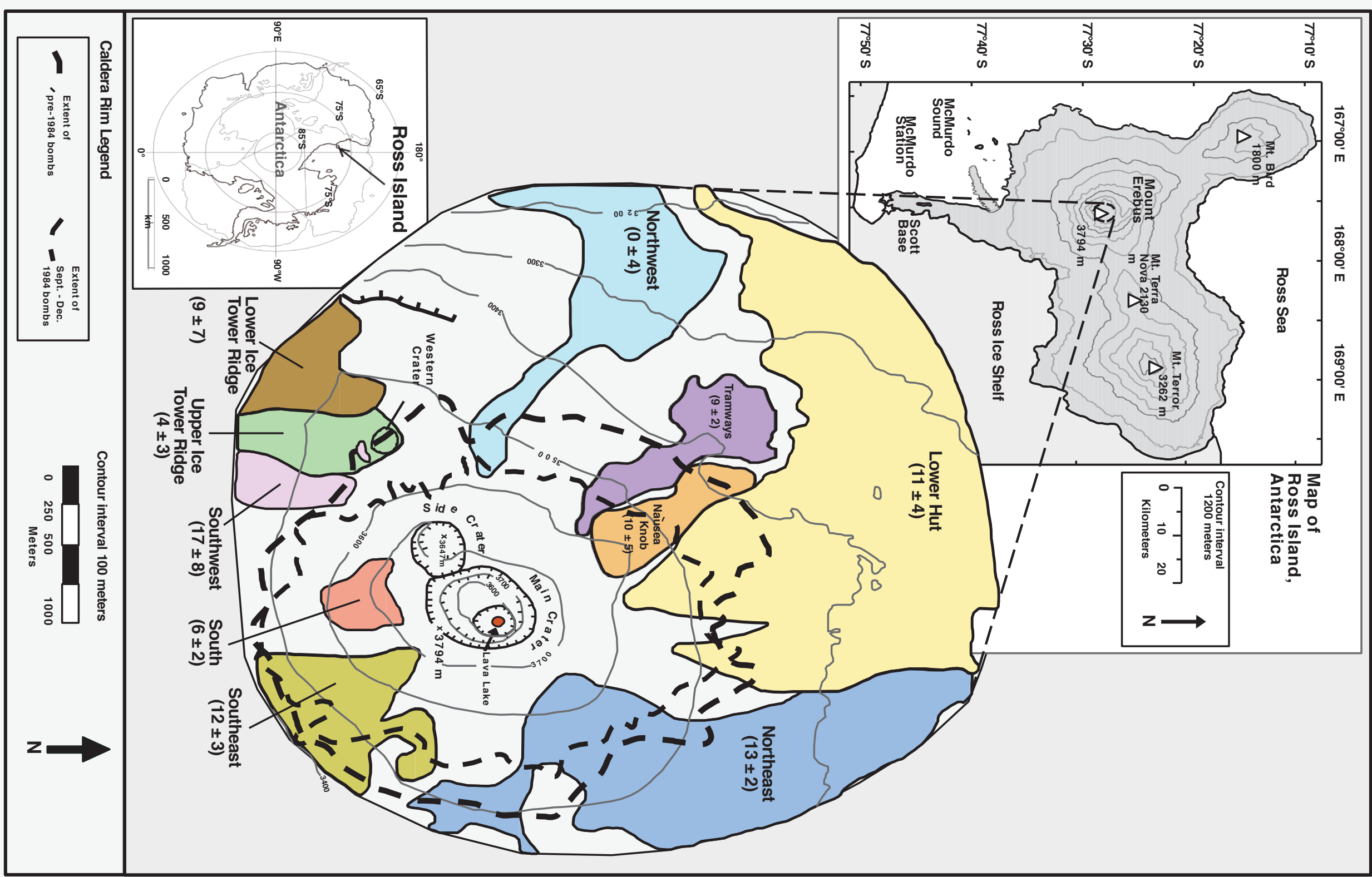




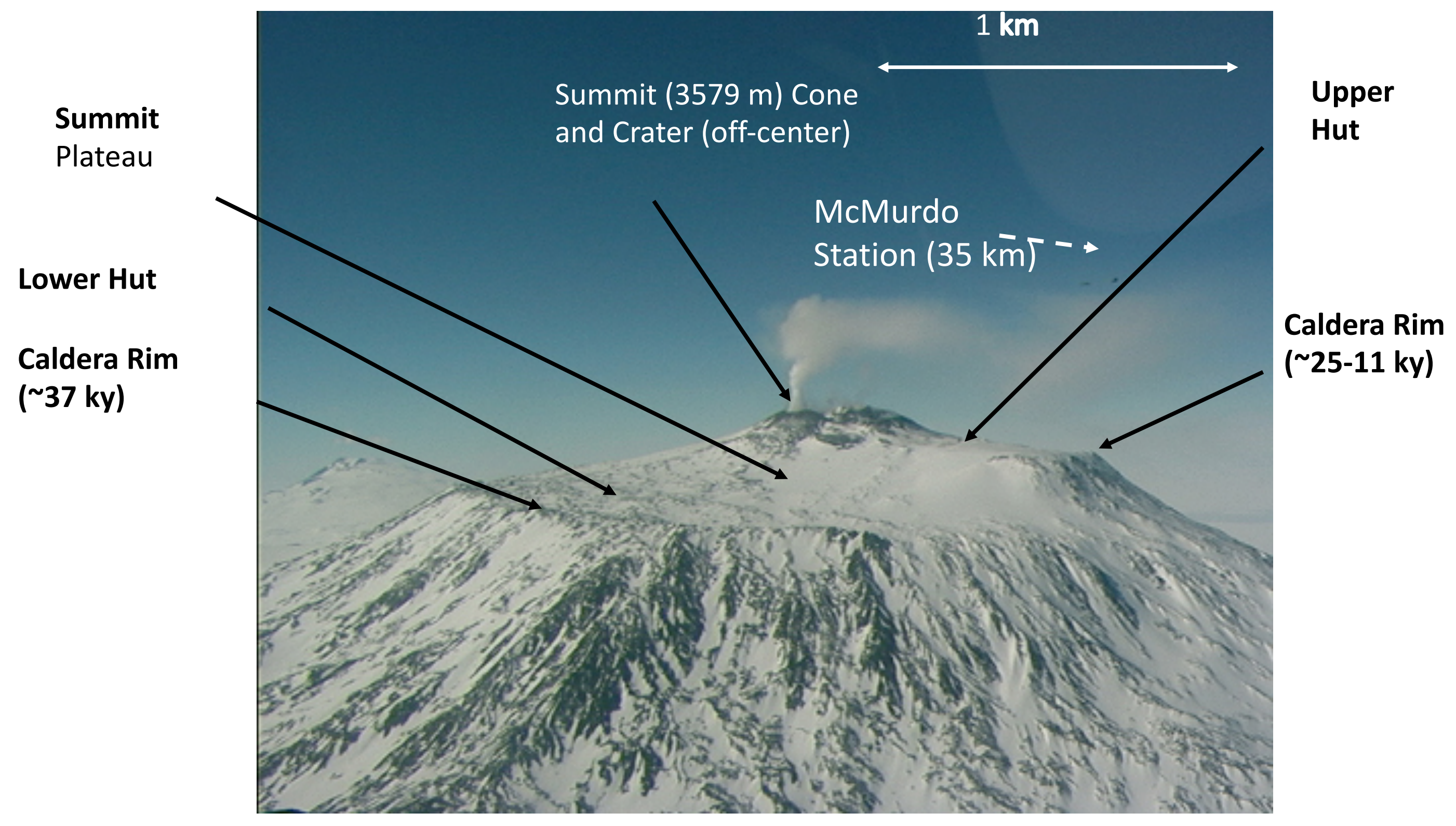


Click here to access/download:figure:Figure 6 Frebus Frebus Crater and Hut.pdf $\stackrel{*}{*}$

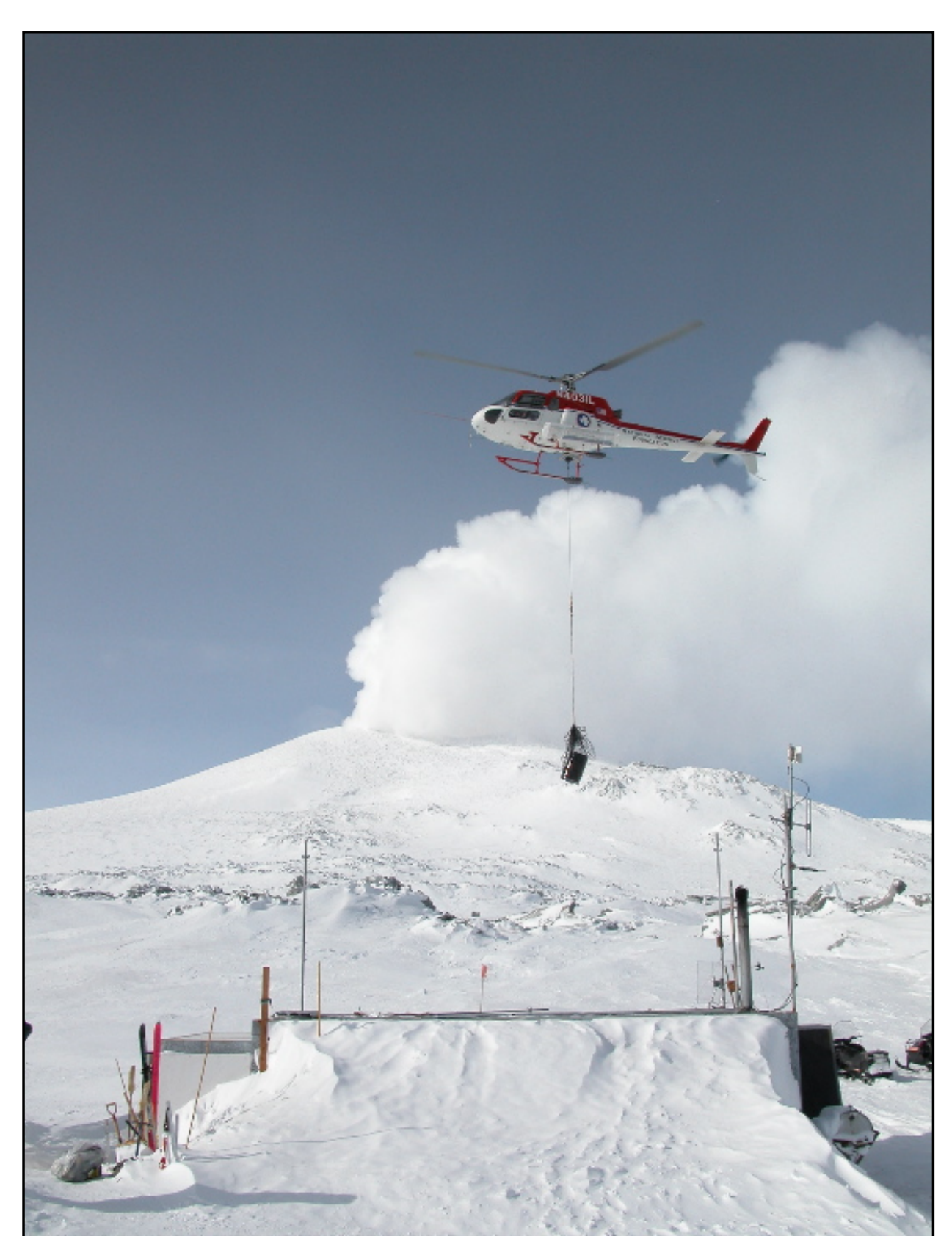

Lower Erebus Hut (3350 m)

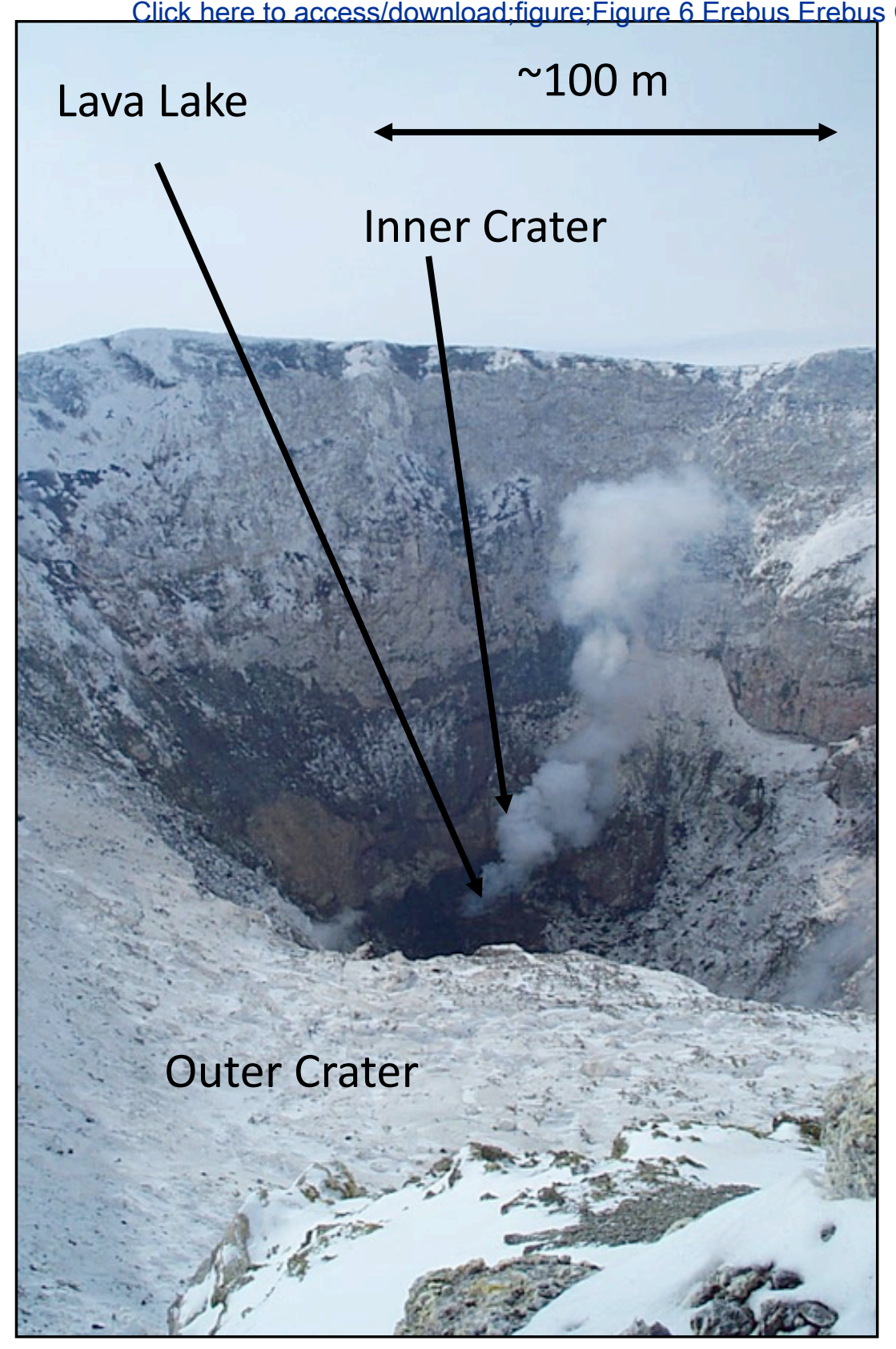

Erebus Crater 

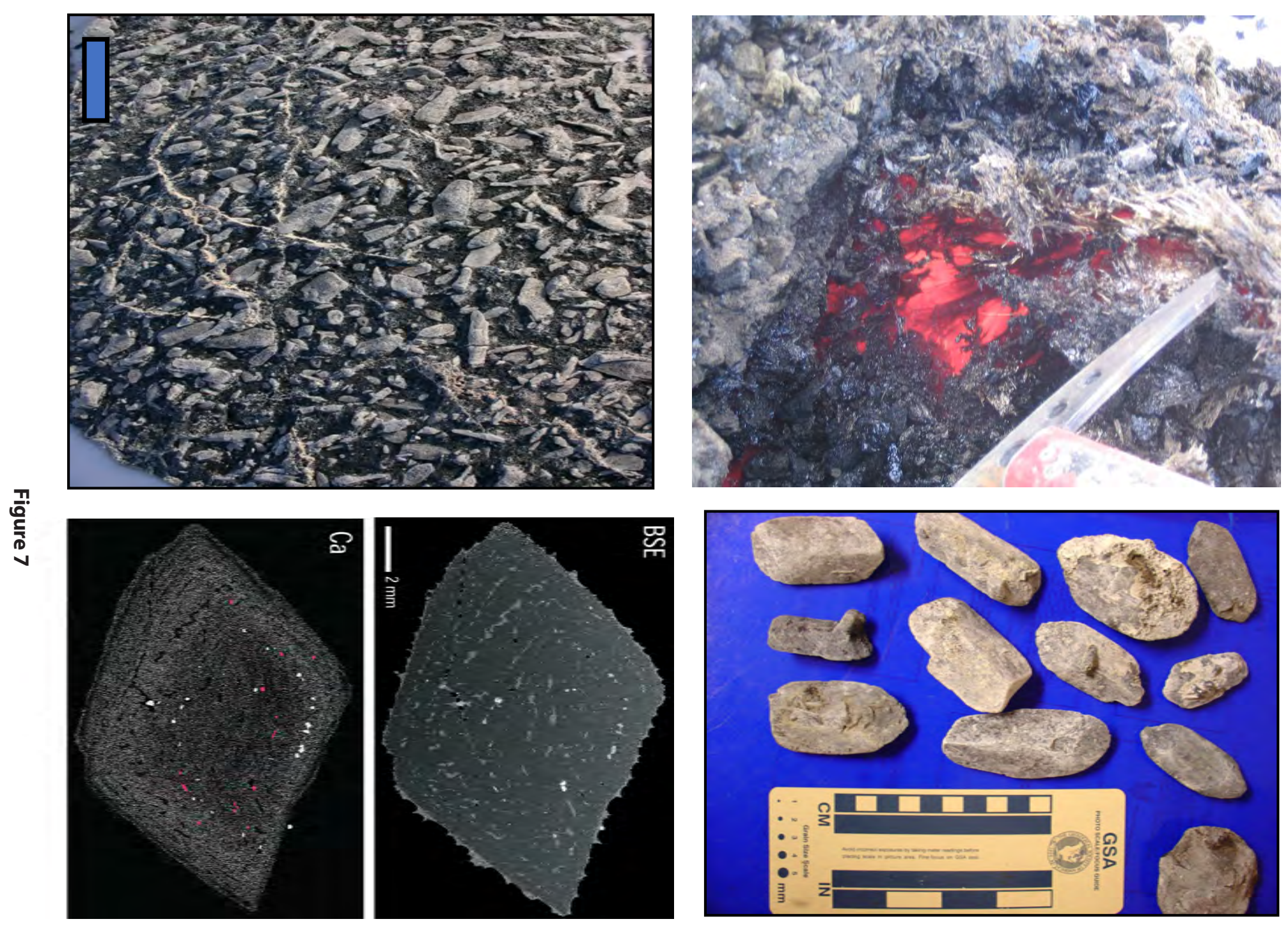


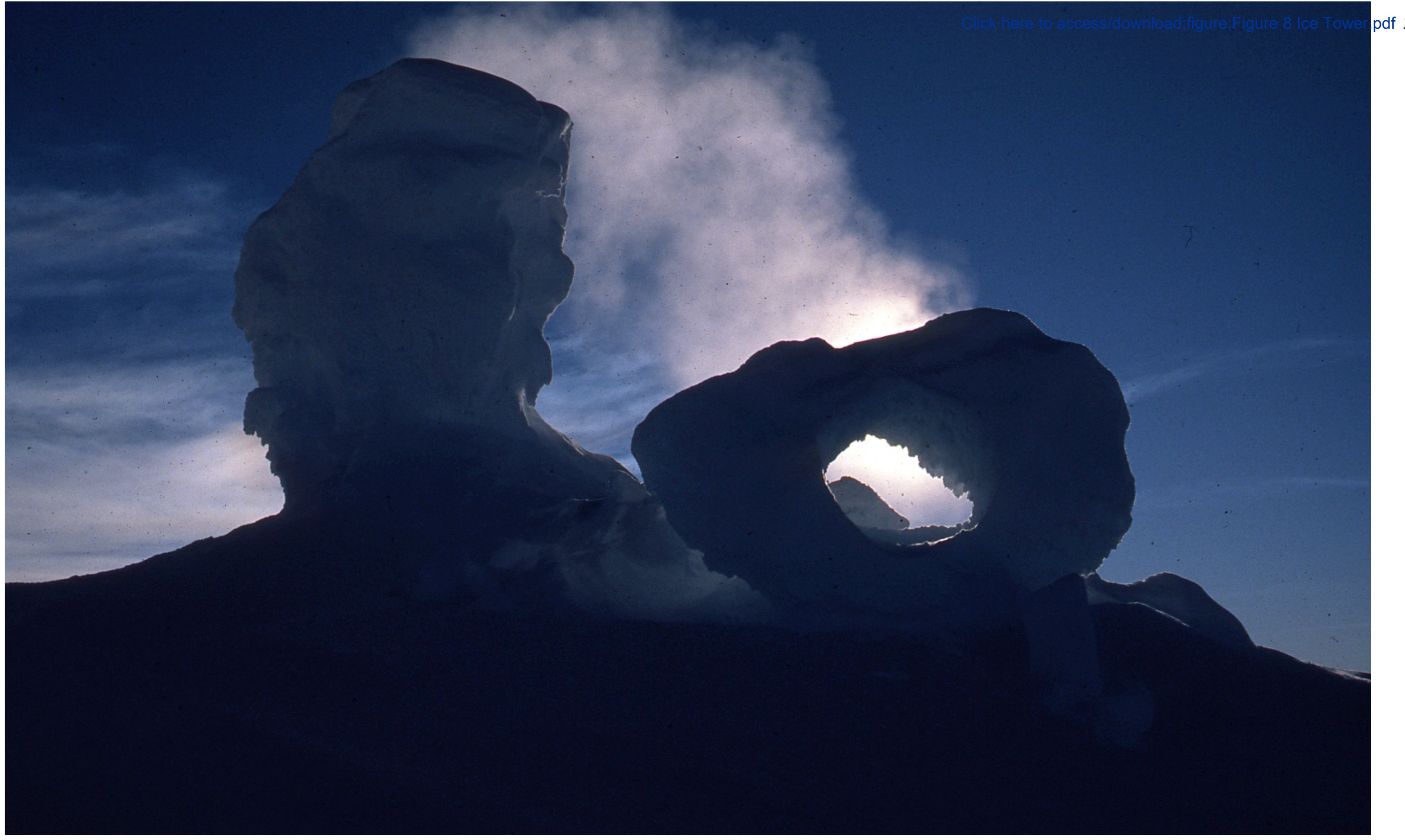

$\mathrm{df}^{\underline{\underline{\boldsymbol{t}}}}$

(
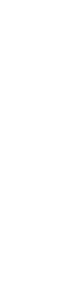


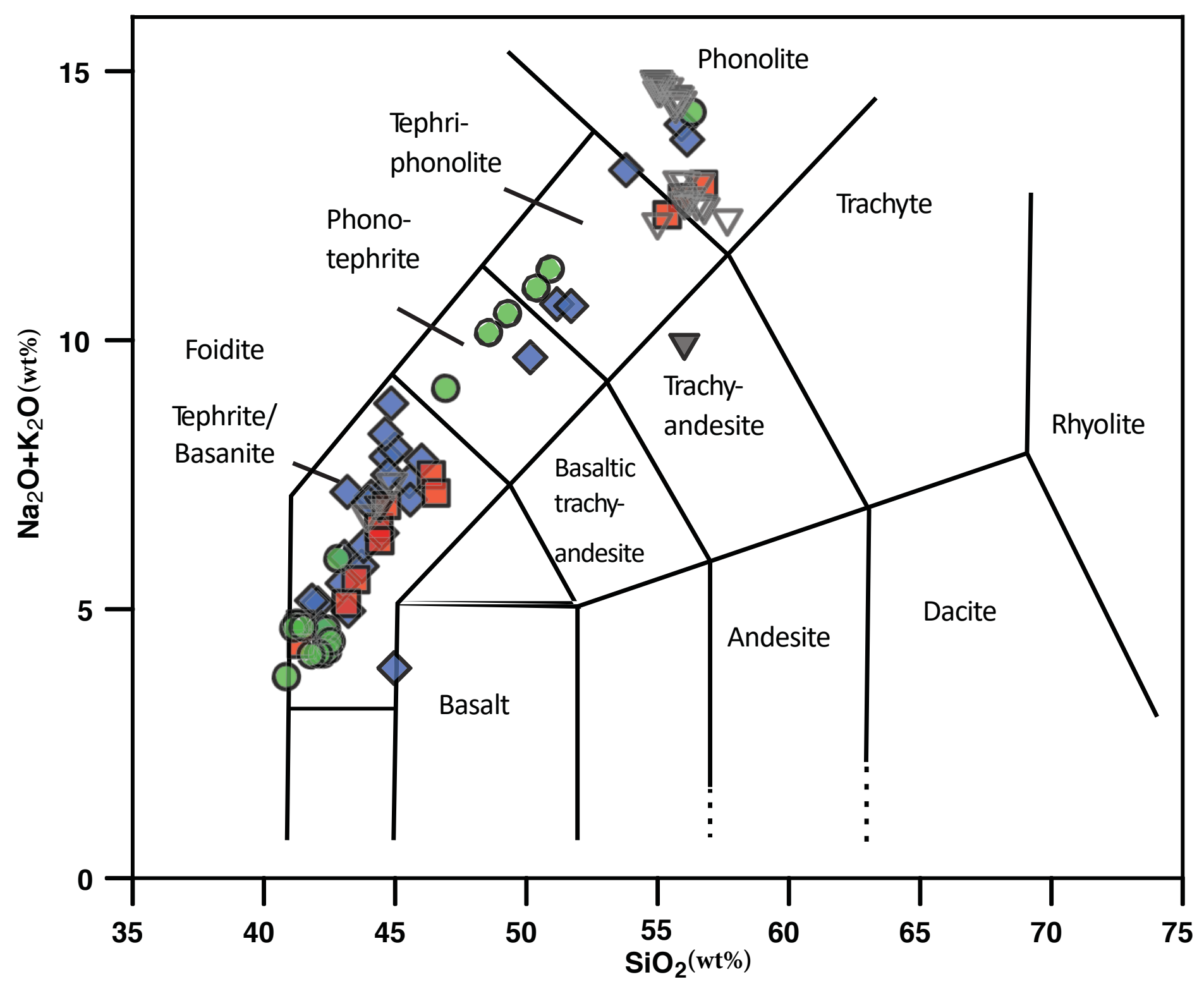

Terror Bird- Phillips et al. 2018 Hut Point- - Phillips et al. 2018

Erebus Lineage- - Phillips et al. 2018

$\nabla$ Erebus Lineage - Sims et al., 2008 


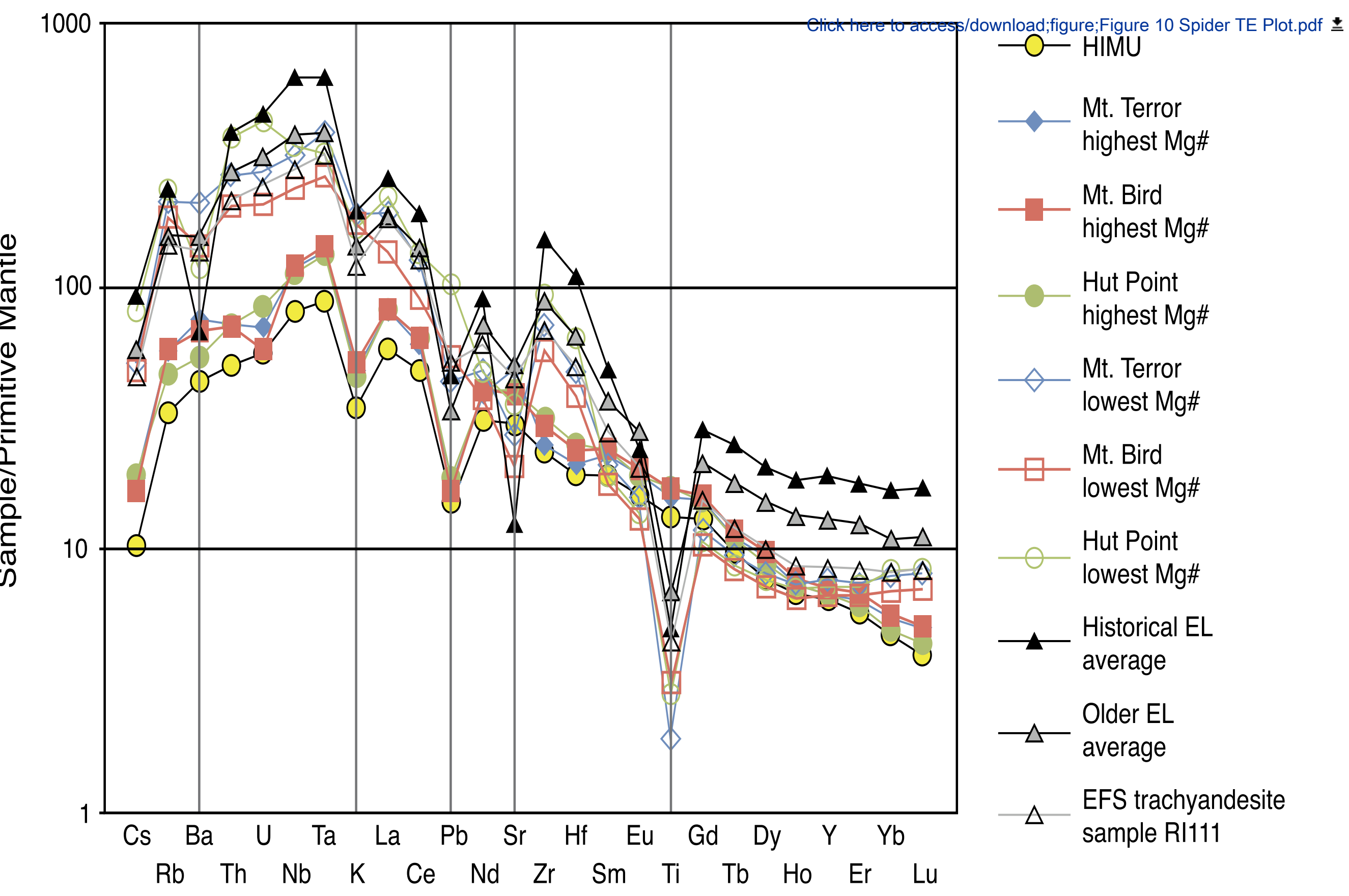




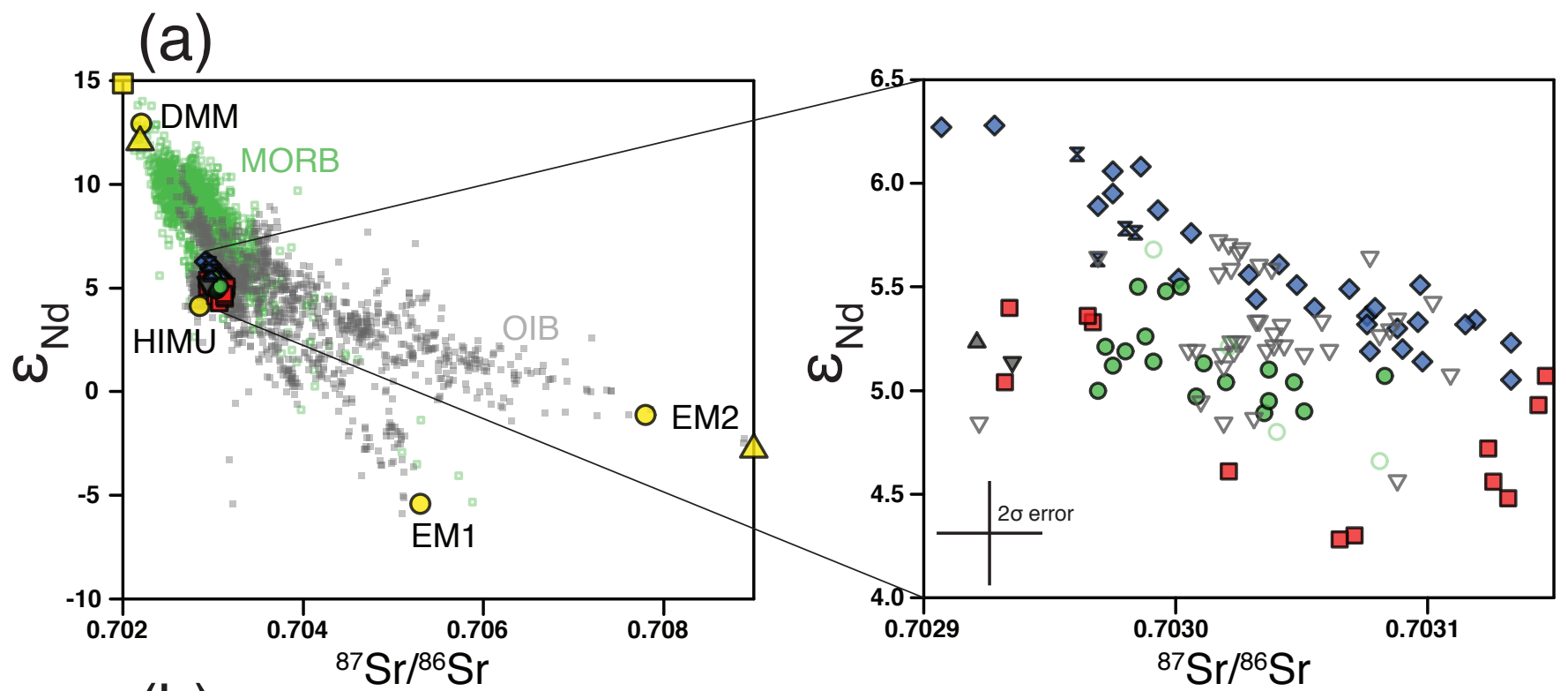

(b)
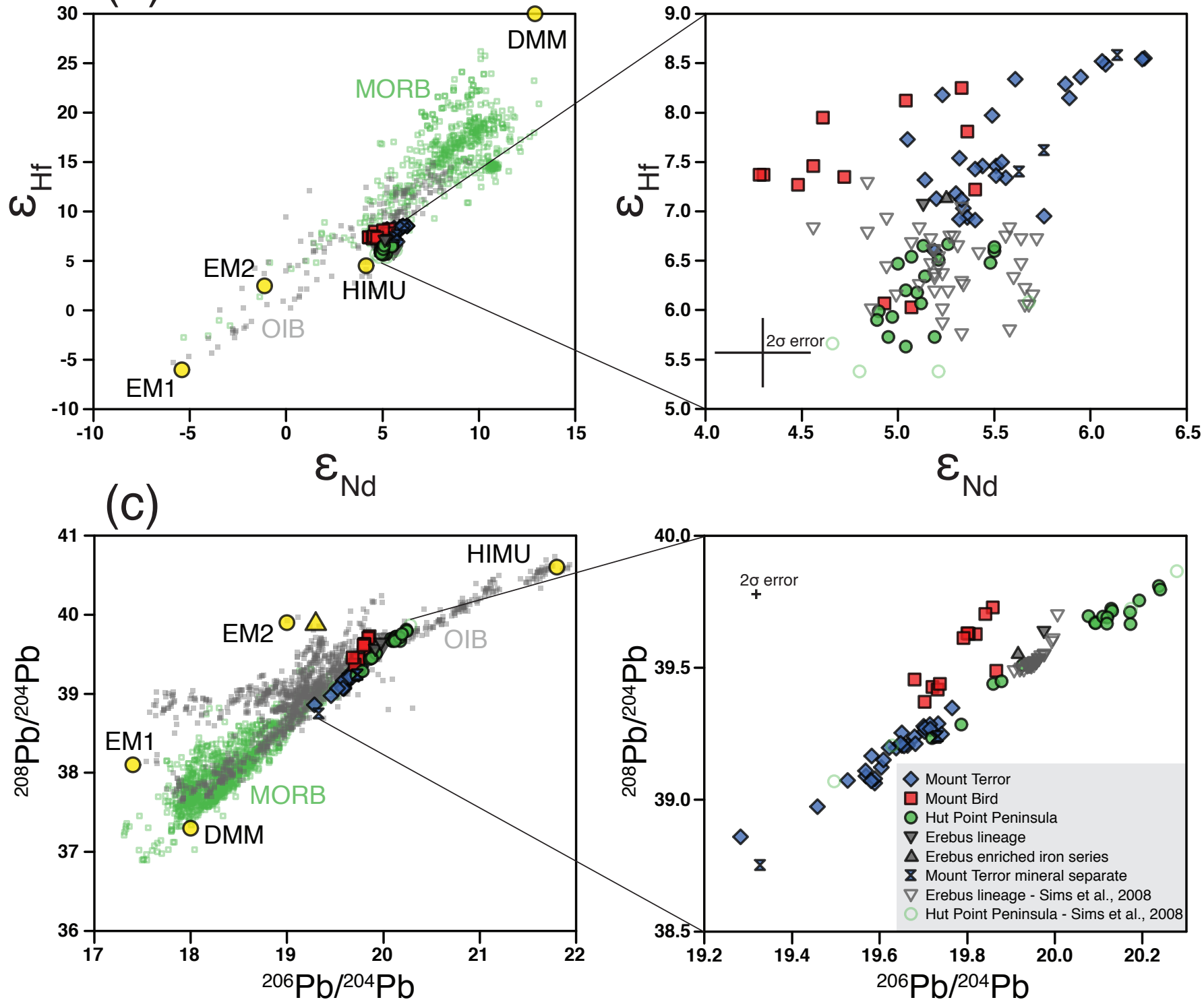

Figure 11 


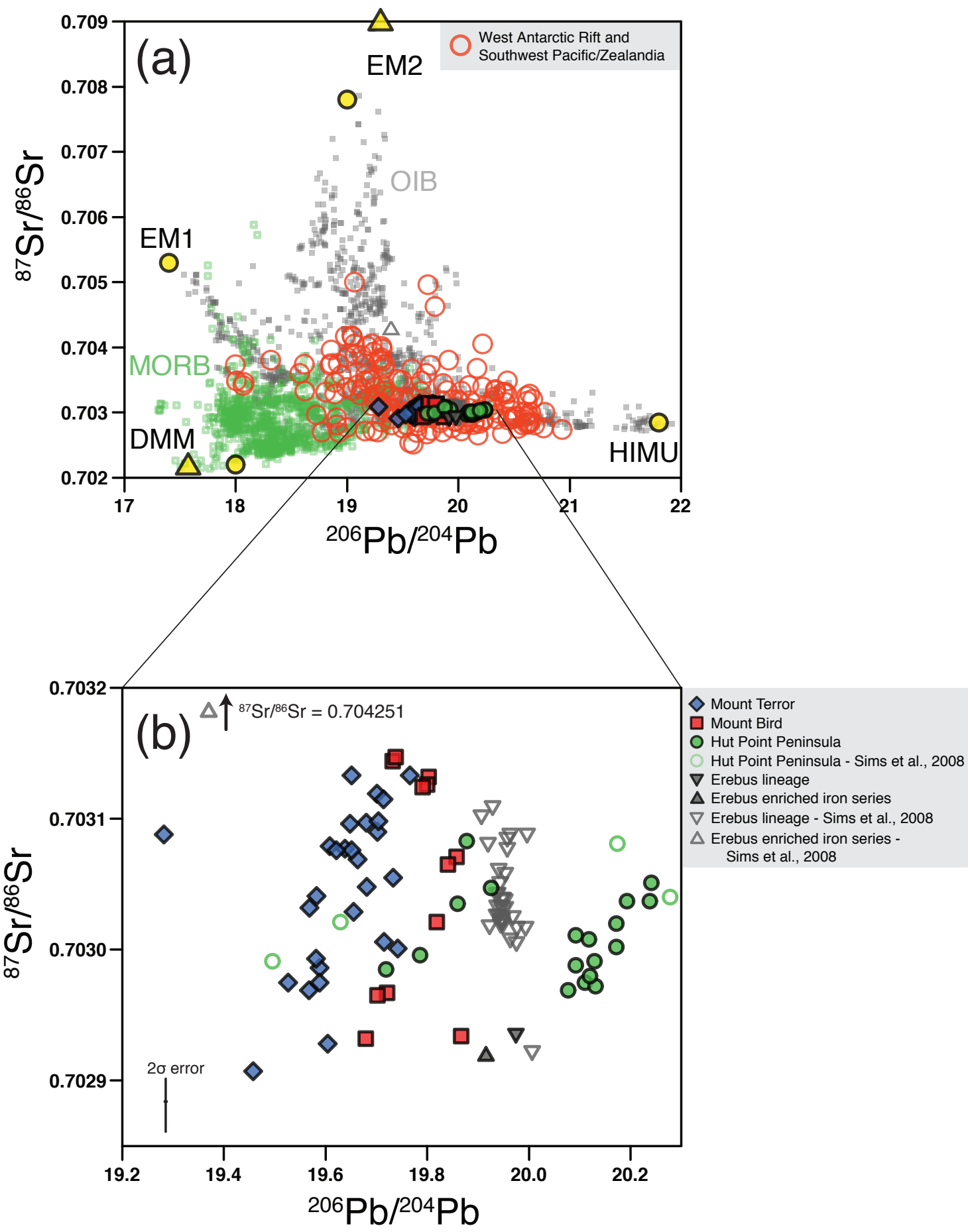

Figure 12 

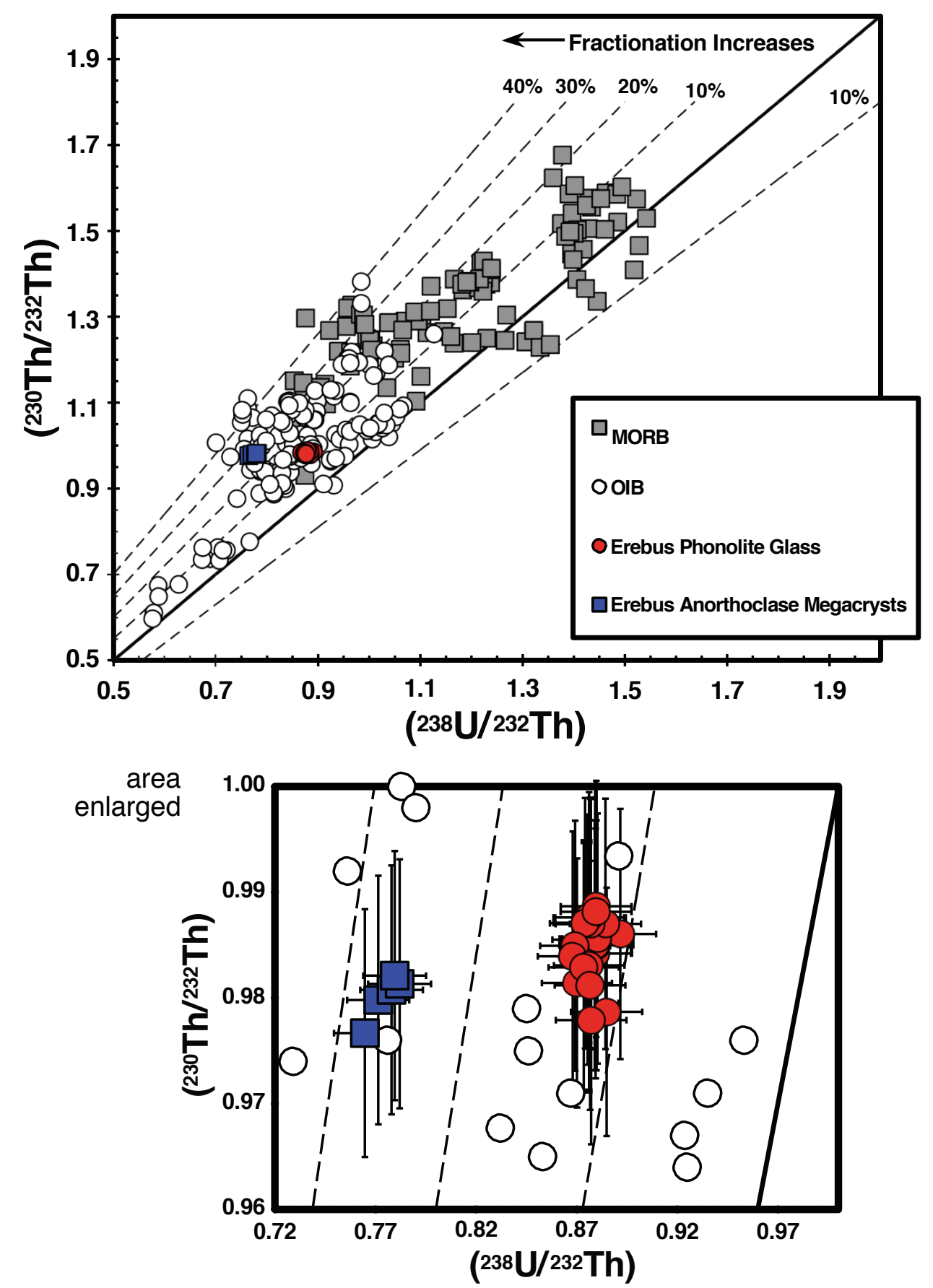


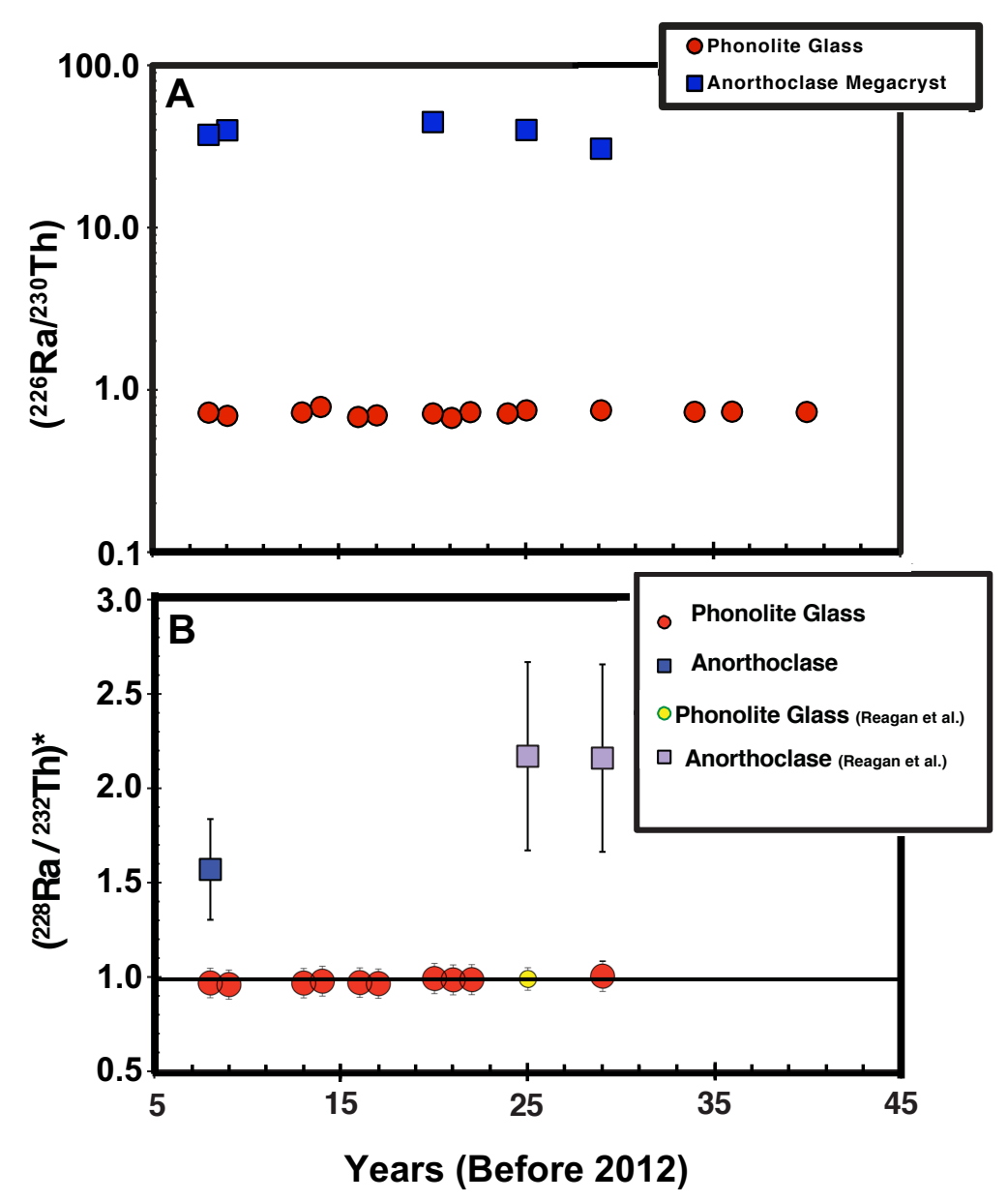

Figure 14 


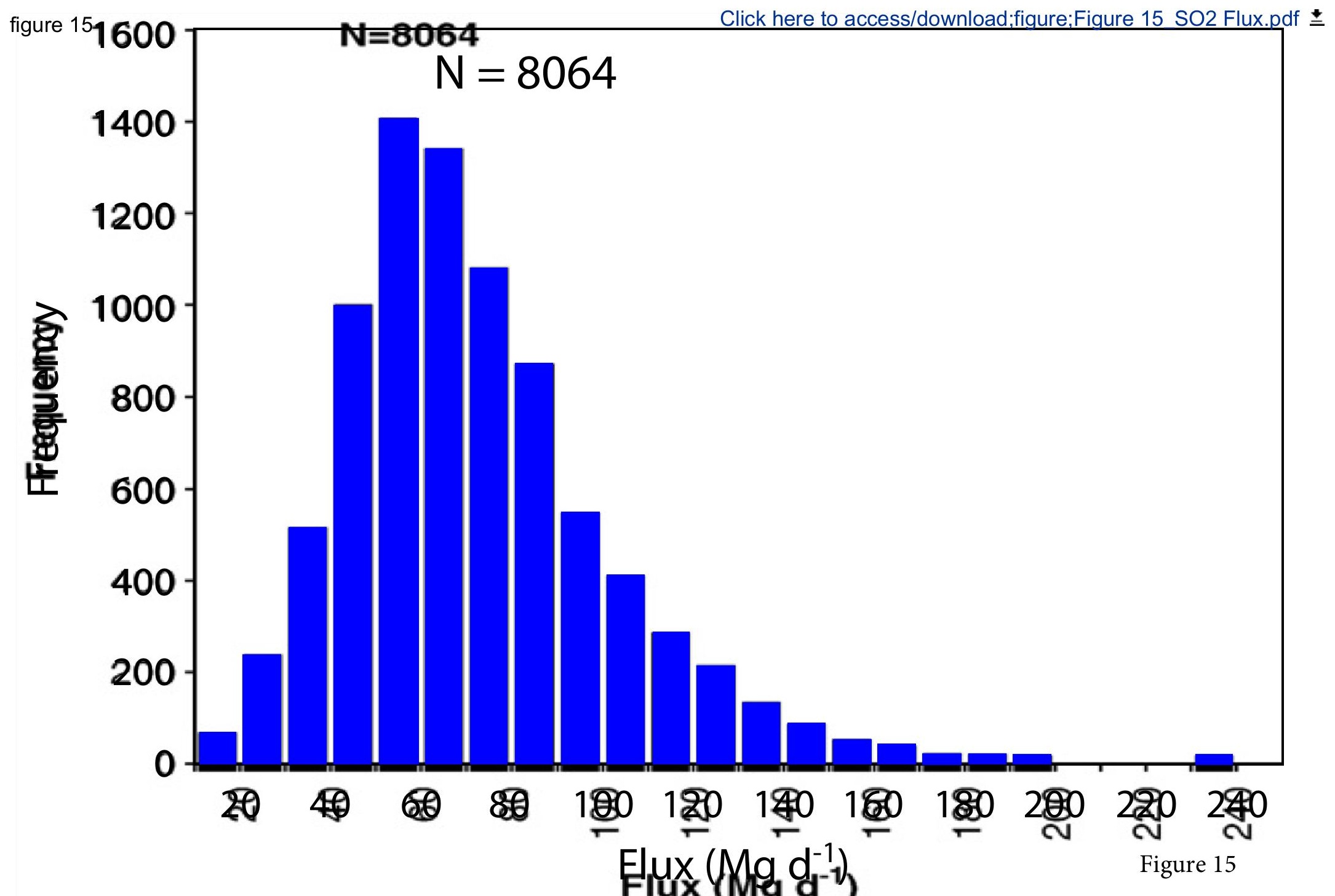



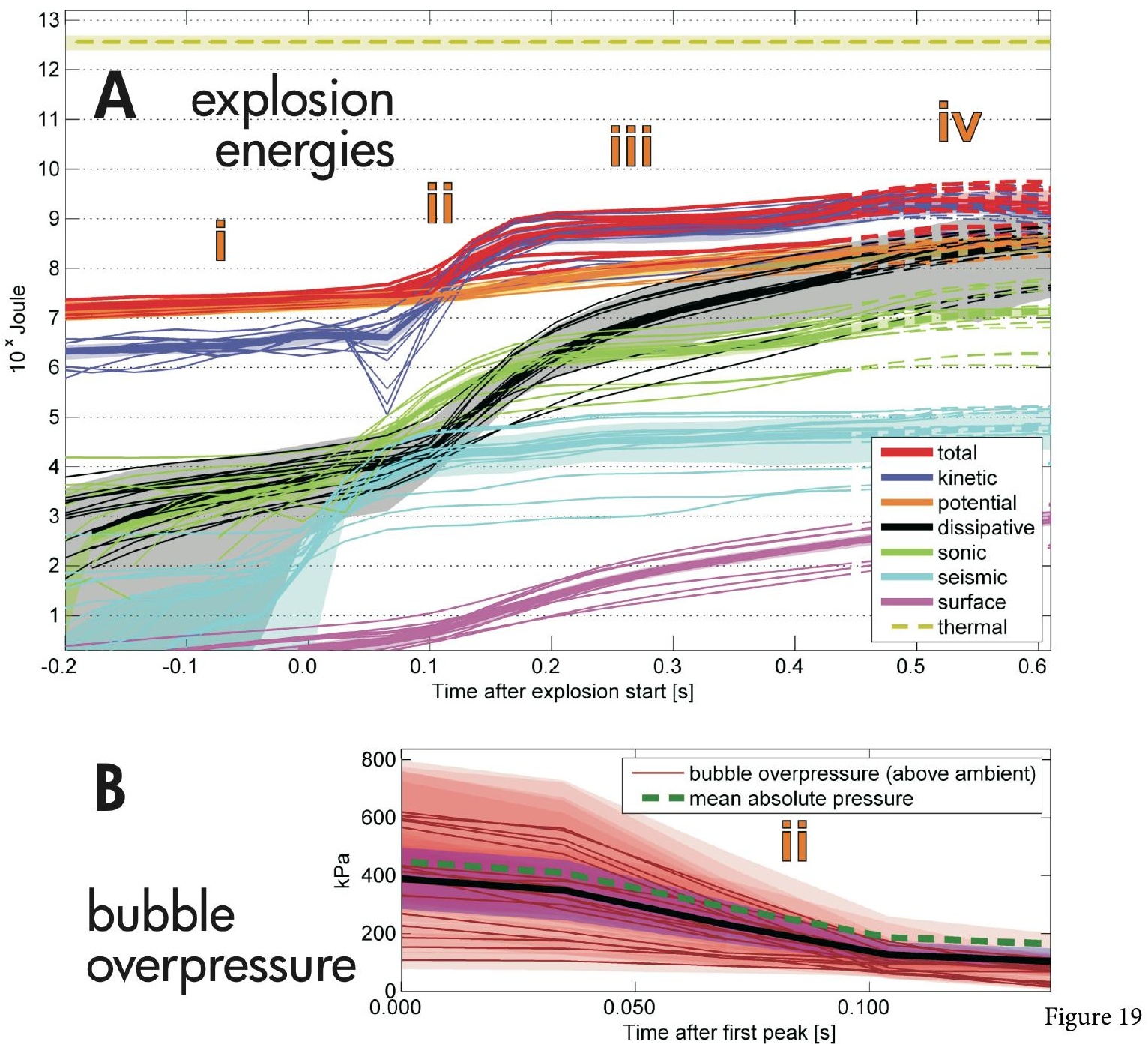


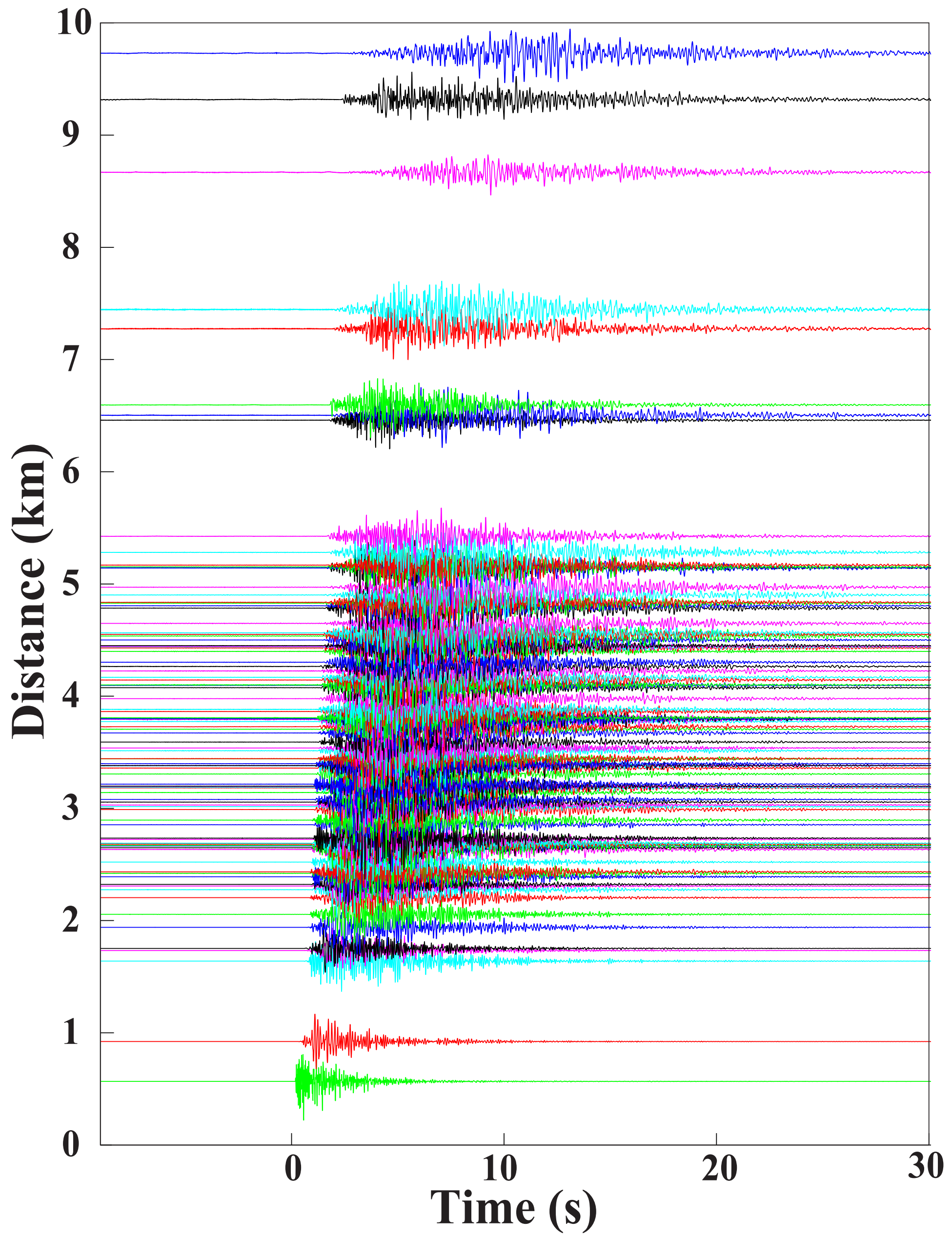




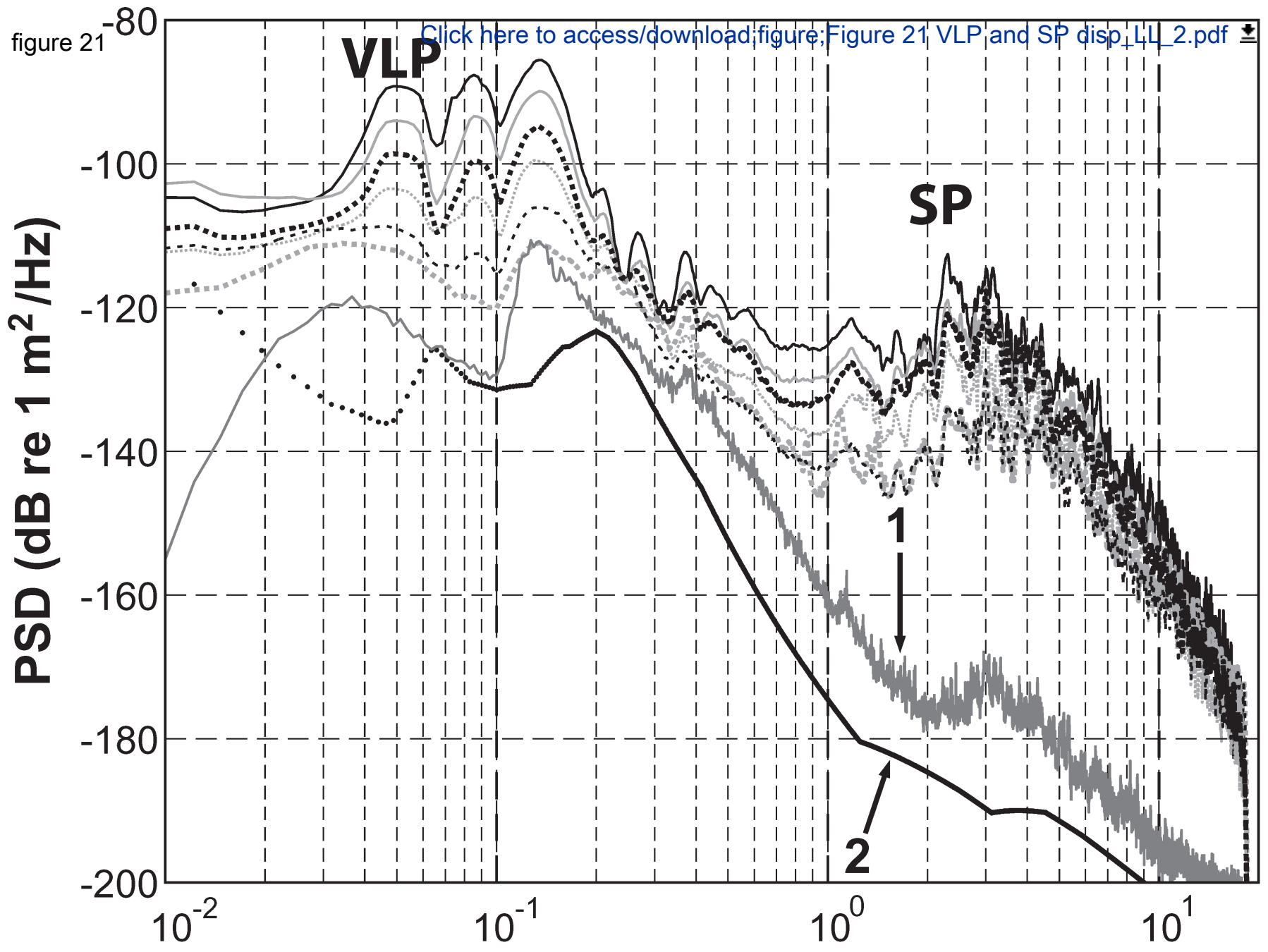




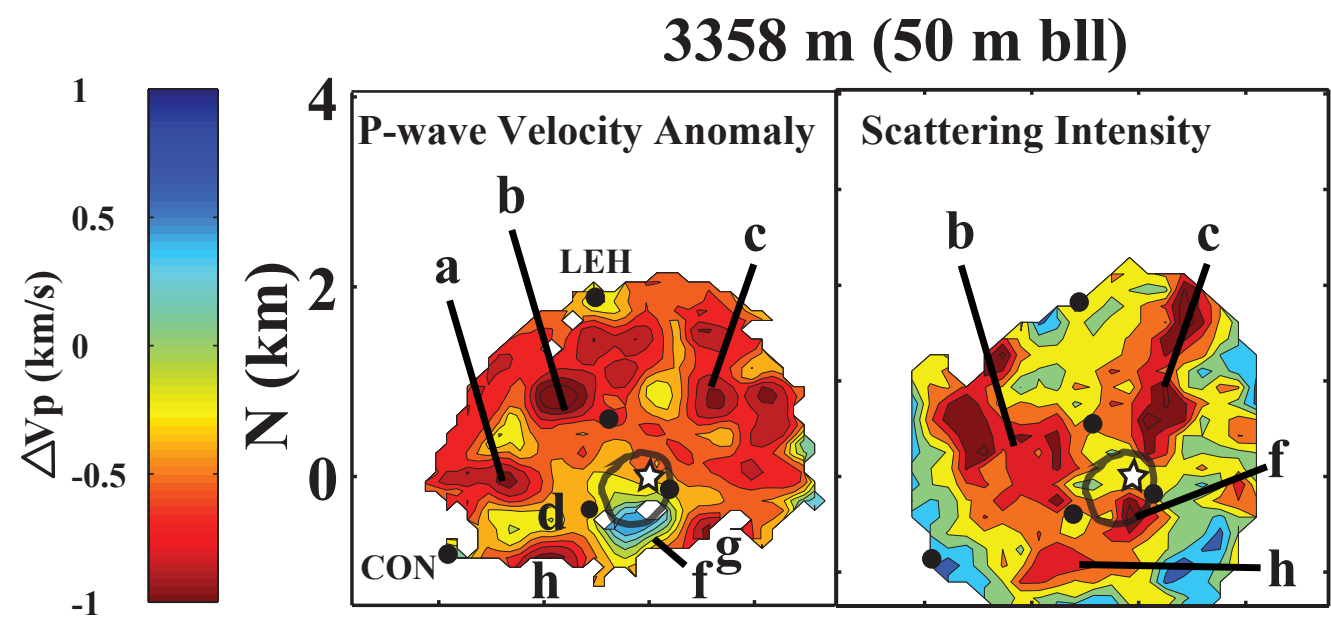

$2958 \mathrm{~m}$ (450 m bll)

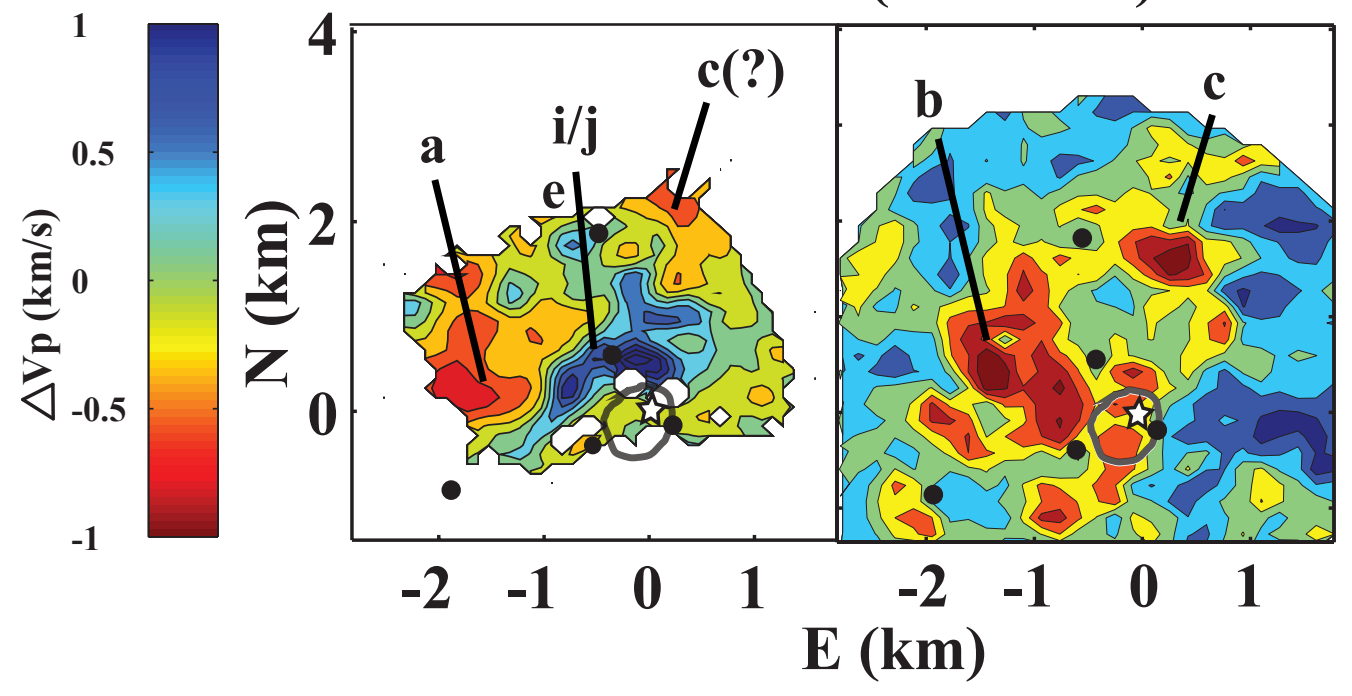

3158 m (250 m bll)

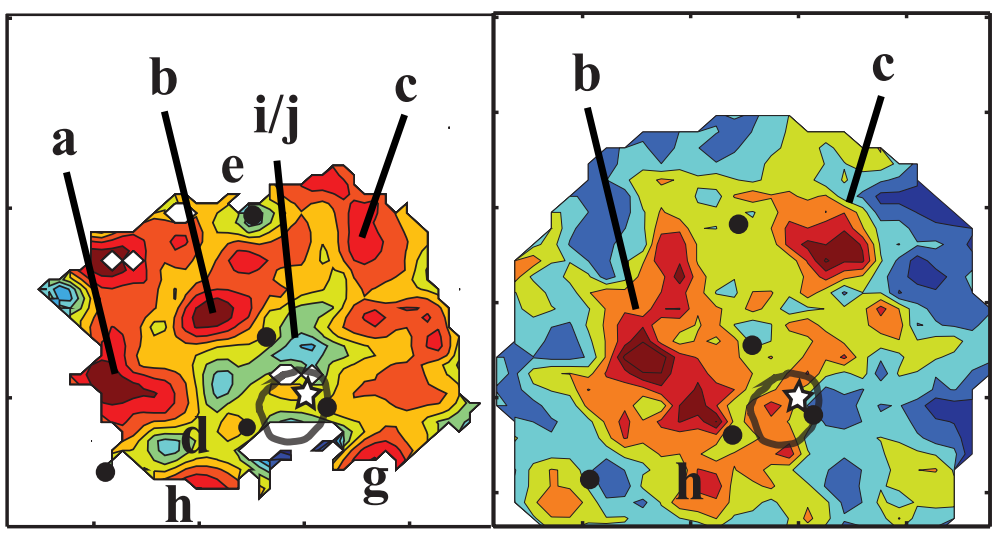

$2758 \mathrm{~m}$ (650 m bll)

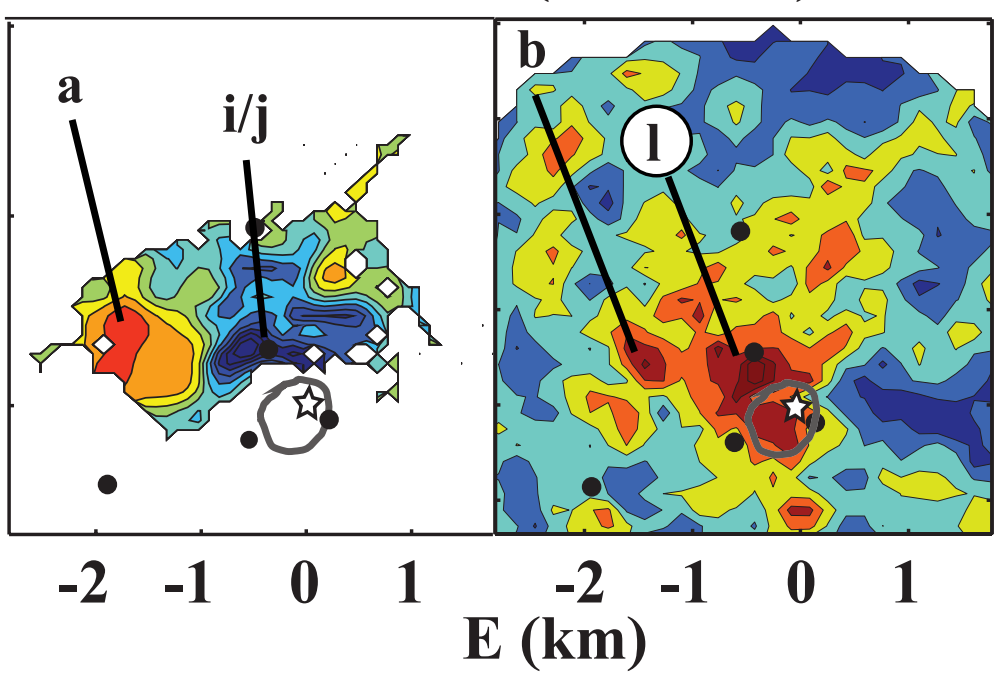

40

30

20

10 ङ

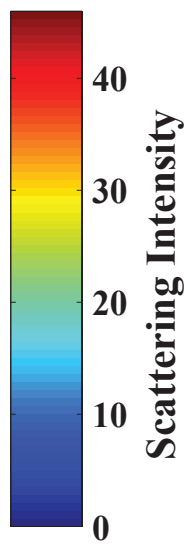

Figure 22 


\section{$\Delta \mathrm{V}_{\mathrm{P}}<-1 \mathrm{~km} / \mathrm{s}$}

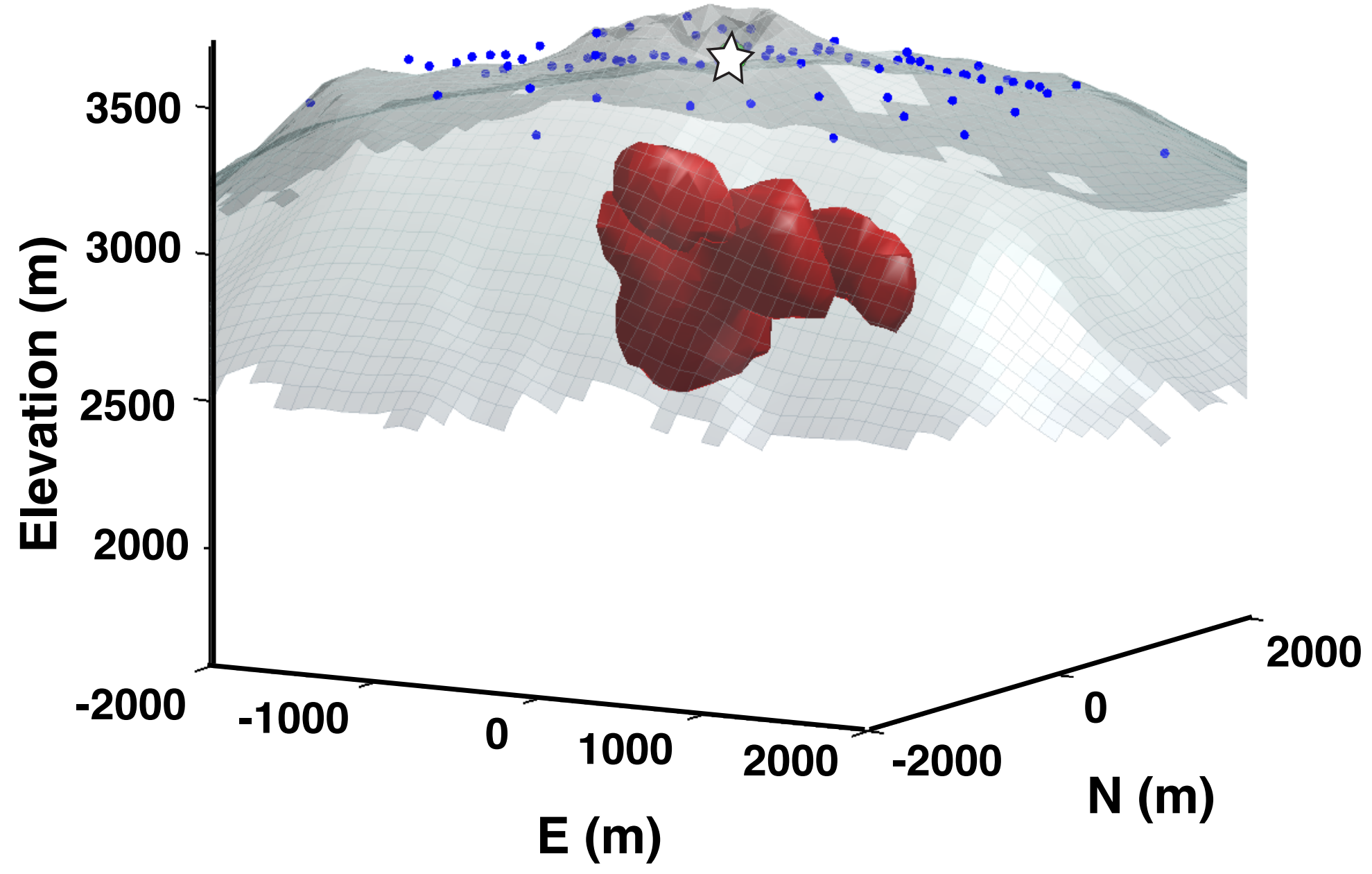

$S>46$

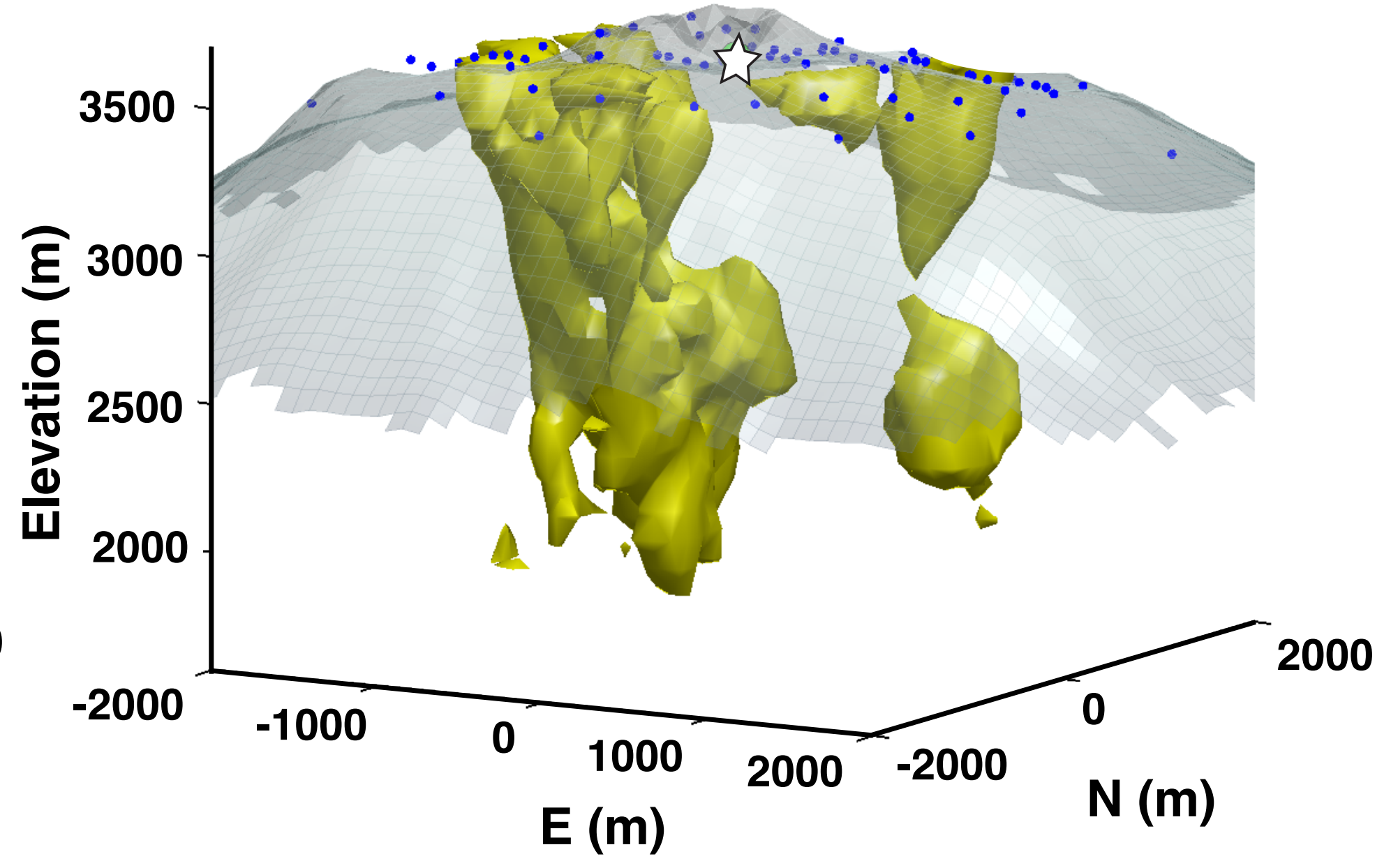

\section{$\Delta V_{P}<-1 \mathrm{~km} / \mathrm{s}$ and $S>46$}
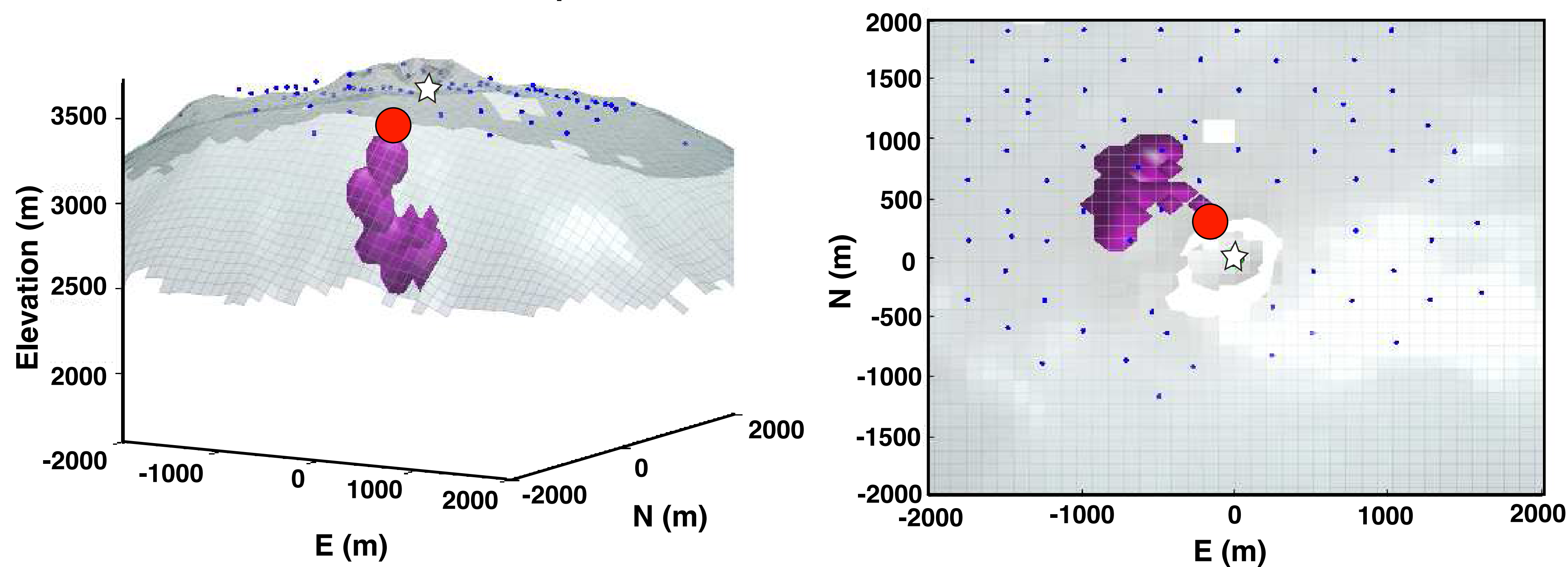


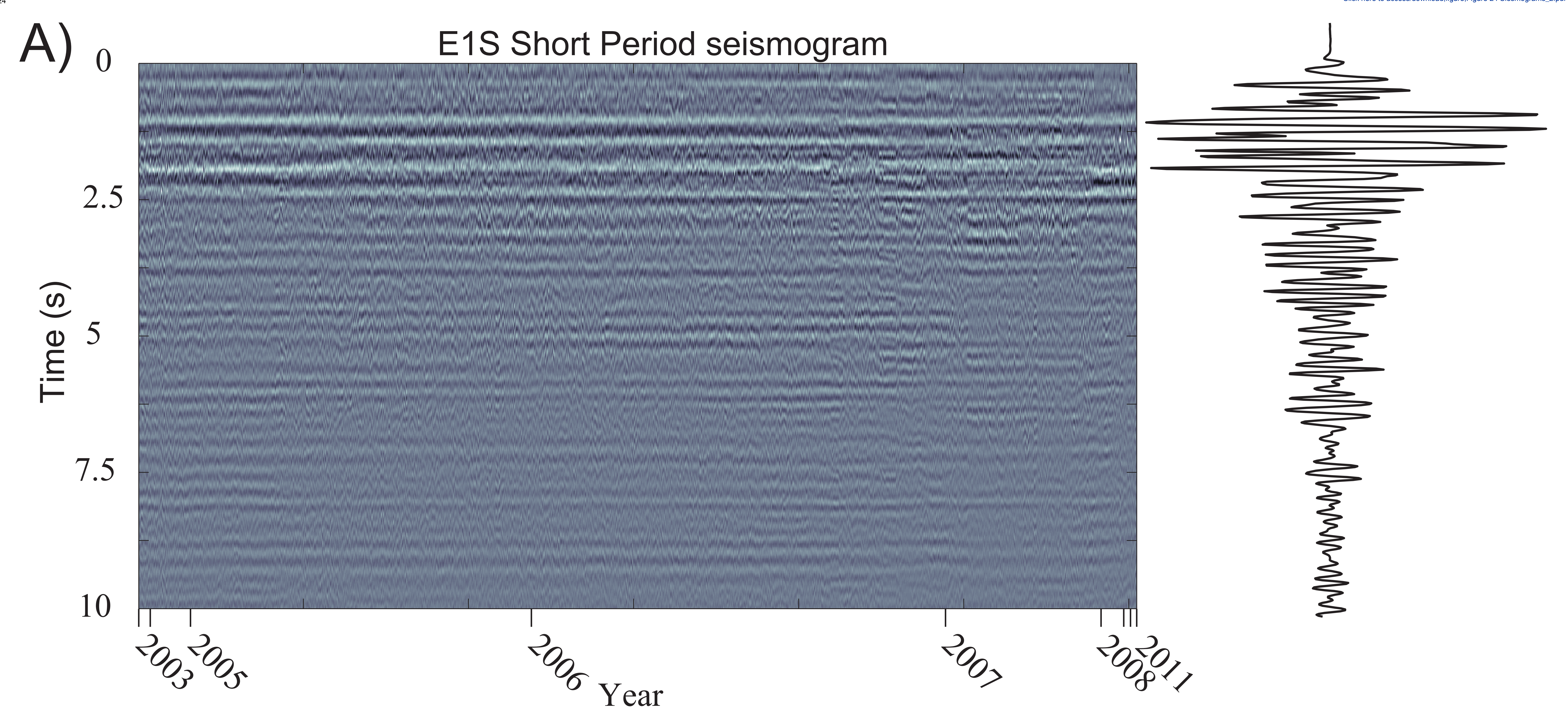

B) E1S Very Long Period seismogram, aligned on SP

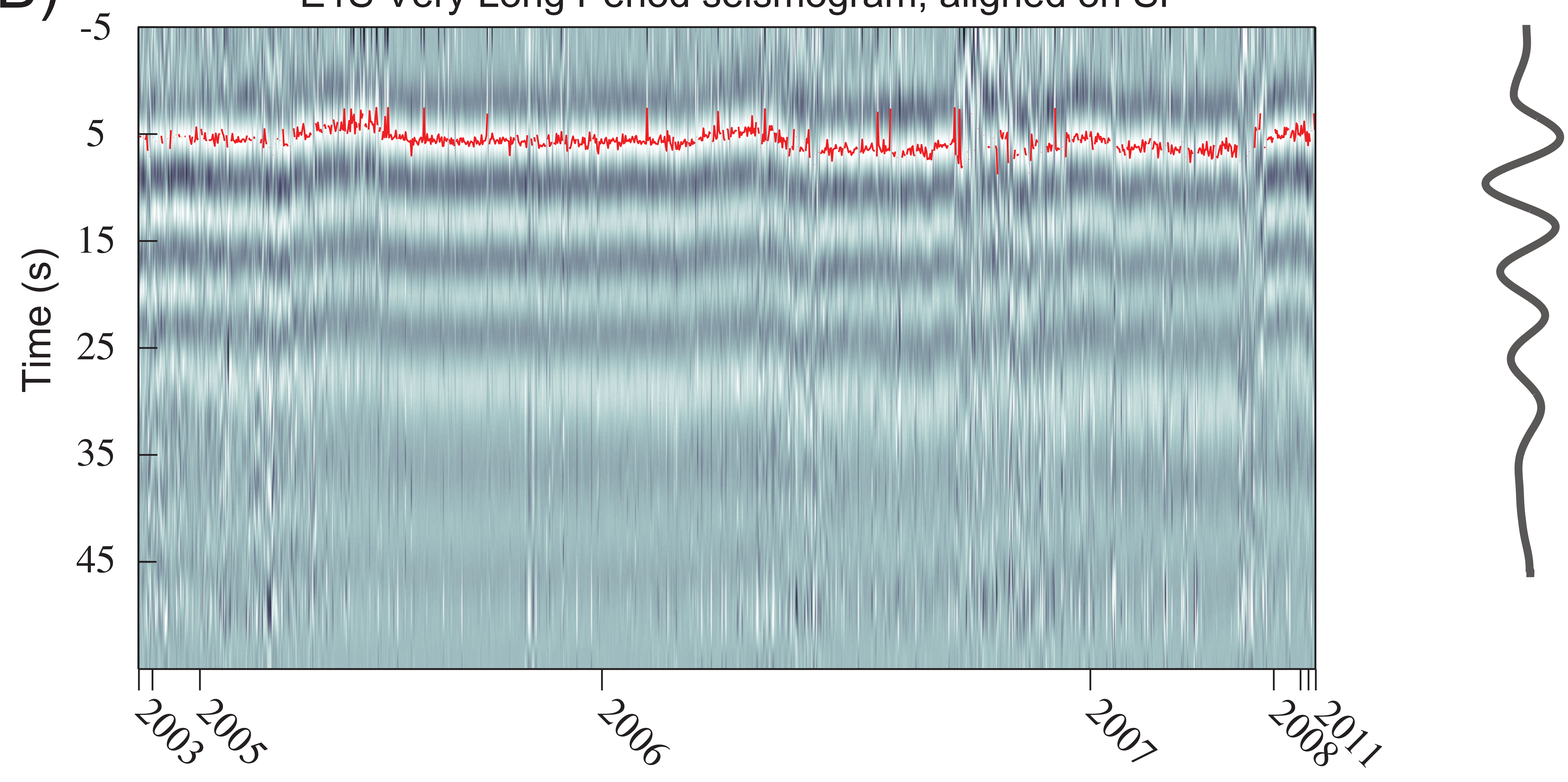



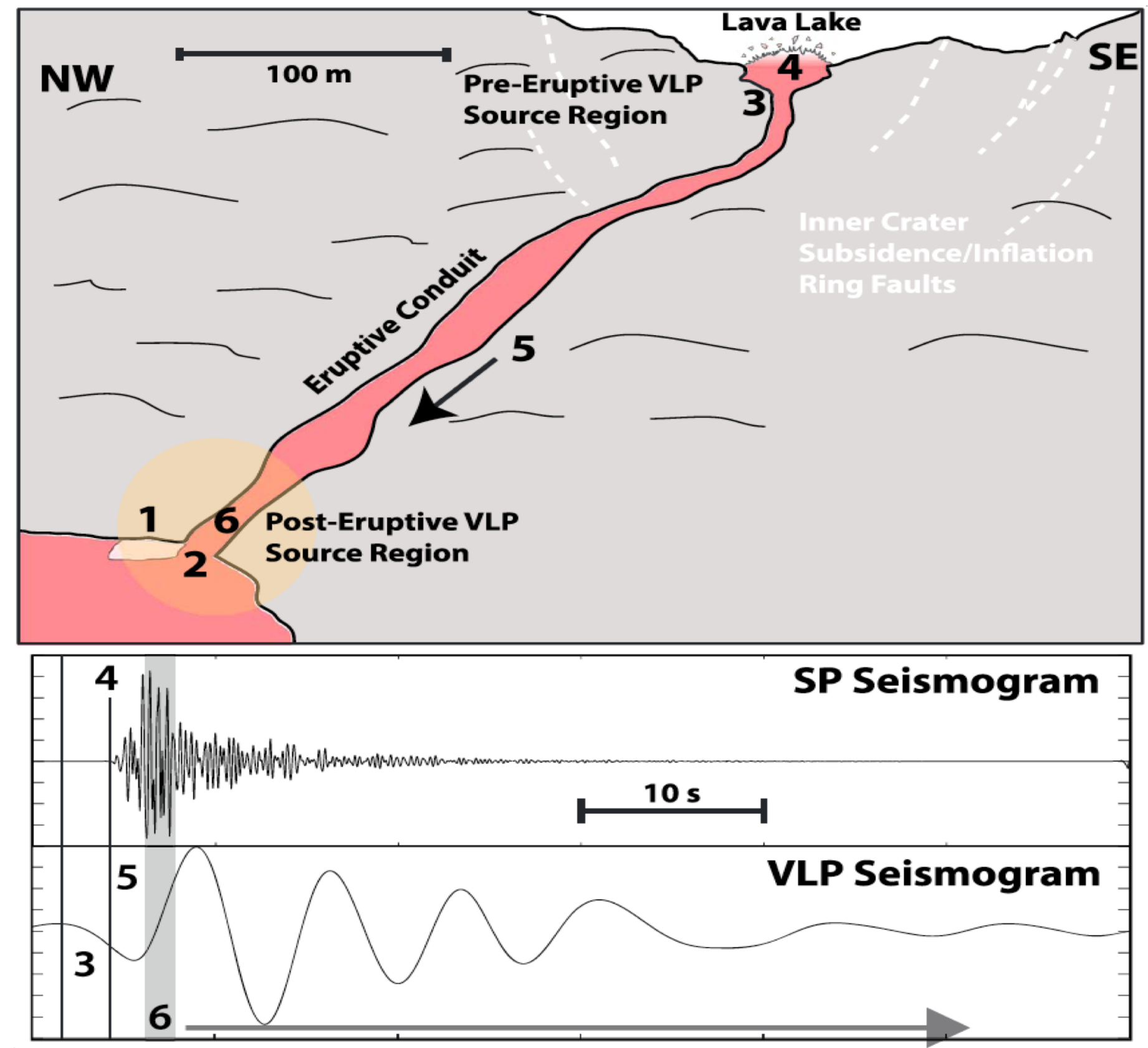

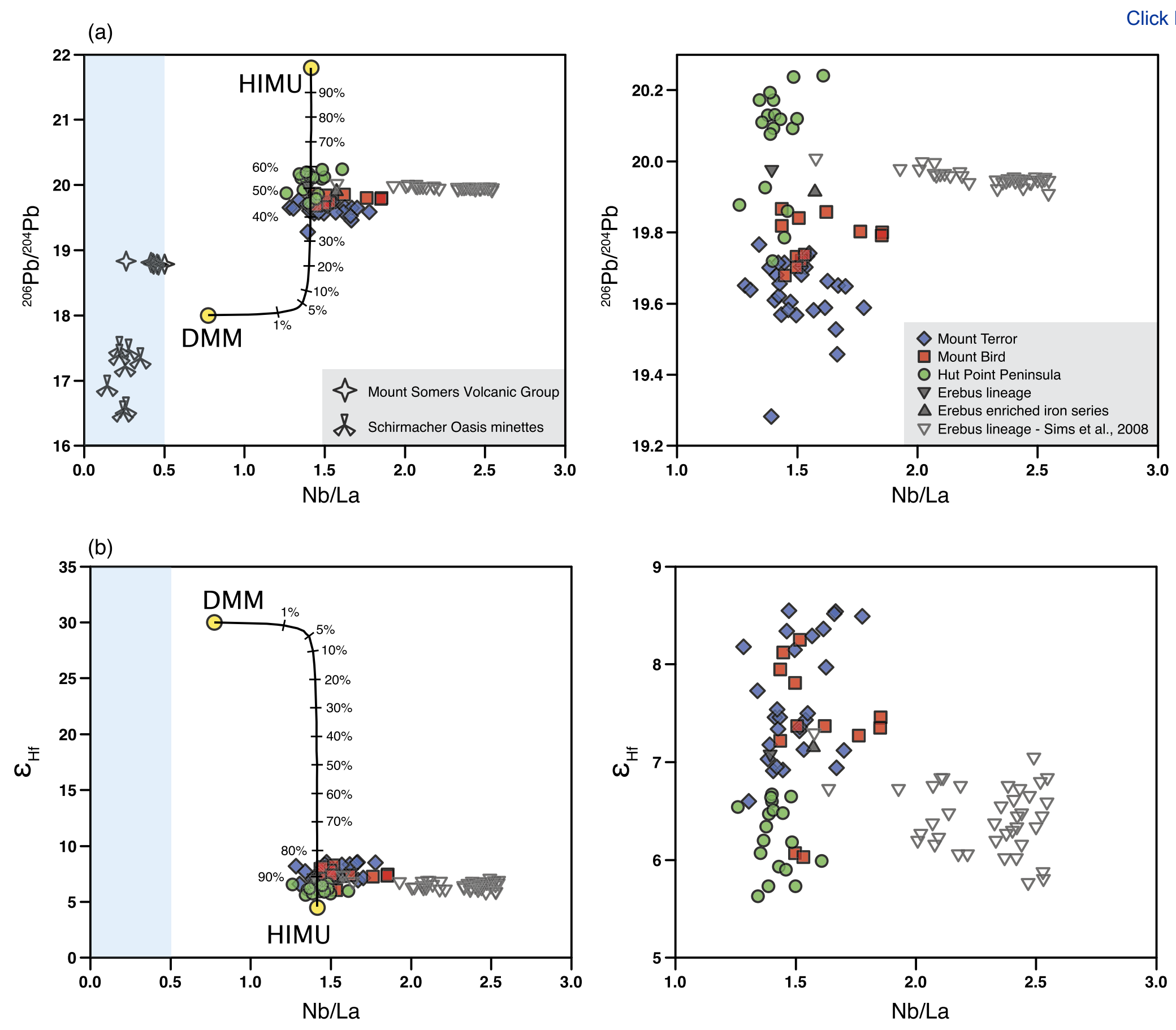


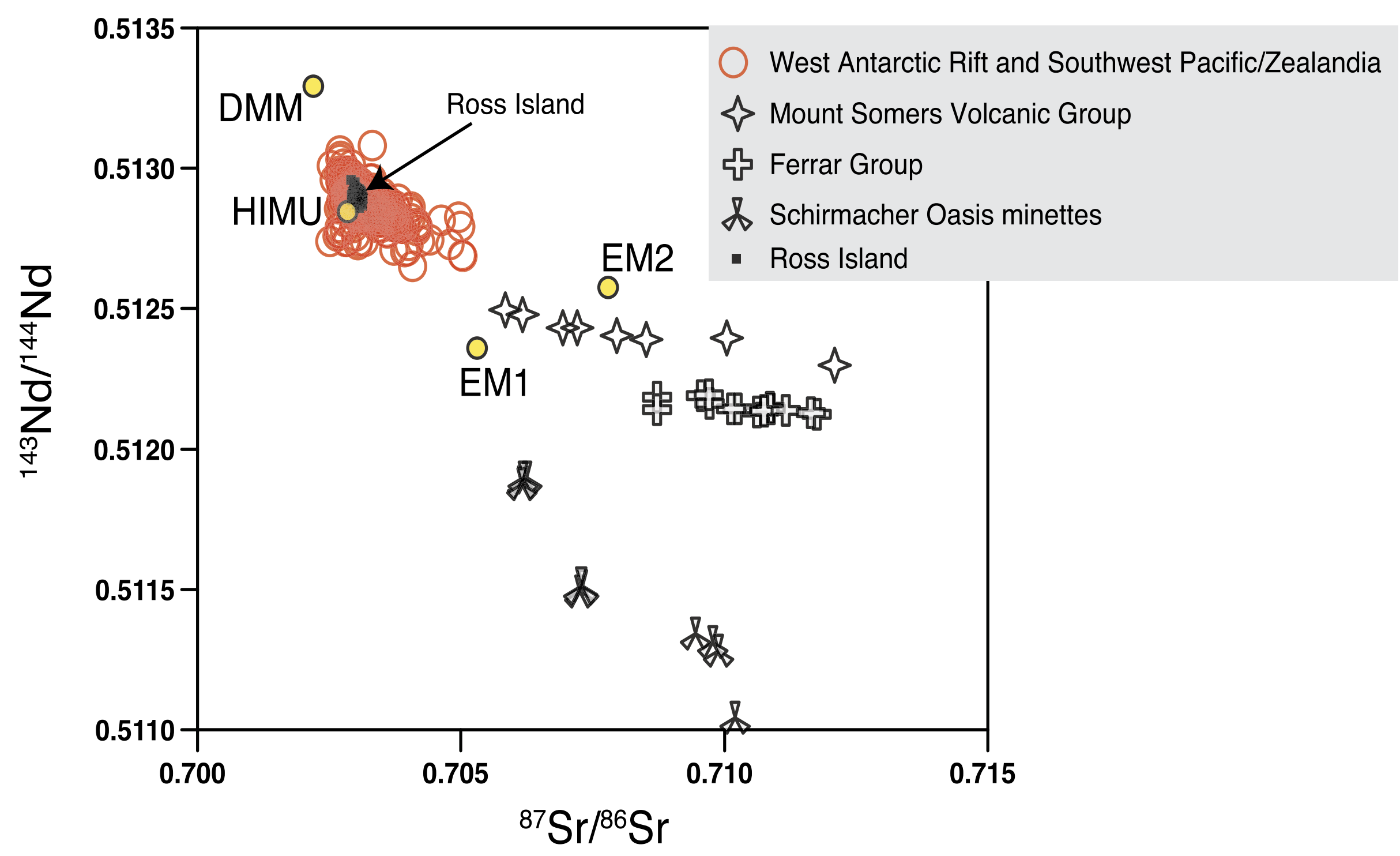



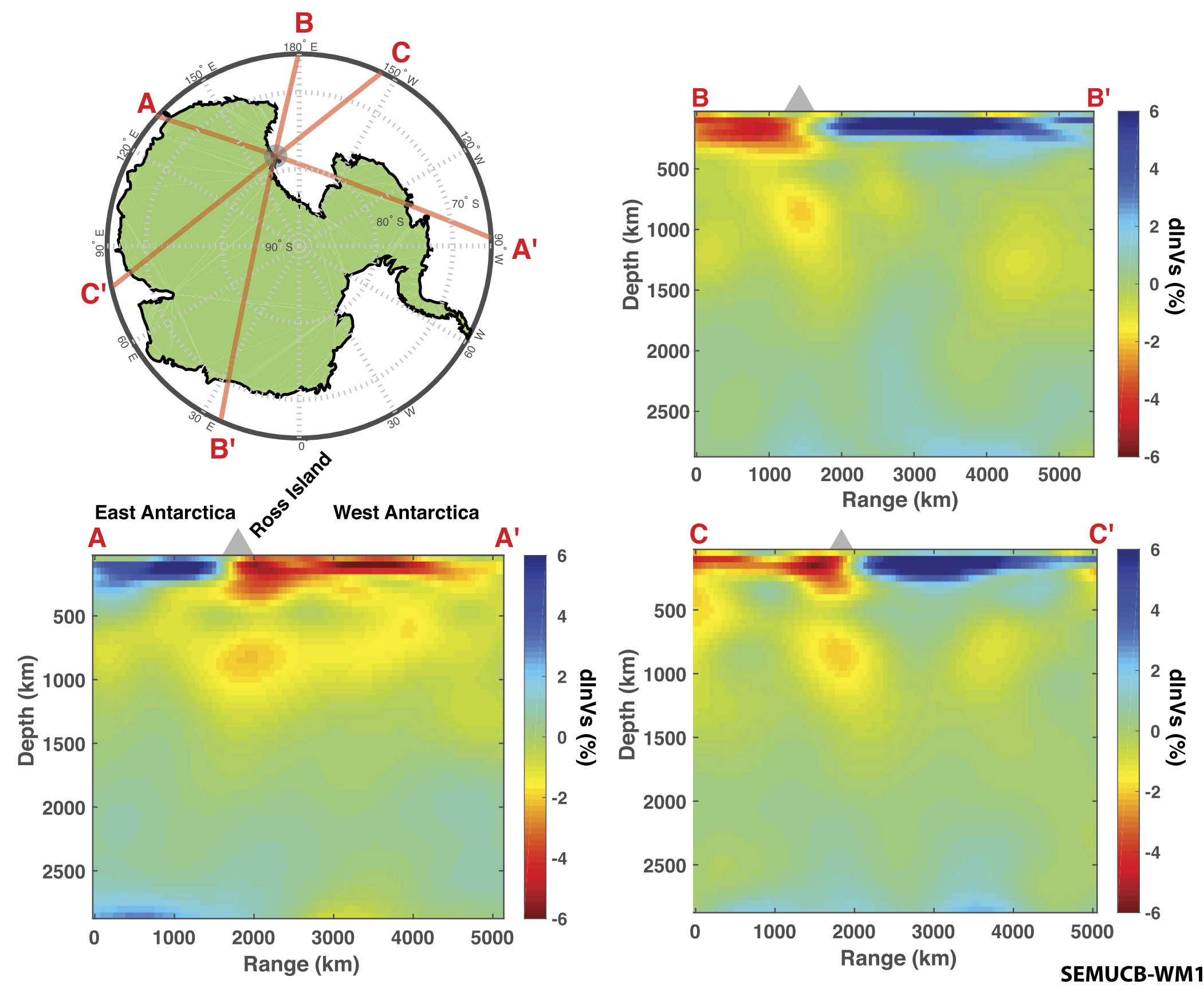


\section{Erebus Volcano: Passive Degassing}

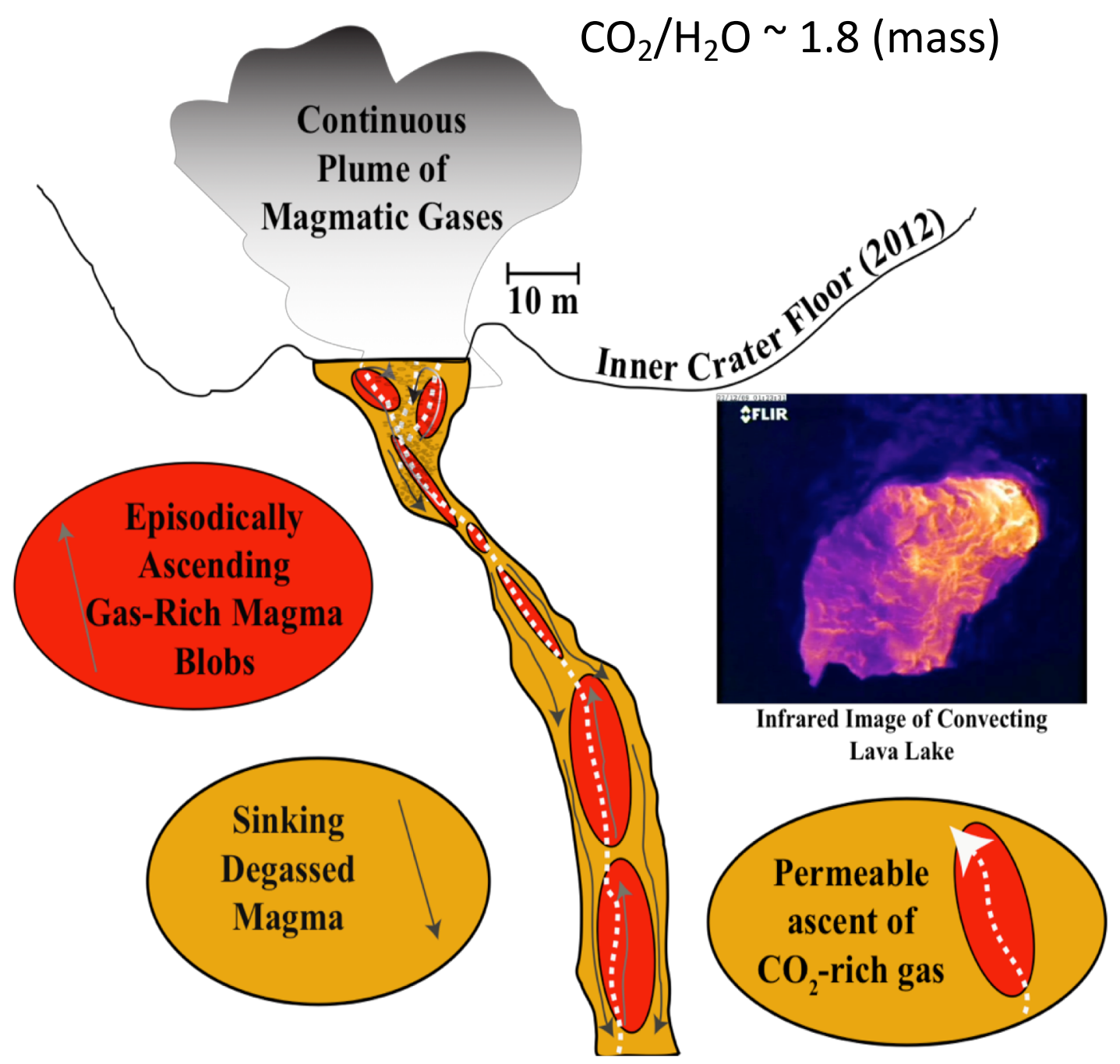

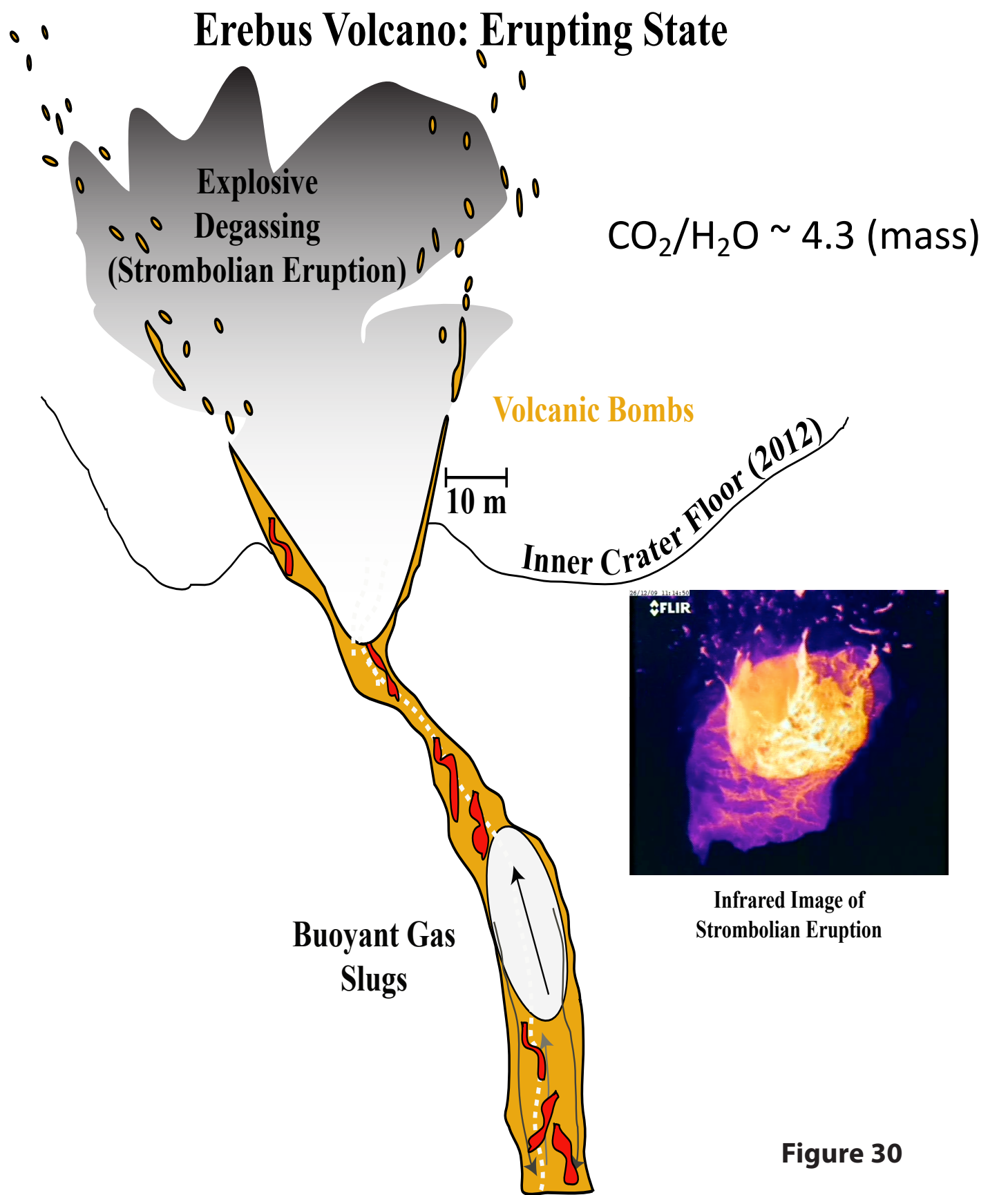


A

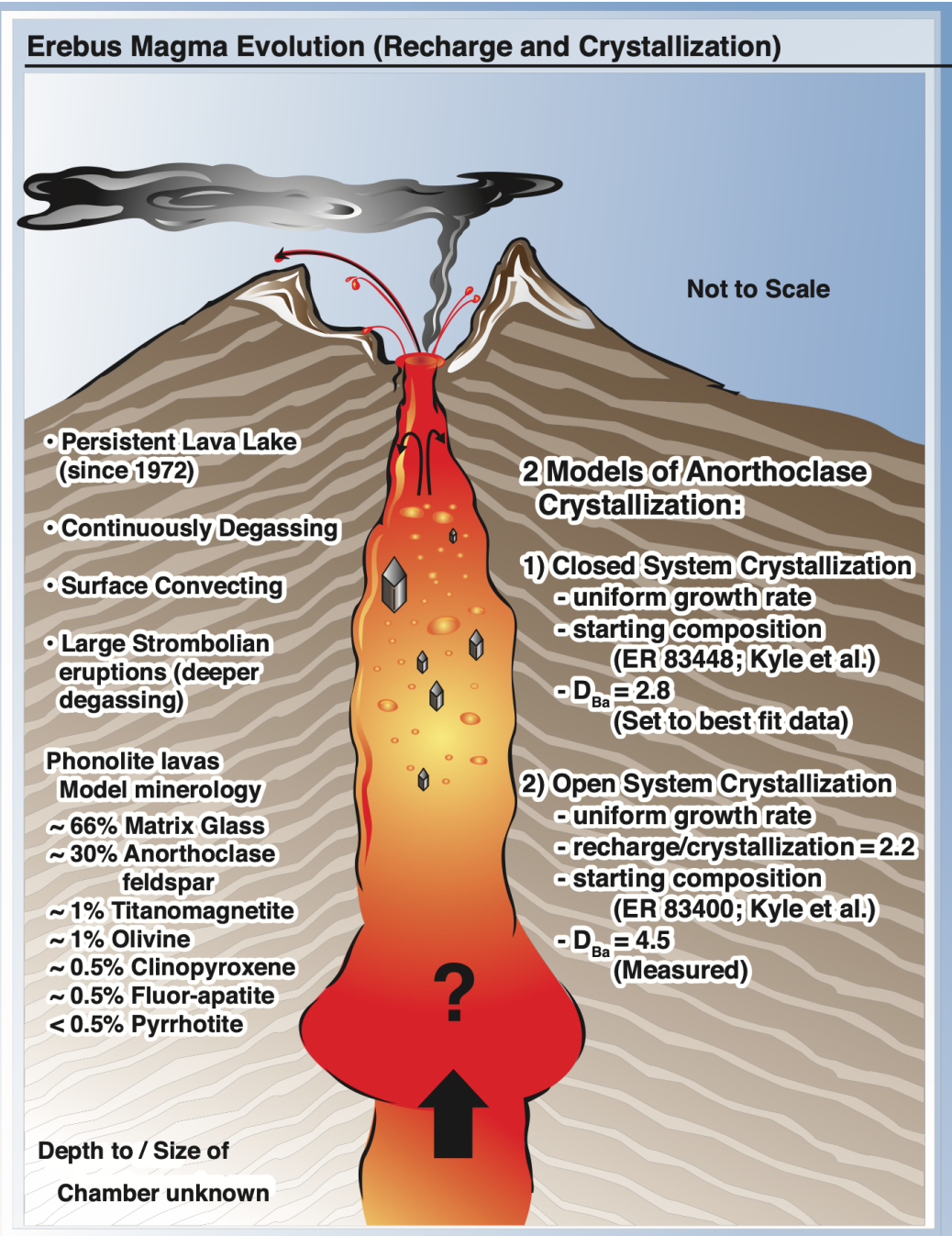

B

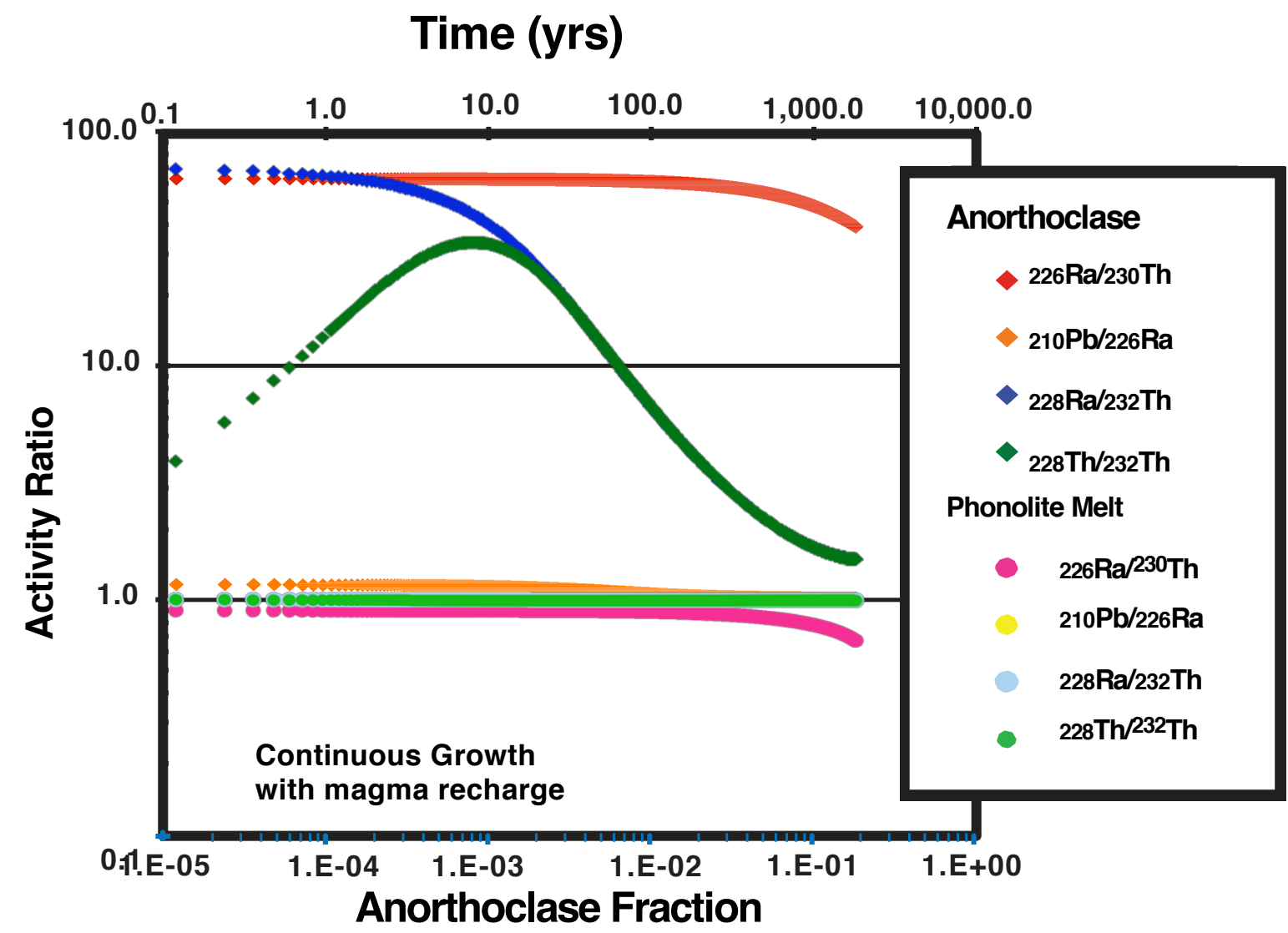




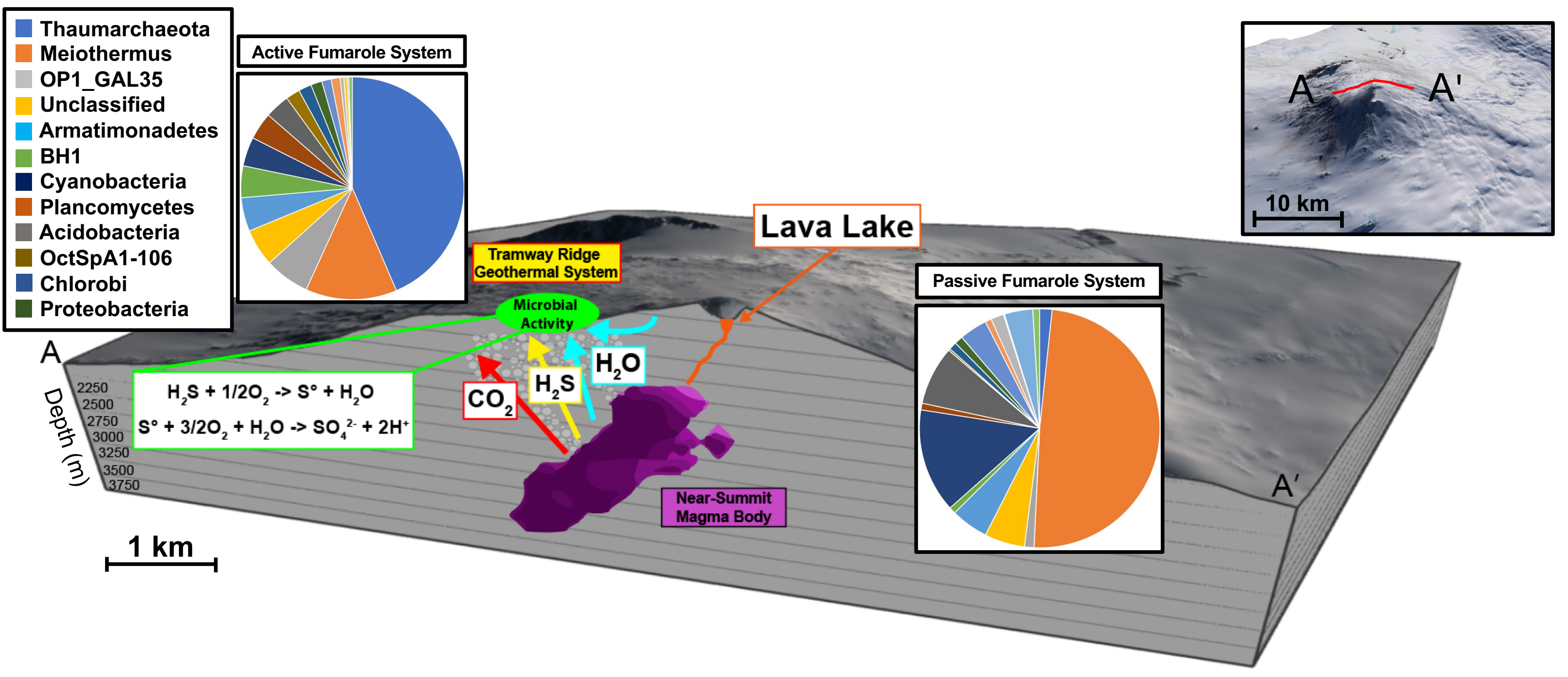

